\title{
In situ determination of strength and stiffness of structural lumber and composite products
}

Jody D. Gray

West Virginia University

Follow this and additional works at: https://researchrepository.wvu.edu/etd

\section{Recommended Citation}

Gray, Jody D., "In situ determination of strength and stiffness of structural lumber and composite products" (2003). Graduate Theses, Dissertations, and Problem Reports. 1321.

https://researchrepository.wvu.edu/etd/1321

This Thesis is protected by copyright and/or related rights. It has been brought to you by the The Research Repository @ WVU with permission from the rights-holder(s). You are free to use this Thesis in any way that is permitted by the copyright and related rights legislation that applies to your use. For other uses you must obtain permission from the rights-holder(s) directly, unless additional rights are indicated by a Creative Commons license in the record and/ or on the work itself. This Thesis has been accepted for inclusion in WVU Graduate Theses, Dissertations, and Problem Reports collection by an authorized administrator of The Research Repository @ WVU. For more information, please contact researchrepository@mail.wvu.edu. 


\title{
In Situ Determination of Strength and Stiffness of Structural Lumber and Composite Products
}

\author{
by \\ Jody D. Gray \\ Thesis submitted to the \\ Davis College of Agriculture, Forestry, and Consumer Sciences \\ at West Virginia University \\ in partial fulfillment of the requirements for the degree of
}

Master of Science

in

Forest Resource Management

Dr. Elemer M. Lang, Chairman

Dr. James P. Armstrong

Dr. R. Bruce Anderson

Division of Forestry

Wood Science

Morgantown, West Virginia

2003

Keywords: NDE, Stress wave velocity, Screw withdrawal force 


\title{
Abstract \\ In Situ Determination of Strength and Stiffness of Structural Lumber and Composite Products
}

\author{
Jody D. Gray
}

Wood is prone to deterioration that reduces its load bearing capabilities. Periodically, older wooden members need to be inspected to ensure the strength and stability of the structure. Historically these inspection methods have consisted of visual inspections lacking scientific basis.

Non-destructive testing (NDT) methods were investigated by this research for the possibility of evaluating modulus of rupture and modulus of elasticity of built-in wooden members. Methods included stress wave timing for dynamic MOE determination and screw withdrawal force (SWF) for MOR and density prediction. Standard ASTM testing procedures were used to determine the actual properties and statistical relationships between these variables identified. Using the developed relationships, simple prediction models were developed to estimate actual properties.

Results of this investigation revealed that stress wave timing is a reliable predictor of the actual MOE of the material. Investigation results also indicated that SWF is a reliable indicator of both density and MOR. 


\section{DEDICATION}

The author wishes to dedicate this thesis to his family. This has been a very long and bumpy road I traveled. I know that throughout the journey there have been times I seemed almost unbearable. I want to say thank you to everybody, particularly my wife Leslie. Without your support and encouragement I would not have been able to make this tough climb to the top. Let us now hope that the rest of this journey we call life is a nice paved road. However, I would especially like to dedicate this to my son Joey, you are daddy's best friend and I love you very much. Now, let's play! 


\section{ACKNOWLEDGMENTS}

The author wishes to thank Allegheny Wood Products in Kingwood and TrusJoist, a Weyerhaeuser business, in Buckhannon for the generous donation of test materials. I would also like to thank Dr. James Armstrong and Dr. Bruce Anderson of West Virginia University for their guidance throughout this project. I would especially like to thank Dr. Elemer Lang of West Virginia University for all the encouragement and knowledge he has provided to me throughout this project. Without his expertise and persistence this project would not have come to reality. Special thanks also go out to Michael Vanderberg and Adam Riley, without you guys this would have been even harder to accomplish. Also, thanks deserve to go to Paul Ludroski for his help in the wood shop and to Shawn Grushecky for all the computer and moral assistance that I received. I would also like to especially thank my best friends Daniel Shorter and Chris Mollohan for all the support and encouragement that they have provided. Thank you to all that I have mentioned and to any that I may have left out. 


\section{TABLE OF CONTENTS}

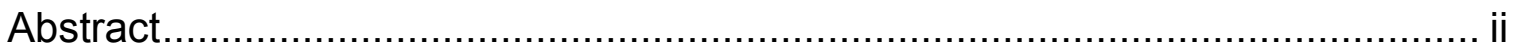

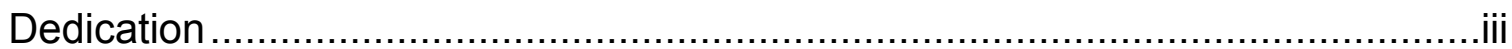

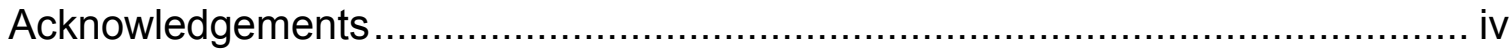

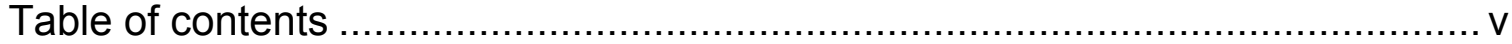

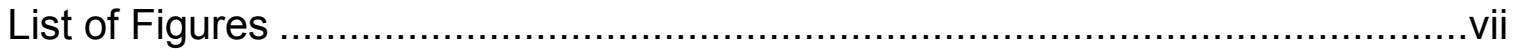

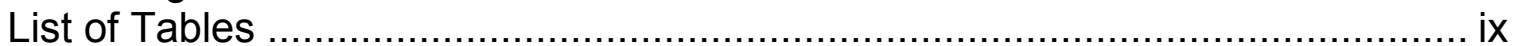

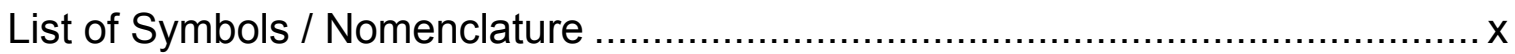

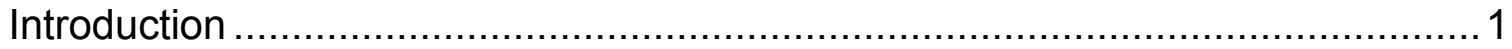

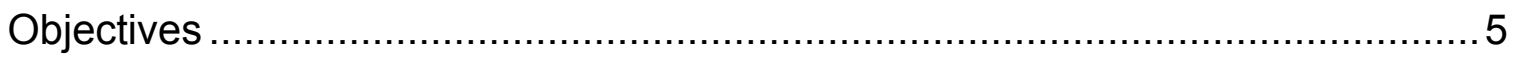

Chapter 1 - Literature Review

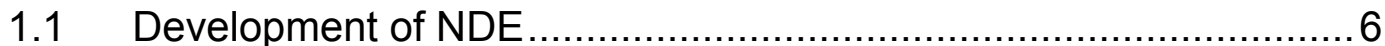

1.2 Evaluating Trees and Logs ........................................................ 7

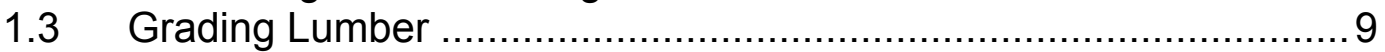

1.4 Identifying Drying Defects.................................................... 12

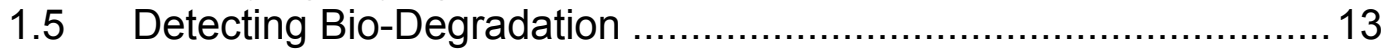

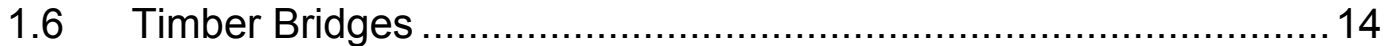

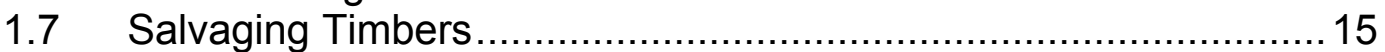

1.8 Effect of Moisture ......................................................................... 16

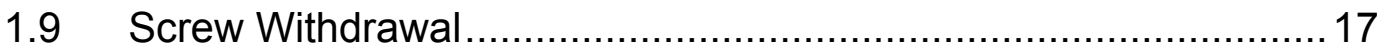

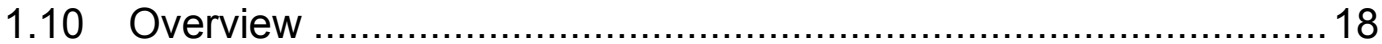

Chapter 2 - Materials and Methods

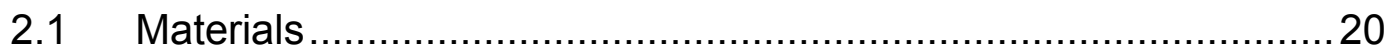

2.2 Methods

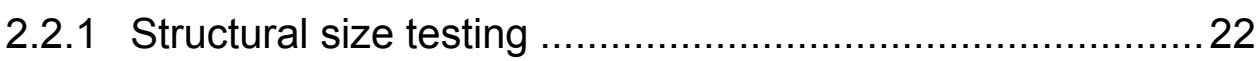

2.2.2 Small specimen testing ................................................. 31

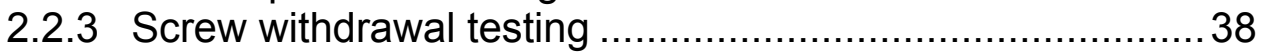

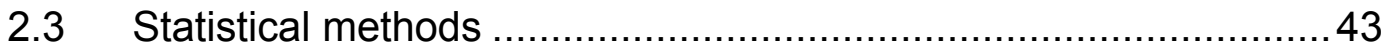

Chapter 3 - Results and Discussion

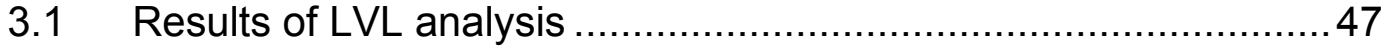

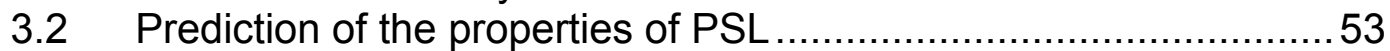

3.3 Regression results for red oak data..........................................58

3.4 Evaluation of data obtained on yellow-poplar ..............................63

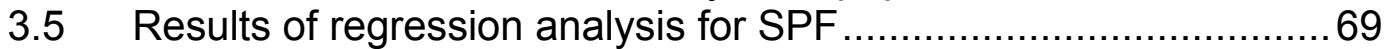


3.6 Investigation findings of SYP.

3.7 Statistical evaluations concerning all groups combined................ 80

Chapter 4 - Conclusions and Recommendations

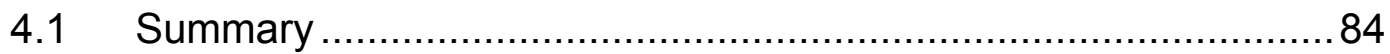

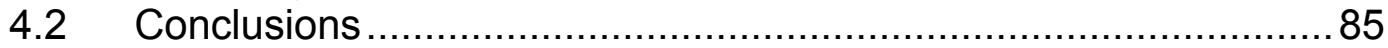

4.3 Recommendations for further research .................................. 87

Chapter 5 - Effect of Creosote Treatment on Screw Withdrawal Force and Dynamic MOE

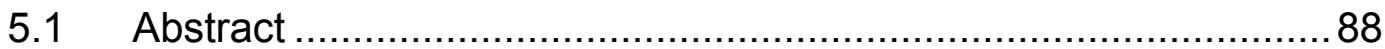

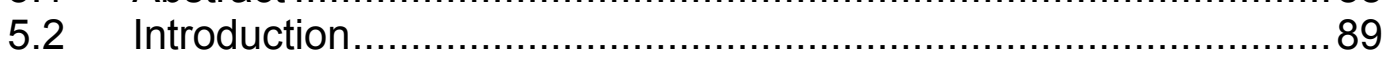

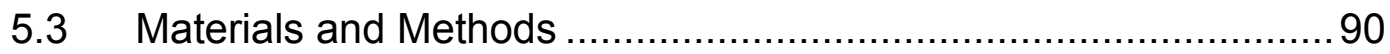

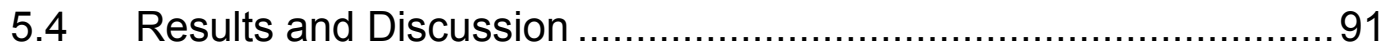

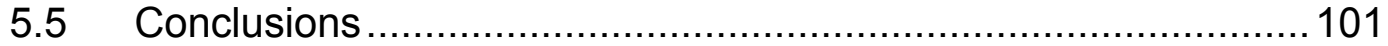

Chapter 6 - Effect of Moisture

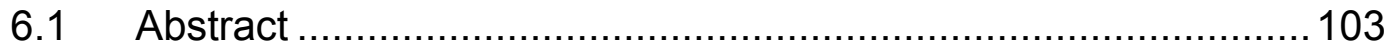

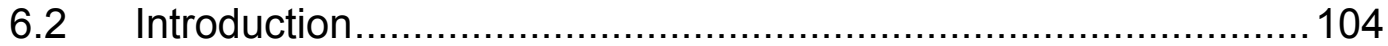

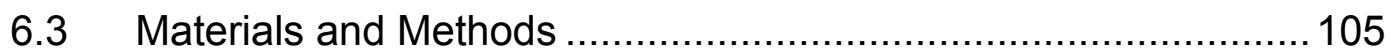

6.4 Results and Discussion ....................................................... 105

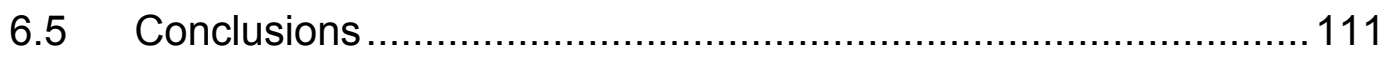

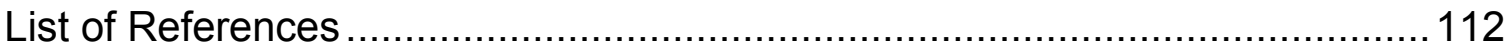

Appendices

Appendix I - GLM of SWF vs. density for small specimens............................ 124

Appendix II - GLM of SWF vs. MOR for small specimens ..............................126

Appendix III - GLM of $E_{D}$ vs. $E_{T}$ for small specimens ................................128

Appendix IV - GLM of $E_{D}$ vs. $E_{T}$ for structural size specimens ....................... 130

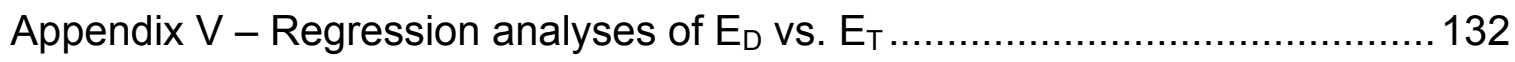

Appendix VI - Regression analyses of SWF vs. density, SWF vs. MOR,

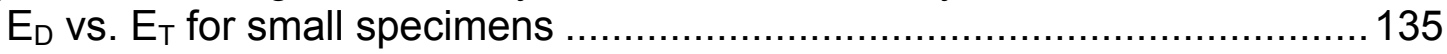

Appendix VII - GLM of PSL and treated PSL ........................................ 145

Appendix VIII - Backward stepwise regression analyses ............................148 


\section{LIST OF FIGURES}

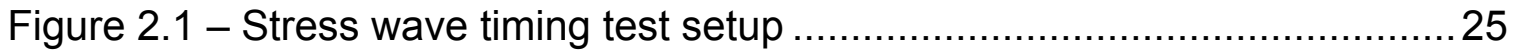

Figure 2.2 - Four point static bending test setup ....................................... 28

Figure 2.3 - Load - deflection diagram, with deflection correction .....................29

Figure 2.4 - Cut pattern for small specimen testing ..................................... 32

Figure 2.5 - Three point static bending test setup ......................................... 35

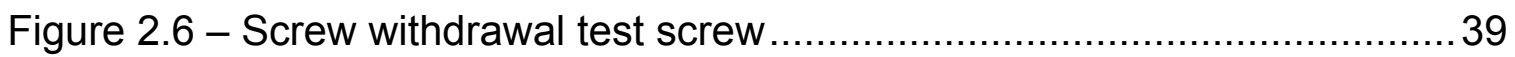

Figure 2.7 - Detailed view of pilot hole and screw insertion ............................40

Figure 2.8 - Testing setup for screw withdrawal testing .............................. 41

Figure 3.1 - Regression analysis of $E_{T} v s . E_{D}$ for LVL ................................. 48

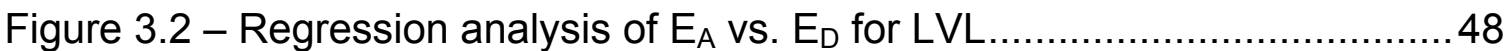

Figure 3.3 - Regression analysis of SWF vs. MOR for LVL ….....................5 50

Figure 3.4 - Regression analysis of Density vs. SWF for LVL ........................50

Figure 3.5 - 3D plot of SWF vs. Density vs. MOR for LVL .............................52

Figure 3.6 - Regression analysis of $E_{T}$ vs. $E_{D}$ for PSL ............................... 54

Figure 3.7 - Regression analysis of $E_{A}$ vs. $E_{D}$ for PSL ................................. 54

Figure 3.8 - Regression analysis of SWF vs. MOR for PSL ...........................55

Figure 3.9 - Regression analysis of Density vs. SWF for PSL ……................ 55

Figure 3.10 - 3D plot of SWF vs. Density vs. MOR for PSL ........................... 57

Figure 3.11 - Regression analysis of $E_{T} v s . E_{D}$ for red oak ............................59

Figure 3.12 - Regression analysis of $E_{A} v s$. $E_{D}$ for red oak ...........................59

Figure 3.13 - Regression analysis of SWF vs. MOR for red oak ...................... 60

Figure 3.14 - Regression analysis of Density vs. SWF for red oak ...................60 60

Figure $3.15-3 D$ plot of SWF vs. Density vs. MOR for red oak ....................... 62

Figure 3.16 - Regression analysis of $E_{T} v s$. $E_{D}$ for yellow-poplar .....................65

Figure 3.17 - Regression analysis of $E_{A} v s$. $E_{D}$ for yellow-poplar .....................65

Figure 3.18 - Regression analysis of SWF vs. MOR for yellow-poplar ............... 66

Figure 3.19 - Regression analysis of Density vs. SWF for yellow-poplar ...........66

Figure 3.20 - 3D plot of SWF vs. Density vs. MOR for yellow-poplar ................. 68

Figure 3.21- Regression analysis of $E_{T} v s . E_{D}$ for SPF ……....................... 70

Figure 3.22 - Regression analysis of $E_{A}$ vs. $E_{D}$ for SPF ............................. 70 
Figure 3.23 - Regression analysis of SWF vs. MOR for SPF …................... 71

Figure 3.24 - Regression analysis of Density vs. SWF for SPF ..................... 71

Figure 3.25 - 3D plot of SWF vs. Density vs. MOR for SPF ........................... 73

Figure 3.26 - Regression analysis of $E_{T}$ vs. $E_{D}$ for SYP ................................ 75

Figure 3.27 - Regression analysis of $E_{A} v s . E_{D}$ for SYP .............................. 75

Figure 3.28 - Regression analysis of SWF vs. MOR for SYP ……………..... 76

Figure 3.29 - Regression analysis of Density vs. SWF for SYP ……............... 76

Figure 3.30 - 3D plot of SWF vs. Density vs. MOR for SYP ............................ 79

Figure 3.31 - Regression analysis of $E_{T} v s . E_{D}$ for all groups......................... 81

Figure 3.32 - Regression analysis of $E_{A} v s$. $E_{D}$ for all groups......................... 81

Figure 3.33 - Regression analysis of MOR vs. SWF for all groups .................. 83

Figure 3.34 - Regression analysis of density vs. SWF for all groups ................8 83

Figure 5.1 - Regression analysis of SWF vs. MOR for PSL ……................... 92

Figure 5.2 - Regression analysis of SWF vs. MOR for treated PSL .................. 93

Figure 5.3 - Regression analysis of SWF vs. Density for PSL ....................... 95

Figure 5.4 - Regression analysis of SWF vs. Density for treated PSL .............. 96

Figure 5.5 - 3D plot of SWF vs. Density vs. MOR for PSL ............................ 97

Figure 5.6 - 3D plot of SWF vs. Density vs. MOR for treated PSL ................... 98

Figure 5.7 - Regression analysis of $E_{D} v s . E_{T}$ for PSL ................................... 99

Figure 5.8 - Regression analysis of $E_{D} v s . E_{T}$ for treated PSL .................... 100

Figure 6.1 - Regression analysis of MC vs. wave time................................ 107

Figure 6.2 - Regression analysis of MC vs. density ................................... 107

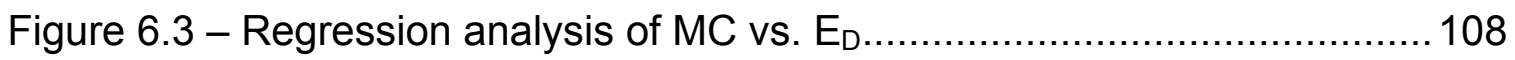

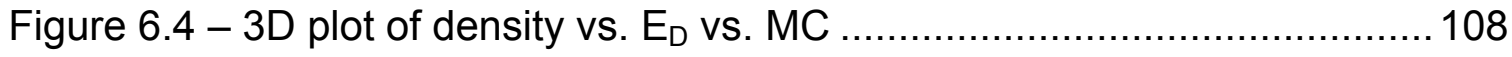

Figure $6.5-3 \mathrm{D}$ parabolic regression of density vs. $E_{D}$ vs. MC ..................... 109 


\section{LIST OF TABLES}

Table 3.1 - Summary statistics table for all groups..................................... 46

Table 3.2 - Parameters and statistics of regression analysis for LVL...............51

Table 3.3 - Parameters and statistics of regression analysis for PSL ...............56

Table 3.4 - Parameters and statistics of regression analysis for red oak ...........61

Table 3.5 - Parameters and statistics of regression analysis for yellow-poplar .. 67

Table 3.6 - Parameters and statistics of regression analysis for SPF …........... 72

Table 3.7 - Parameters and statistics of regression analysis for SYP ............... 77

Table 5.1 - Prediction equations for treated PSL ........................................ 101 


\section{LIST OF SYMBOLS / NOMENCLATURE}

\begin{tabular}{|c|c|}
\hline$E_{A}$ & apparent modulus of elasticity (psi) \\
\hline$h$ & average height (in, $\mathrm{cm}$ ) \\
\hline$a$ & average width (in, $\mathrm{cm}$ ) \\
\hline$r^{2}$ & coefficient of determination \\
\hline$R$ & correlation coefficient \\
\hline$\Delta$ & deflection (in) \\
\hline$\rho$ & density $\left(\mathrm{g} / \mathrm{cm}^{3}, \mathrm{~kg} / \mathrm{m}^{3}\right)$ \\
\hline$Y$ & dependent variable \\
\hline$F_{b}$ & design estimation of bending strength ( $\mathrm{psi}, \mathrm{Pa})$ \\
\hline$E_{D}$ & dynamic modulus of elasticity (psi) \\
\hline$g$ & grams \\
\hline in & inch \\
\hline$X$ & independent variable \\
\hline$L V L$ & laminated Veneer Lumber (LVL) \\
\hline$l$ & length of specimen (in, $\mathrm{cm}$ ) \\
\hline$F$ & load (lbs) \\
\hline$m$ & meter \\
\hline$\mu s$ & micro-second $(1 / 1,000,000 \mathrm{~s})$ \\
\hline$G_{X Y}$ & modulus of rigidity (psi) \\
\hline MOR & modulus of rupture (psi) \\
\hline$M$ & moment (in-lbs) \\
\hline$I_{x}$ & moment of inertia $\left(\mathrm{in}^{4}\right)$ \\
\hline$P S L$ & parallel strand lumber (PSL) \\
\hline $\mathrm{Pa}$ & pascal \\
\hline$l b s$ & pounds \\
\hline psi & pounds per square inch \\
\hline$P$ & probability factor \\
\hline$\alpha$ & probability of making type I error \\
\hline$R O$ & red oak (Quercus sp.) \\
\hline
\end{tabular}




$\begin{array}{ll}\beta_{0}, \beta_{1}, \ldots & \text { regression coefficients } \\ S W F & \text { screw withdrawal force }(\mathrm{lb}) \\ s & \text { second } \\ S_{x} & \text { section modulus }\left(\mathrm{in}^{3}\right) \\ S Y P & \text { southern yellow pine (Pinus sp.) } \\ S P F & \text { spruce-pine-fir (Picea sp., Pinus sp., Abies sp.) } \\ S W T & \text { stress wave time }(\mathrm{s} ; \mu \mathrm{s}) \\ L & \text { testing span (in) } \\ E_{T} & \text { true modulus of elasticity (psi) } \\ v & \text { velocity (m/s) } \\ V & \left.\text { volume (m }{ }^{3}\right) \\ Y P & \text { yellow-poplar (Liriodendron tulipifera) }\end{array}$




\section{INTRODUCTION}

For centuries wood has been a primary constituent in residential and commercial constructions. Technology has been highly integrated into the forest products industry to provide advanced building materials and to ensure more efficient ways of producing these much needed products. Extensive research, aided through advances in technology, has provided a more in-depth understanding of the complexity and variability of wood. Due to the aging infrastructure of the buildings in the United States and world wide, technology needs to be refined so that one can nondestructively assess the mechanical properties of older wooden members.

Load supporting elements in structures need to be inspected periodically to ensure strength and stability of the buildings. Bio-degradation, primarily caused by fungi or insect attack, can lead to a significant decline in the strength of wooden members. Other types of degradation that effect the strength of structural wood includes heat, ultra-violet light, and the effects of weathering. These weathering effects consist of seasonal temperature and relative humidity changes, and tiny dust particles that are blown by the wind and erode the wood fibers. Since wood experts are held responsible for their decisions on the strength of these wooden members, often perfectly sound elements are replaced for safety reasons. Bio-degradation and the weathering effect are easily detected by visual inspection, however the exact loss to the modulus of rupture (MOR), or bending strength, is difficult to assess (Divos et al. 1998). Thermal- 
degradation, UV-degradation and others are very hard to detect by visual means. These are some of the primary driving forces behind non-destructive testing and in situ measurements for determining strength and stiffness.

One method in particular that provides promise for in situ determination of the mechanical properties of old structural elements, including joists, girder beams, and columns is stress wave timing. This method uses sound wave propagation and specimen density to estimate the dynamic modulus of elasticity. A sound wave is transmitted into the specimen, the wave travels through the cell walls and is received by a receiver. The velocity of the wave is then used in the calculation to determine the dynamic MOE (Emerson et al. 1999).

Stress waves move slower through less dense wood or wood with voids, such as deteriorated wood or wood with loose knots. Consequently, the calculated dynamic MOE is also low. Moisture content also plays an important role in the speed at which the wave propagates. The sound waves move slower through wood cells that are filled with water (Forest Products Laboratory 1999), resulting in a lower dynamic MOE. Another factor greatly influencing the dynamic MOE is the orientation of the wood fibers in relation to the longitudinal axis of the element (Armstrong et al. 1991). The speed of the wave and the dynamic MOE is reduced with every degree of deviation from parallel. Thus, wood that has sloping grain will have a lower dynamic MOE. It has also been shown through static testing that these same conditions affect the true MOE.

Over the past few years non-destructive evaluation of strength and stiffness has been the focal point of a lot of research. Non-destructive evaluation 
(NDE) of a material is, by definition, the science of identifying the physical and mechanical properties of a piece of that material without altering its end-use capabilities (Ross 1992). Originally the concept of non-destructive evaluation was applied to standing timber, which aided in tree selection for cutting (Soltis et al. 2000). Stress wave propagation has been studied for determination of strength of in-service wood based composites such as plywood sheathing (Shibusawa et al. 2000). Other studies were performed to predict the mechanical properties of older structural elements to determine if they could be salvaged and perhaps used for another application. Structural members, such as treated poles (Wang et al. 2000) and switch ties (Schad et al. 1995), that have been removed from service may still have high enough mechanical properties to be considered for other applications. Due to the decline in availability of large diameter trees, the ability to recycle large wooden members could prove to be valuable to industry (Falk et al. 2000).

Another non-destructive measurement that may be performed in situ is screw withdrawal force. This method requires that a small diameter pilot hole be drilled in the wooden element to a known depth and perpendicular to the longitudinal axis of the specimen. A screw of specific diameter and length of threads is then inserted into the pilot hole to a second pre-determined depth, greater than the depth of the pilot hole. Force is then applied to the screw parallel to the longitudinal axis and the maximum amount of force required to extract the screw is recorded. This procedure leaves a very small hole in the tested material, which may be easily filled with epoxy and a small dowel rod of 
the same species as the member. It is assumed that the maximum force required to extract the screw has a direct relationship to the density and MOR of that member.

With the aging infrastructure in the world today, a reliable method for nondestructively determining the strength and stiffness of in-service wooden members needs to be established. Stress wave timing and screw withdrawal force holds promise for answering this problem. However, a few questions need to be answered. Is there a direct relationship between maximum screw withdrawal force and density? Does a relationship exist between maximum screw withdrawal force and true modulus of rupture? Is stress wave timing a valid predictor of the true modulus of elasticity, as determined through static bending? This research was designed to investigate the answers to the questions, mentioned above, according to the objectives as follow. 


\section{OBJECTIVES}

There is no standard testing procedure for evaluating mechanical properties of built-in structural wood materials. The overall goal of a comprehensive research project conducted at WVU, Division of Forestry is to develop a reliable method for non-destructive evaluation of structural wood materials.

The specific objectives of this phase of the project were:

1. To develop a substantial database of the structural wood materials regarding their strength and stiffness;

2. To develop an experimentally valid measuring technique capable of evaluating the strength and stiffness of built-in structural wood elements;

3. To investigate the effect of moisture content on stress wave velocity;

4. To investigate the effect of creosote treatment on the results of the nondestructive evaluations. 


\section{CHAPTER 1 - LITERATURE REVIEW}

\subsection{Development of NDE}

The concept of lumber and tree grading has seen many faces throughout history, particularly the last century. Grading of lumber and trees has primarily based on visual techniques since the 1930's. For lumber, the grader looks at and takes into consideration natural occurring defects in an attempt to make an assessment of the strength of a particular board. Knots, decay, and sloping grain are a few of the defects that are known to reduce the mechanical properties of wood and thus lowering the grade. However, using visual techniques alone one is not capable of determining the exact loss of mechanical properties such as modulus of elasticity or bending strength.

The grading of living trees and logs has also used visual techniques with the addition of growing site evaluation. Site evaluation takes into consideration things such as terrain and soil type in an attempt to assess the quality of the lumber to be sawn from the tree/log. A method that has been used for centuries to attempt to determine the amount of decay within a tree/log is sound. Sounding a tree/log consists of striking it with a hammer while a trained expert listens to the tone of the sound to determine the interior structure. A trained expert can distinguish between a solid and deteriorated log. The expert knows that sound 
waves move or sound differently in solid wood as compared to decayed wood but again this method is limited in accuracy of predicting mechanical properties.

Based on the old technique of sounding a log, the travel of a sound wave through wood has been investigated closer in recent years. It has been determined that sound waves move faster through solid wood containing densely packed cells as opposed to decayed cells containing more air space. It is also known that the bending strength and stiffness is related to the density of a specimen. With this in mind it seems reasonable that one could use the time required for a sound wave to travel through a piece of wood as a measure of strength, providing there was a controlled standard upon which to base an assessment. Once the wave propagation time and strength property relationship for a given species is established, a more precise prediction of the mechanical properties may be made.

\subsection{Evaluating trees and logs}

Traditional harvesting practices depend on visual inspection of the trees and the site in which they grew in order to predict the quality of the wood obtained. However, it is also known that neither visual inspection of the tree, nor of the site, is a good indicator of the mechanical properties that lie within the sawn lumber of the tree. Wagner et al. (2001) did a study using stress-wave timing to predict the mechanical properties of Douglas-fir (Pseudotsuga 
menziesii) trees. In their results they found a high correlation between the dynamic MOE of the tree and the lumber, for the trees with the least variation in the sawn lumber. However, they found that there was a low correlation for the trees with the most variation in the sawn lumber.

An investigation, performed on young growth Sitka spruce (Picea sitchensis) and western hemlock (Tsuga heterophylla) stands (Wang et al. 2000), proved that there was a significant relationship between the dynamic MOE of the logs and the true MOE, determined through static bending, of the lumber obtained. Wang et al. set out using stress wave timing to predict the mechanical properties and to assess silvicultural practices on the end properties of the timber. Results of the investigation provided a correlation coefficient of 0.91 , at the $99 \%$ confidence level, for the two species combined concerning the relationship between the dynamic and true MOE of the logs and lumber.

There has also been considerable research concerning the use of stress-wave timing in detecting defects of logs. Wood degradation along with defects, such as voids and knots, affect the quality and processing time of lumber. Stresswave timing has proved to have the ability to detect areas of high degradation, knots, or large voids. The sound waves move slower through these regions, which results in a longer transmission time and a lower dynamic MOE (Shad et al. 1996).

A research project was performed evaluating different nondestructive techniques for assessing the mechanical properties of logs also showed high correlation between the dynamic and the true MOE, determined through static 
bending, (Wang et al. 2001). Their results provided correlation coefficients between the dynamic and static MOE of 0.87 for the red pine (Pinus resinosa) logs and 0.77 for the jack pine (Pinus banksiana) logs. Other research has found that a weak relationship exists between the visual sawlog grade and the actual MOE of the lumber obtained, and that the dynamic MOE of the log correlates well with the actual MOE of the lumber (Ross et al. 1997).

\subsection{Grading lumber}

Nondestructive testing techniques have also been evaluated to predict the MOE of sawn lumber and timbers. Traditional methods for grading lumber and timbers consist of visual inspection techniques that originated in the 1930's. One study, by Anderson et al. (1997), stated that the economic benefit of scanning lumber to identify the occurrence of honeycomb of surface checks will outweigh the costs of implementing the equipment in the sawmill.

An industry that relies heavily on machine stress graded wood material is the composite industry. Wood composite products such as parallel strand lumber (PSL), plywood, and laminated veneer lumber (LVL) depend upon knowing the mechanical properties of the wood that goes into the product, particularly the layered products such as plywood and LVL. To produce these products, factories use a layering system that puts the higher quality material furthest from the neutral plane, thus increasing the effective stiffness of the entire 
panel. Stress wave NDE techniques to sort incoming veneer into strength categories allow the facility to adjust the forming system and achieve the desired results. Ross et al. (1999) researched the use of stress wave timing to predict the potential quality of veneer obtained from a log. Results of this study indicate a high correlation between the tree length stress wave velocity and that of the short log velocity. This revealed that it would be possible to use log transmission times to accurately estimate the potential quality of veneer that would be obtained from that $\log$.

Stress wave propagation has also been used in several investigations for artificial defect detection. In these studies artificial defects were cut into the specimens at different widths and depths. Stress wave propagation time was used to determine the dynamic MOE of solid wood specimens. Static bending was then executed and the true MOE calculated. Tanaka et al. (1999) found that at distances between two loading points, across defects, it was possible to estimate the residual bending strength by stress wave propagation. In a similar study, Divos et al. (2001) noted that shallow cuts caused essentially no effect on velocity, as there was ample wood material for the wave to travel through. They also noted that the amplitude of the stress wave dropped linearly with the depth of the cut.

The concept of stress-wave evaluation has also been researched for the large timber manufacturing industry, particularly for hardwoods. Large timber industry produces timbers of large cross-section and length for use in bridge construction, girder beams, and various other heavy loading construction 
applications. The procedures used for machine stress rated lumber that is typically used to rate nominal 2" thick lumber has not yet been adapted to handle the large sizes of timbers produced by the large timber industry (Kretschmann and Green 1999). This industry still relies on visual inspection to assess the mechanical properties of the products. The timbers produced by the large timber industry are likely to be used for main load supporting elements, thus there is a need for a better means to predict the mechanical properties of the products.

Various investigations have examined machine stress rating as the means for evaluating the mechanical properties of these large timbers all with similar results. Green et al. (1996) found a significant correlation between the MOEMOR by regression analyses of their study on red oak (Quercus rubra). They also stated that no technical barriers were identified that would discourage the use of machine stress rating of lumber. Green et al. (1993) noticed in their study on various species that there is also a stress wave time change associated with temperature. They found that the average observed MOE increase for the species was 7.8 percent when going from $32^{\circ}$ Fahrenheit to $75^{\circ}$ Fahrenheit. However the main limitation of machine stress rating of lumber is that it can usually not be performed in situ. 


\subsection{Identifying drying defects}

Drying is a critical step in manufacturing hardwood lumber (Ross et al. 1995). Degradation caused by surface checking and honeycomb is especially severe in certain hardwood species. Surface checks are usually easily detected by visual inspection, however honeycomb is not. An investigation performed by Fuller et al. (1994) evaluated the use of stress wave timing to detect honeycomb in dried red oak lumber. They determined that sound wave transmission time perpendicular to the grain increased significantly with the presence of honeycomb, from this they concluded that stress-wave timing provides promise for detection of surface checks and honeycomb. Ross et al. (1995) noted that $82 \%$ of the specimens having sound wave velocities greater that 400 microseconds/foot contained honeycomb or surface checking. Other researchers have investigated stress wave timing in regards to evaluating the wave propagation time with the moisture content of drying lumber. Simpson (1998) found that the stress wave velocity was sensitive to changes in moisture content starting at moisture contents above 30 percent. Simpson also observed three distinct linear regions of wave time throughout the drying process in which the moisture content for these regions varied between species. The first of such regions was observed to be above 30 percent moisture content where the moisture content had been previously undeterminable through resistance type non-destructive meters. Simpson and Wang (2001) stated that the stress-wave 
propagation time decreased linearly with the moisture content, thus having the potential for use in controlling kiln schedules.

\subsection{Detecting bio-degradation}

Wood in service can be attacked by a variety of organisms. Such organisms feed on the constituents of wood, thereby reducing its mechanical properties (Ross et al. 1996). DeGroot et al. (1994) found in their research of non-destructive assessment of wood decay and termite attack that wave speed was not a good indicator of the percentage of wood tissue that had been lost due to degradation. They did, however, note that wave speed was correlated with the maximum load in compression. Yang et al. (1999) used stress wave timing in comparison with weight loss measurement to predict the MOE and MOR loss of OSB panels exposed to both white and brown rot fungi. They noticed that stress wave timing revealed incipient decay in just two weeks, much earlier than the weight loss measurements. Winandy and Morrell (1993) found in their study of Douglas-fir, that a weight loss of 1 to $18 \%$ was linearly related to a strength loss of 5 to $70 \%$.

Lee and Oh (1999) noted that a stress wave time greater than 350 $\mu$ sec./ft. could distinguish between sound and decayed members with great accuracy. They also observed that one could classify a member as severely decayed if it has a stress wave time of $600 \mu \mathrm{sec}$./ft or greater. 


\subsection{Timber bridges}

Wood has been used as a bridge building material in the United States for hundreds of years (Wipf et al. 1999). The $20^{\text {th }}$ century experienced a decline in the interest of using wood for bridges. However, in recent years the use of wood in bridges has shown renewed interest. With this new interest comes the quest for a new way to evaluate these structures. Stress wave timing is being researched as a means by which to perform this evaluation. "Sounding the wood surface by striking it with a hammer or other object is one of the oldest and most commonly used inspection methods to detect interior deterioration" (Ross et al. 1999). This method involves a trained inspector to listen and determine the amount of decay based on the sound made from striking the surface. Stresswave timing is a more advanced method that uses a timing device to record the wave propagation time. With this information, one can determine the exact loss of MOE. It has been shown to be a valid and accurate method for determining the extent of unsoundness due to decay in timber structures (Pellerin et al. 1996). Current research at West Virginia University is nondestructively monitoring the deterioration of the decking on an experimental timber bridge. This bridge is experimental in that creosote treated PSL was used as the decking of the structure. The PSL in the structure is made from yellow poplar (Liriodendron tulipifera), which is primarily viewed as not naturally durable to environmental elements. Ross et al. (1996) performed a study in which the dynamic and static MOE was observed for southern pine (Pinus sp.) specimens 
used in the construction of a bridge deck. After the deck was constructed more dynamic MOE measurements were taken. The results indicate that dynamic MOE is as good a predictor of true MOE for individual members as it is for entire bridge decks.

\subsection{Salvaging timbers}

Due to the lack of a technically sound, comprehensive, and economically feasible means by which to asses the mechanical properties of in-service wooden members, sometimes historical buildings are demolished (Soltis et al. 2000). These structures may or may not be as "unsafe" as they are perceived to be, but the lack of a quantitative means of evaluating the structure leads to its destruction. Stress-wave techniques are being used more frequently in evaluating old wooden members. Research conducted by Ross et al. (1998) used stress-wave NDE to examine the soundness of the oldest floating commissioned ship in the world, the USS Constitution. In their inspection they stated that stress-wave NDE techniques proved to be successful in locating deteriorated members.

More disturbing is the fact that once these buildings are demolished, the wooden members are usually discarded. The wood that is removed from these structures may still have high enough mechanical properties to be used for other applications. Schad et al. (1995) used stress wave timing to determine the quality 
of lumber that may be sawn from recycled switch ties. They observed that MOE of lumber cut from a tie may be predicted using sound waves, although the accuracy of the prediction of lumber MOE decreased with the size of the members. The more members cut from the tie, the less accurate the prediction for each was. They also observed a strong relationship between pulse echo and dynamic MOE for both green and dry lumber. Surveys have also concluded that preservative-treated wood piles still contain wood material that is suitable for exterior structural applications, and that stress wave timing is an accurate predictor of their mechanical properties (Wang et al. 2000, Wang et al. 2001). Ross et al. (2001) noted that a significant relationship was found between stress wave time and the residual strength of compression parallel and perpendicular to the grain for large Douglas-fir (Pseudotsuga menziesii) timbers that had been removed from service. Through these analyses it was determined that stresswave NDE proved to be a valid method for evaluating the mechanical properties of salvaged wood.

\subsection{Effect of moisture}

Moisture content of solid wood and wood based composite is one important variable that has an effect on the stress wave propagation. It has been noted that in solid wood, stress wave velocity decreases as the moisture content increases (Gerhards 1975). Through the hygroscopic range Wu 
(1999) noted that the velocity of the stress wave decreases by about $1 \%$ per increase in moisture content percent change. Seeling (1999) observed that reducing the moisture content from 18 to $10 \%$ led to an average increase in dynamic MOE of $700 \mathrm{MPa}$ for all specimens. Bradshaw et al. (1997) examined the relationship between moisture content or preservative treatment and the dynamic MOE. Their results proved a definite relationship between the green and dry dynamic MOE, however, each species tested had different regression equations to fit the data. They also noted that preservative treatment did not appear to have any affect on the stress wave velocity on the veneer.

\subsection{Screw withdrawal}

Screw withdrawal resistance is a relatively new concept in which a screw is inserted into a wooden member and the amount of force required to extract the screw is recorded. Researchers have been testing this method to try to correlate it with either the modulus of rupture or density of the member in question. Winandy et al. (1998) states that screw withdrawal force has been shown to be a simple indicator of the reduction in MOR by thermal degradation. They also noticed in their study on fire retardant plywood that when using screw withdrawal force as the predictor of MOR, the same regression equation could be used regardless of the treatment level of the plywood. Divos et al. (1998) used screw 
withdrawal force in their NDE of a castle in Papa, Hungary. What they found were good correlation coefficients for screw withdrawal force vs. MOR, screw withdrawal force vs. density, and screw withdrawal force vs. shear modulus, with $r^{2}$ values of $0.72,0.79$, and 0.86 , respectively. They also noted that it was expected for the best correlation to be between screw withdrawal force and the shear modulus, as shear was the main stress type observed in their investigation.

\subsection{Overview}

Nondestructive evaluation (NDE) of materials is, by definition, the science of identifying the physical and mechanical properties of a piece of material without harming that material (Suprenant et al. 1992). With the aging infrastructure the world is experiencing, a reliable method for in situ determination of mechanical properties needs to be developed. The previously defined objectives of this research were aimed to answer some of the queries that related to the non-destructive evaluation of wooden structural members. The reminder of this work provides discussion of materials and methods, results, and conclusions in the next five chapters as follows:

Chapter 2 - Contains the materials and methods used during this research. Here a detailed description of the methods used in achieving the objectives of this 
investigation can be found. All materials used, along with solid wood species and composite products tested can also be found in this chapter.

Chapter 3 - Contains results of this investigation along with a discussion of the findings. The results of this experiment are broken down by the solid wood species or composite group tested and discussed individually. A summary of the results is also included along with findings in regards to the combined data.

Chapter $4-$ In this chapter the conclusions for this research are presented. Recommendations for further research are also presented in this chapter.

Chapter 5 - A side-study concerning the effect of creosote treatment was also performed in this research. This chapter contains a brief introduction, materials and methods, results, and conclusion section for this particular investigation.

Chapter 6 - The effect of moisture on the stress wave timing technique being developed by this research was also investigated. Chapter 6 contains all sections of this investigation regarding the effect of moisture on this particular non-destructive testing method. 


\section{CHAPTER 2 - MATERIALS AND METHODS}

\subsection{Materials}

This research was aimed at determining the relationship, if any, of various non-destructive testing method results to the true mechanical and physical properties of the specimens across several species and composite products. Development of such relationships would aid the in situ determination of strength and stiffness of members. The relationship between dynamic and true MOE along with dynamic and apparent MOE are two of the mechanical properties were investigated. Another mechanical property, MOR, was investigated as to it's relationship with the non-destructive testing method screw withdrawal resistance. Screw withdrawal force was also investigated as a predictor of the density of the specimen.

In this research four types of solid structural lumber were investigated as to the relationship between dynamic and true MOE along with screw withdrawal force to MOR, and screw withdrawal force to density:

1. Spruce-Pine-Fir (SPF) - (Picea spp., Pinus spp., Abies spp.)

2. Southern Yellow Pine (SYP) - (Pinus spp.)

3. Red Oak - (Quercus spp.)

4. Yellow-Poplar - (Liriodendron tulipifera) 
Furthermore, the following two types of structural composite lumber products were analyzed for the same items mentioned previously:

Parallel Strand Lumber (PSL) - (Liriodendron tulipifera)

Laminated veneer Lumber (LVL) - (Liriodendron tulipifera)

Hardwood structural lumber was obtained from a Kingwood, West Virginia sawmill and the softwood species were obtained from a Morgantown, West Virginia building supply center. The initial specimen size of solid structural lumber was of nominal 2 in. by 6 in. by $8 \mathrm{ft}$. (1.5" x 5.5" x 8 ' actual). The grades of the solid structural lumber were varied between Select, \#1 common, and \#2 common for the hardwood species using hardwood grade rules based on appearance from the National Hardwood Lumber Association. Allegheny Wood Products performed the grading of the hardwood lumber. Grades for the structural size softwood species were also varied between select structural, \#1, and stud grade. All softwood lumber species were graded under product standard 20-94 from the U.S. department of standards. Varying grades provided a range of mechanical property values for each species. This range allowed the evaluation of the stress wave timing and screw withdrawal force throughout different types of defects that may normally decrease the mechanical properties of wood. Some of these defects included knots, juvenile wood, slight fungal attack, and sloping grain. The previously mentioned are defects that could typically be encountered when performing an in situ evaluation, thus it was felt to be in good interest to subject the tests to the same undesirable defects as previously mentioned. The testing was also performed on some higher-grade 
lumber such as Select and Select structural, so as to test some more defect free specimens.

Composite products were obtained from TrusJoist, a Weyerhaeuser business, in Buckhannon, WV. Initial specimen size of the LVL composite product was $1.75 \mathrm{in}$. by $5.5 \mathrm{in}$. by $8 \mathrm{ft}$. actual. The PSL specimens were cut to dimensions of 1.5 in. by $3.5 \mathrm{in}$. by $8 \mathrm{ft}$. actual.

\subsection{Methods}

\subsubsection{Structural size testing}

For at least 30 days prior to any testing, and between stages of testing, all specimens remained in a conditioning chamber where the moisture content was allowed to equalize. The conditions in the chamber, both temperature and relative humidity, were monitored and controlled such that the resulting moisture content of the specimens would be 10 percent using the dry-basis calculation (ASTM D4442-92). Average conditions in the chamber were $85^{\circ}$ Fahrenheit and $57 \%$ relative humidity. Immediately prior to testing the specimens were checked with a hand held moisture meter, with species correction, to ensure that the moisture content was within the range of $9-11 \%$ moisture content.

After the equalization period the specimens were numbered $1-100$ by species or composite product and initial cross sectional measurements were taken. Each specimen was measured in three places along the length for width 
and thickness using digital calipers accurate to 0.001 centimeter. Measurement locations were three inches in from both ends and once at the center point of the specimen. Specimens were also measured for length using a steel tape measure accurate to 0.03125 inch (1/32") and the measurement converted to centimeters. Mass of each specimen was determined using a digital balance accurate to 0.1 gram. All measurements were recorded for future use in calculations of section modulus, moment of inertia, volume, and density. Section modulus of each specimen was calculated using the following formula:

$$
S_{x}=\frac{a h^{2}}{6}
$$

Where:

$S_{x}=$ section modulus $\left(\mathrm{in}^{3}\right)$

$a=$ average width of specimen (in)

$h=$ average height of specimen (in)

The formula used for the calculation of moment of inertia $\left(\mathrm{I}_{\mathrm{x}}\right)$ is as follows:

$$
I_{x}=\frac{a h^{3}}{12}
$$

Where:

$I_{x}=$ moment of inertia $\left(\mathrm{in}^{4}\right)$

$a=$ average width of specimen (in)

$h=$ average height of specimen (in) 
Density $(\rho)$ of each specimen could then be calculated using the following formula:

$$
\rho=\frac{m}{V}
$$

Where:

$\rho=\operatorname{density~}\left(\mathrm{kg} / \mathrm{m}^{3}\right)$

$m=\operatorname{mass}(\mathrm{kg})$

$V=$ volume $\left(\mathrm{m}^{3}\right)$

Stress wave timing was then performed on each specimen. The specimens were held securely to a bench through a bench-mounted vise. A cardboard under-layer was used as to reduce any interference that may be created by the wooden bench top. The stress wave timer used was a FAKOPP digital stress wave timer, which measures wave propagation times in microseconds ( $\mu \mathrm{s})$. This device consists of a timer, receiver and a transmitter. The transmitter and receiver were inserted into the specimen at approximately $45^{\circ}$ angles and at an entry distance of 2.0 meters (m) apart. Figure 2.1 shows the testing setup. Stress waves are sent through the specimen by striking the transmitter with a small hammer. The wave travels through the specimen until it reaches the receiver, upon which the timer relays the time from which the wave was sent until it was received. The timer requires a $26.5 \mu$ s correction factor be deducted from the wave time, to correct for the time of the signal to travel through the cables and time to be processed by the device. 


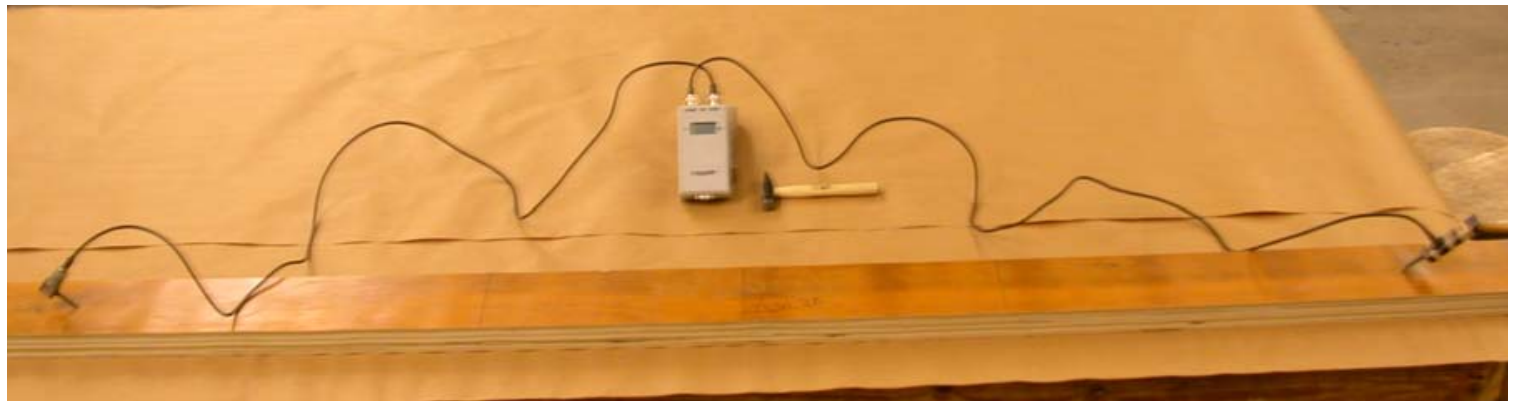

Figure 2.1. - Testing setup for stress wave timing experiment. 
Five consecutive waves were sent through each specimen and recorded. Average wave time was used in the calculation of the velocity. The calculation used for the velocity is as follows:

$$
v=\frac{L}{S W T}
$$

Where:

$v=$ velocity $(\mathrm{m} / \mathrm{s})$

$L=$ testing span $(\mathrm{m})$

$S W T=$ stress wave time $(\mathrm{s})$

The dynamic modulus of elasticity $\left(\mathrm{E}_{\mathrm{D}}\right)$ may then be calculated using the following formula:

$$
E_{D}=v^{2} \rho
$$

Where:

$E_{D}=$ dynamic modulus of elasticity $(\mathrm{Pa})$

$v=$ velocity $(\mathrm{m} / \mathrm{s})$

$\rho=\operatorname{density}\left(\mathrm{kg} / \mathrm{m}^{3}\right)$

Each specimen was then tested in static bending using a four-point setup to determine the true modulus of elasticity (ASTM 198-94). For this testing a Baldwin universal testing machine with a $20,000 \mathrm{lb}$. load cell was used. Prior to start the load cell was calibrated using a calibration ring. Testing setup was such that the total span was 90 inches with the load application heads spaced thirty 
inches apart, providing three equally spaced sections. The radius of the load application heads was in accordance with ASTM D 198-94 (1995). Deflection was measured using a potentiometer attached to a support yoke. The testing yoke was hung from two small support nails inserted into the specimen at the neutral plane of the specimen. Support nails were spaced 30 inches apart, directly under the load application blocks, such that only deflection was measured in the shear free region. The linear pot meter was hung from the center point between the two support nails and also in the neutral plane of the specimen. Figure 2.2 is a diagram of the testing setup. Load was applied through the specimen at a rate of 0.1 inch per minute (ASTM D 198-94). A computer data acquisition program collected load deflection data at a rate of one reading per second throughout the test. The specimens were tested only to a load of $2000 \mathrm{lbs}$ before the test was terminated.

The load deflection data is then plotted in a simple scatter plot using the calibrated load values as $Y$ values and deflection as $X$ values. Linear regression is then performed on the plotted data and the deflection is then corrected to pass through the 0,0 position of the graph. Figure 2.3 is a representation of a load/displacement diagram with correction. From this corrected load and displacement data the moment and true MOE can be calculated. 


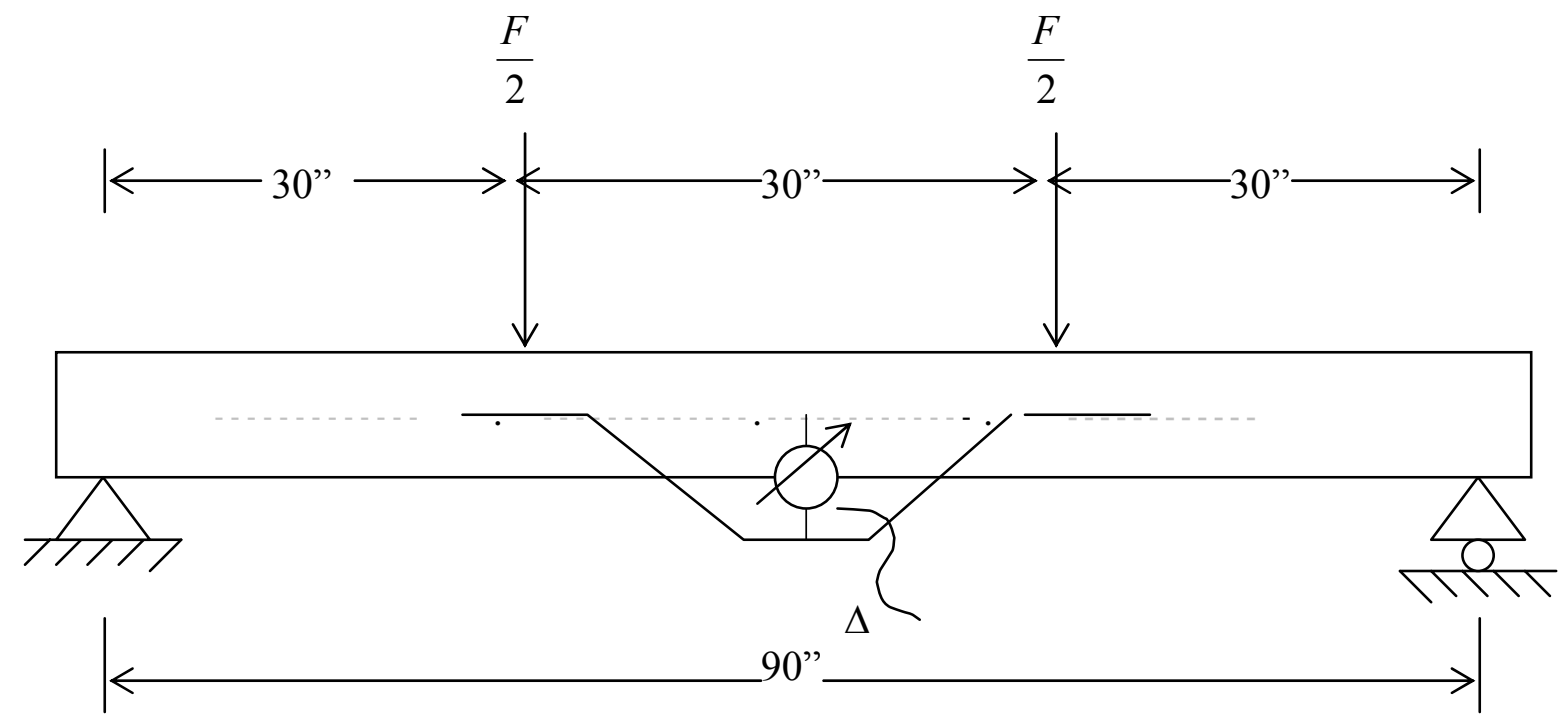

Figure 2.2. - Four-point static bending setup. 


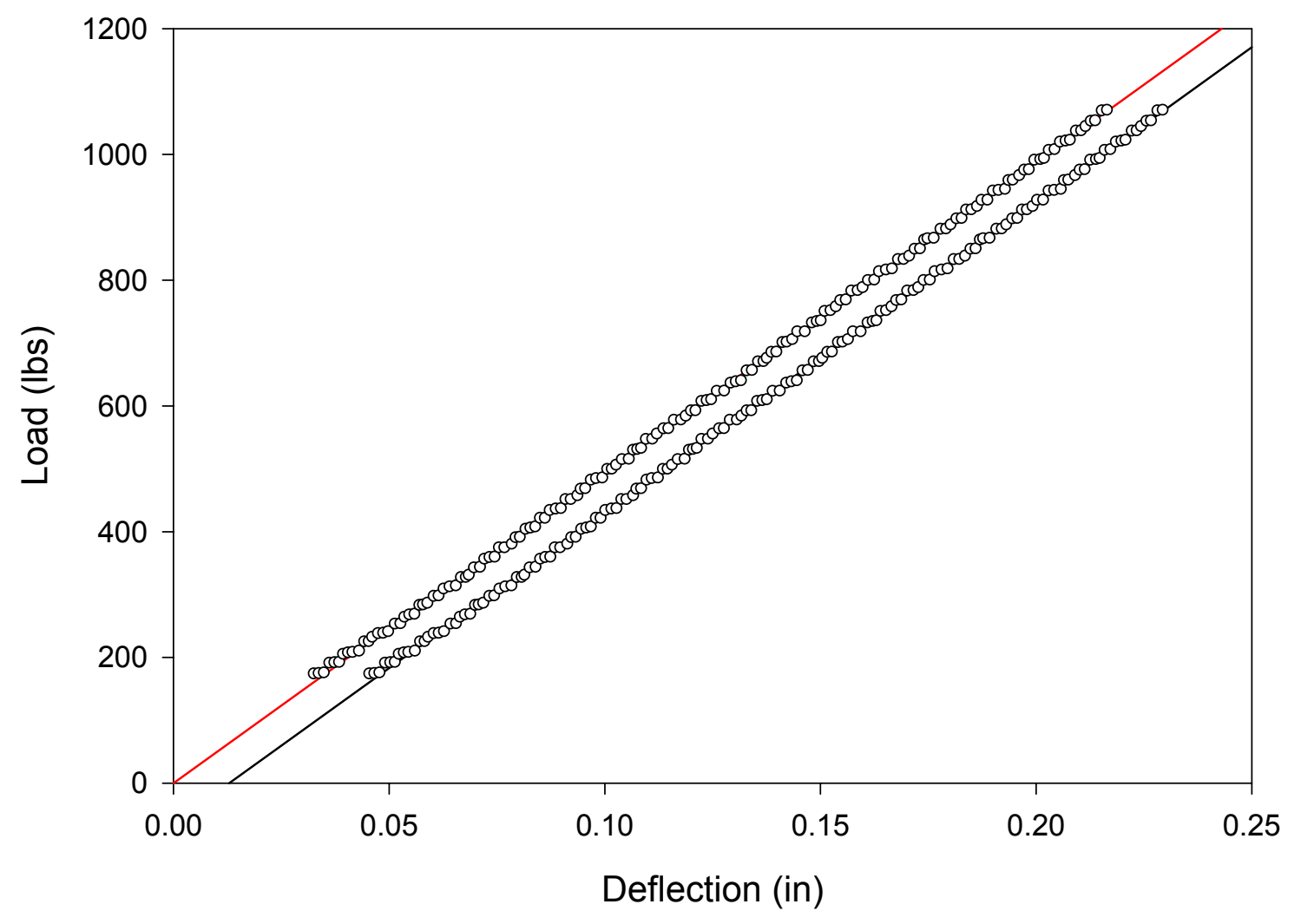

Figure 2.3. - Load deflection diagram, containing deflection correction, for LVL. 
The formula used for the calculation of moment is as follows (ASTM D198-

94):

$$
M=\frac{F}{2} \frac{L}{3}
$$

Where:

$M=$ moment (in-lbs)

$F=\operatorname{load}(\mathrm{lbs})$

$l=$ testing span (in) (90)

Finally the true MOE could be calculated using the following formula (ASTM D198-94):

$$
E_{T}=\frac{M \cdot L^{2}}{8 I_{x} \Delta}
$$

Where:

$E_{T}=$ true modulus of elasticity (psi)

$M=$ moment (in lbs)

$L=$ test span in which deflection was measured (in) (30)

$I_{x}=$ moment of inertia $\left(\mathrm{in}^{4}\right)$

$\Delta=$ deflection (in) 


\subsubsection{Small specimen testing}

From each of the six groups of structural size specimens 25 were randomly chosen for further testing. Four smaller specimens were cut from each of the 25 structural size specimens, resulting in an additional 100 specimens of each type that could be tested in small specimen bending for apparent MOE and MOR. The exception to this is the PSL group. The cross section of the structural size PSL specimens only allowed two small specimens to be cut, so the number of structural size specimens used was 50 so as to attain 100 small specimens.

The small specimen testing was to be in accordance with ASTM D 143 (1983) with the exception of specimen size. Since the original structural size specimens were only 1.5 inches in width the resulting small specimens were cut to the dimensions of $1.5 \mathrm{in.} \times 2.0$ in. by $30.0 \mathrm{in}$. These specimens were cut two from each end of the structural size specimens. Figure 2.4 represents the cut pattern for the small specimens.

After all specimens were cut, cross sectional measurements were taken. Measurement placement, frequency, and devices used were the same as described in the previous section, 2.2.1. From the measurements acquired the section modulus, moment of inertia, density, and volume could then be calculated using the same equations presented in 2.2.1. 


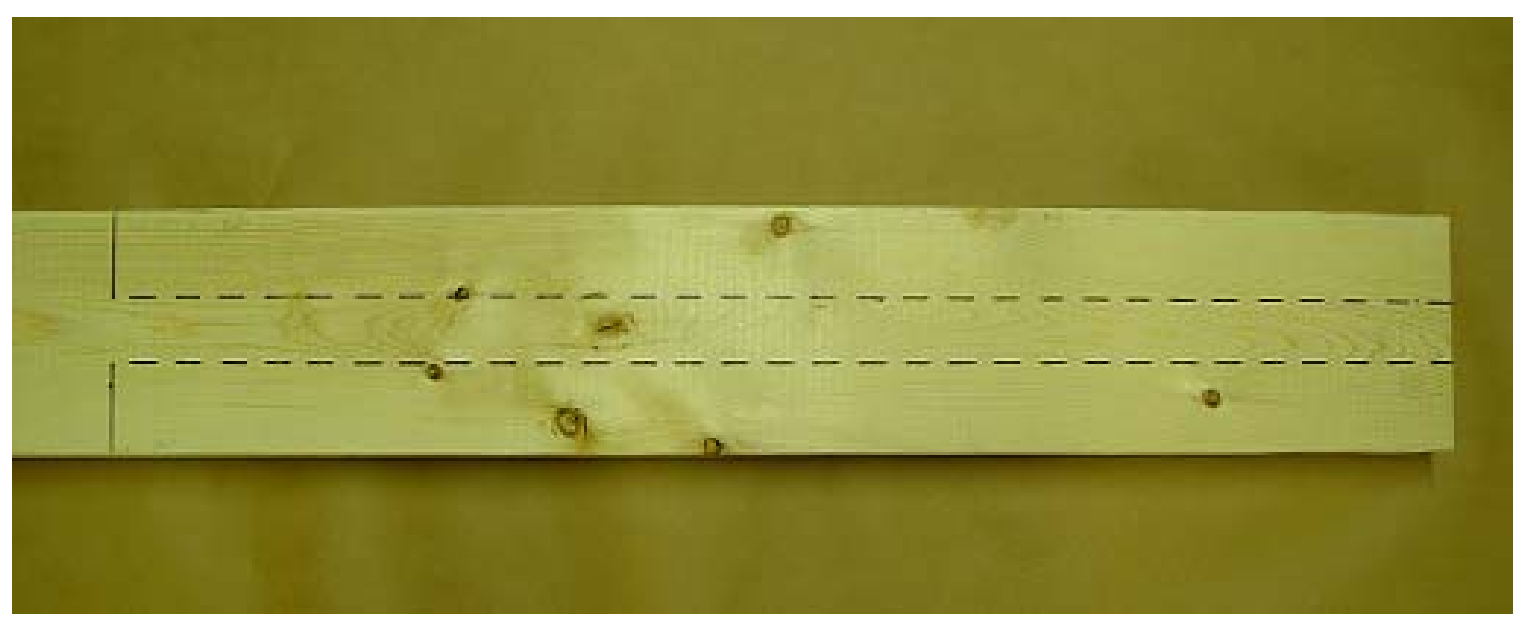

Figure 2.4. - Representation of cut pattern for extracting small test specimens from structural size specimens. 
Next the specimens were tested using stress wave timing. The specimens were again secured to the test bench using the vise and cardboard insulation pad. The transmitter and receiver were inserted into the specimen at approximately $45^{\circ}$ angles and at an entry distance of $0.635 \mathrm{~m}$ (25 in). Five waves were sent through each specimen and the average wave velocity, minus $26.5 \mu$ s correction factor, was used in the calculation of the dynamic MOE. The formula used to calculate the dynamic MOE is equation number 5 , presented in section 2.2.1.

The specimens were then tested in static bending for MOR and apparent MOE. The MOE in this testing was only apparent MOE as it was biased by additional deflection caused by shear. An Instron universal testing machine with a $10,000 \mathrm{lb}$. load cell, checked for calibration prior to testing, was used for this testing. The testing setup was three-point bending with a span of 28 inches and one load application block that was centered between the supports. The radius of the load application block was in accordance with ASTM D-143. Deflection was measured across the testing span of 28 inches using a potentiometer attached to a support yoke. Supporting the yoke were two small nails, which were inserted into the specimen as to be located directly above the end supports and in the neutral plane. The pot meter was attached at the center point of the specimen and again in the neutral plane. Load was applied to the specimen through the load application block at a constant rate of 0.1 in. per minute. Specimens were tested to the point of failure while a computer data acquisition 
system captured the load and deflection data. Figure 2.5 represents the threepoint bending test setup. 


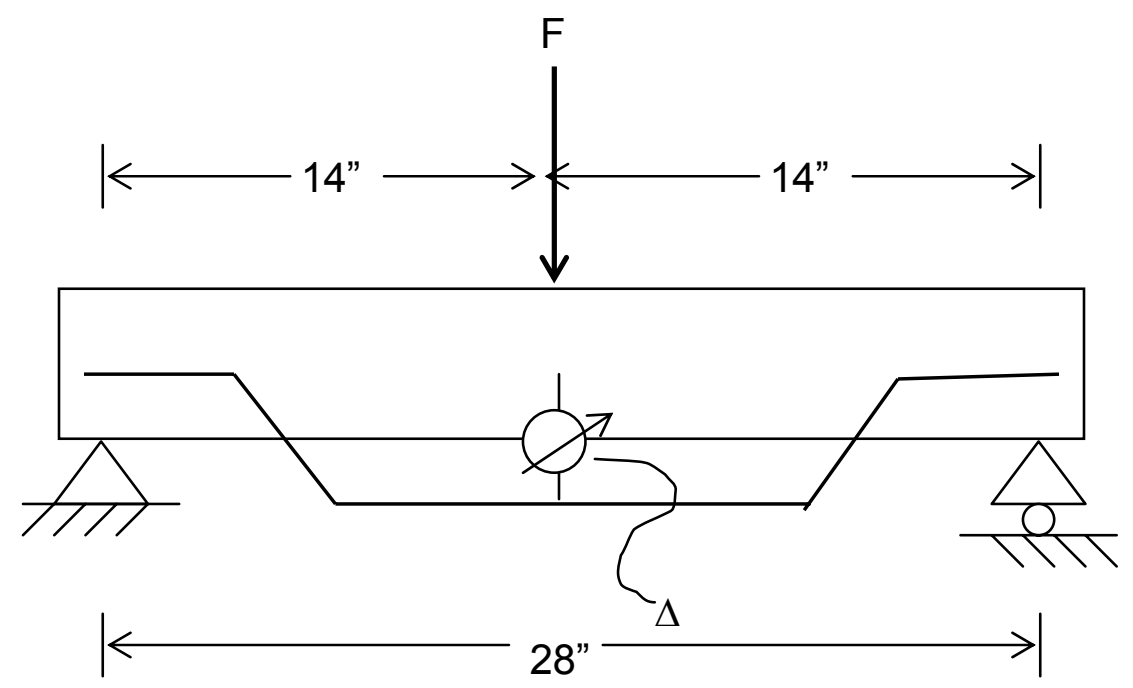

Figure 2.5. - Three-point static bending setup. 
Once testing was complete, the load and deflection data were plotted against each other as a simple scatter plot using the load data as $Y$ values and the deflection data as $\mathrm{X}$ values. Linear regression was performed to the data and the deflection was corrected to pass through the 0,0 point of the graph (Figure 2.3). Once the load and deflection data is corrected the maximum moment, MOR, and apparent MOE can be calculated using the corrected data. Maximum moment was calculated using the following formula (ASTM D 143 1983):

$$
M_{\operatorname{Max}}=\frac{F_{\operatorname{Max}} L}{4}
$$

Where:

$M_{M a x}=$ maximum moment (in-lbs)

$F_{M a x}=$ maximum breaking force (lbs)

$L=$ testing span (in)

MOR was calculated using the formula (ASTM D 143 1983):

$$
M O R=\frac{M_{\operatorname{Max}}}{S_{x}}
$$

Where:

$M O R=$ modulus of rupture $(\mathrm{psi})$

$M_{\text {Max }}=$ maximum moment (in-lbs)

$S_{x}=$ section modulus $\left(\right.$ in $\left.^{3}\right)$ 
The apparent MOE was calculated using the following formula (ASTM D 143 1983):

$$
E_{A}=\frac{F L^{3}}{48 I_{X} \Delta}
$$

Where:

$E_{A}=$ apparent modulus of elasticity (psi)

$F=\operatorname{load}(\mathrm{lbs})$

$L=$ testing span (in) (28)

$I_{x}=$ moment of inertia $\left(\mathrm{in}^{4}\right)$

$\Delta=$ deflection (in) 


\subsubsection{Screw withdrawal testing}

After the small specimen static testing, each specimen underwent screw withdrawal testing. In this procedure two pilot holes were drilled into the specimen approximately four inches in from either end. The pilot holes had a diameter of $4.90 \mathrm{~mm}$. and a depth of one inch. This was performed using a drill press equipped with a depth stop. Next a screw was inserted into the pilot hole to a total depth of 1.75 inches. This was such that the entire thread length of the screw was in solid wood and only the shank of the screw remained in the pilot hole. The screw was a \#10 stainless steel screw having a thread length of $20 \mathrm{~mm}$ ( $0.75 \mathrm{in})$; the rest of the threads had been milled off using a metal lathe. Figure 2.6 is a representation of the screws used for this testing. Figure 2.7 is a detailed view of the pilot hole and pilot hole with an inserted screw.

An MTS universal testing machine, using a $2000 \mathrm{lb}$. load cartridge, was used for the screw withdrawal testing. The specimen was first clamped to a support base using clamps, as to ensure its stability throughout the test. Next the screw head was inserted into the clamping plate. This plate was a $3 / 16$ " flat steel plate of square shape with a groove cut leading to center. At the center point there is a rounded recessed portion where the screw head rested. The steel plate was then attached to the cross head through the use of a special fixture which supported the plate on two opposite edges. Figure 2.8 is a representation of the testing setup used. 


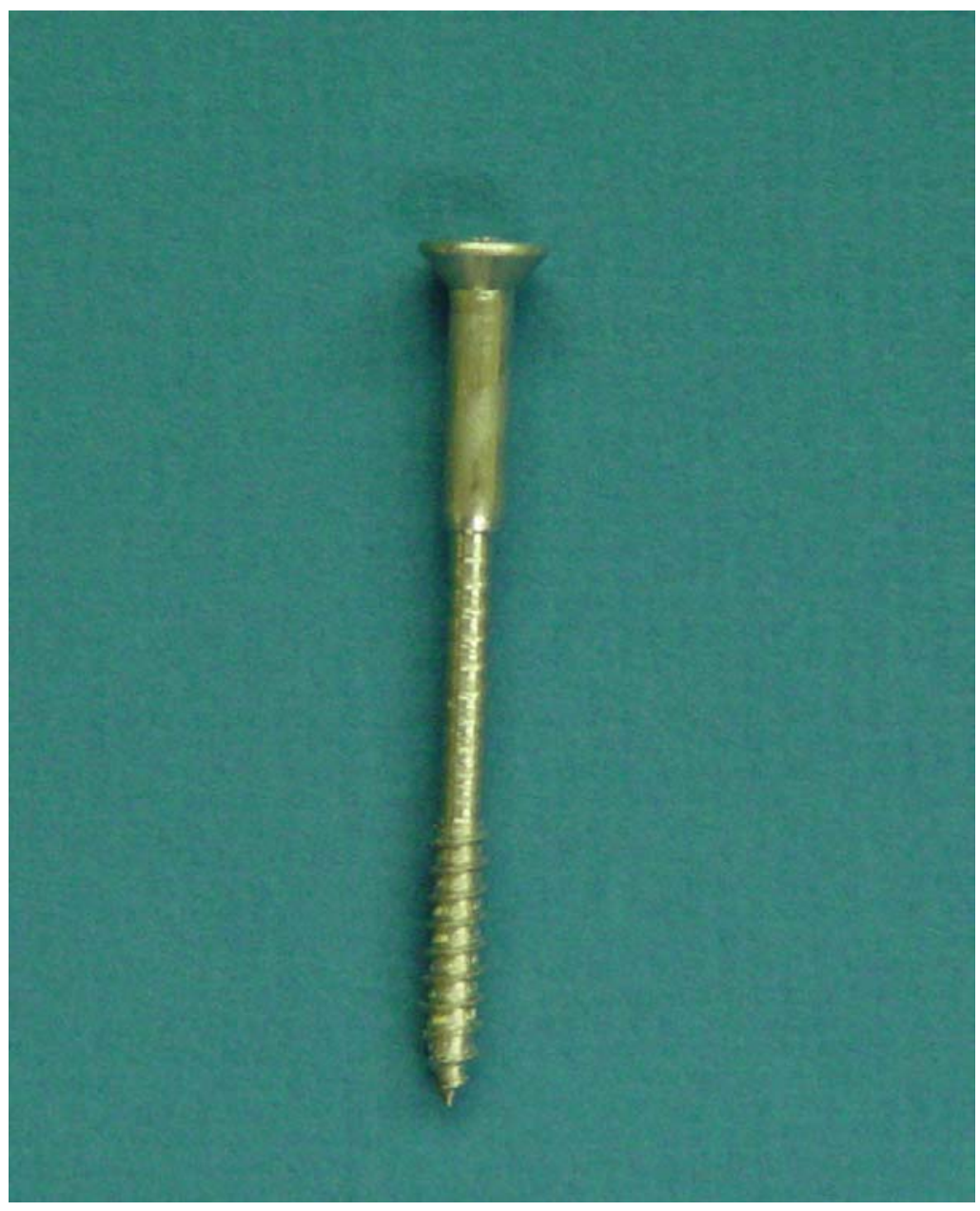

Figure 2.6. - Screws used for screw withdrawal testing. 


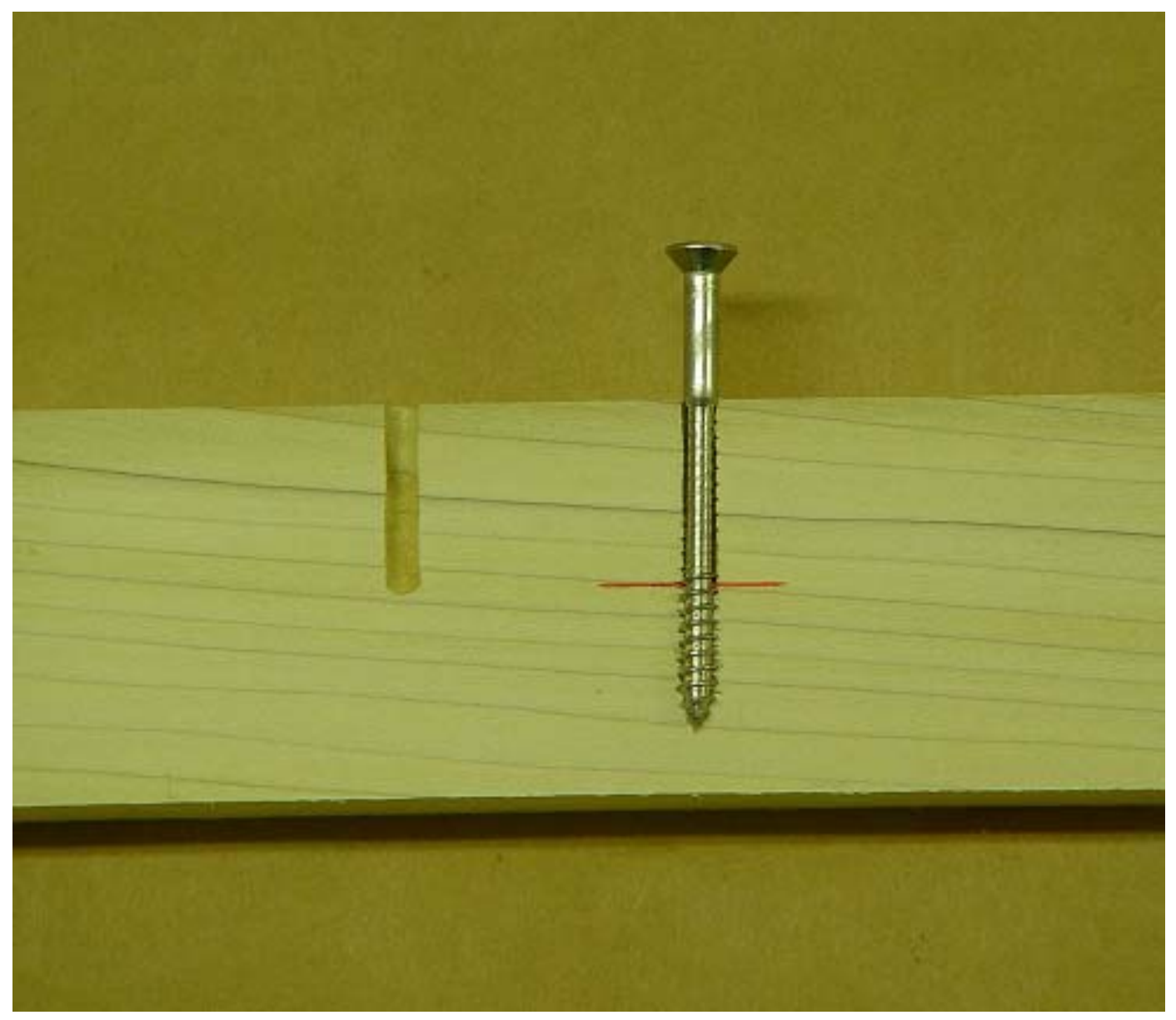

Figure 2.7. - Screw withdrawal testing pilot hole and screw insertion detail. 


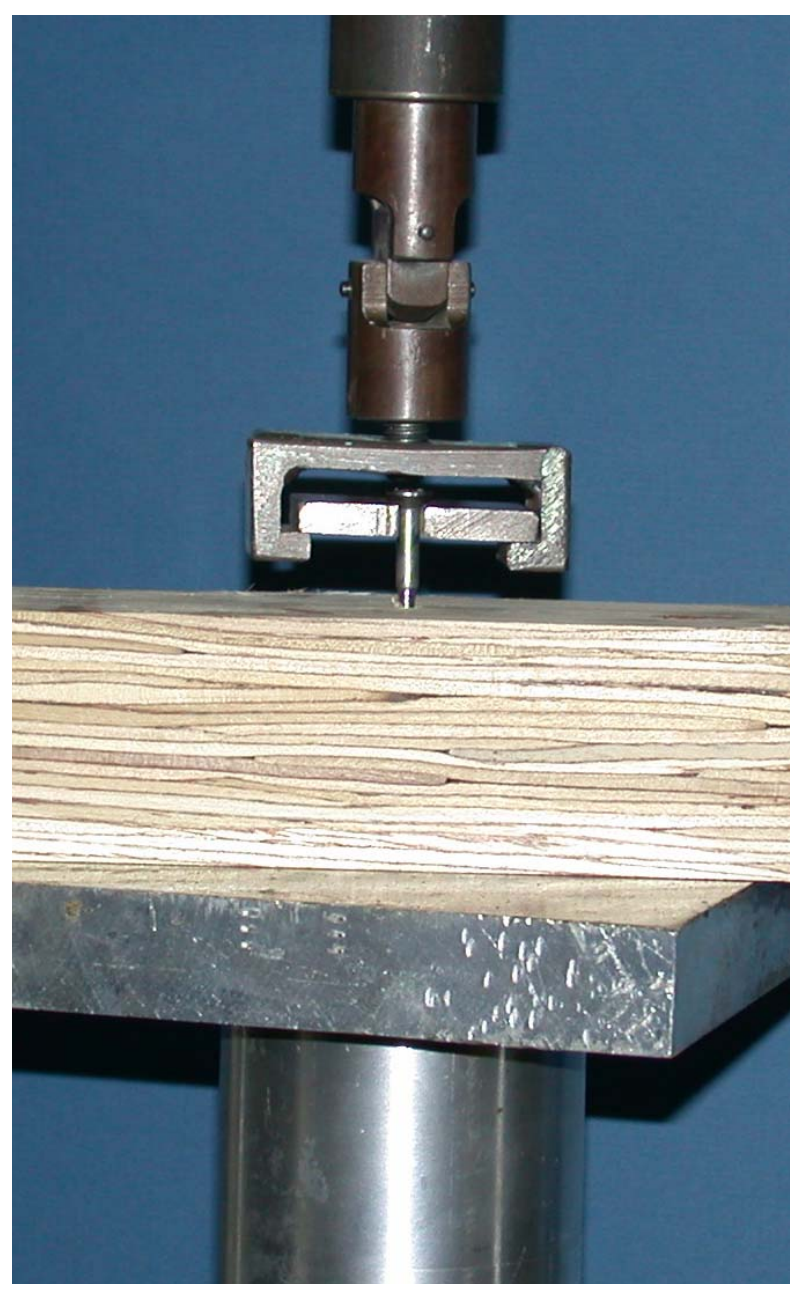

Figure 2.8. - Screw withdrawal testing setup. 
For screw withdrawal load was applied through the screw, parallel to the longitudinal axis, at a constant rate of movement at 0.1 inches per minute. The maximum amount of force required to extract the screw from the specimen was recorded. Two screws were extracted from each specimen and the average withdrawal force was used for comparison purposes.

All raw measurements were entered into a Microsoft Excel spread sheet according to group. Calculations for density, volume, dynamic MOE, section modulus, moment of inertia, and cross sectional area were then performed. The load deflection data from each specimen was analyzed using Sigma Plot and the true MOE, apparent MOE, and MOR calculated. Once these calculations were determined the results were also entered into the appropriate Microsoft Excel spreadsheet. After all data had been collected and all calculations performed, the data was analyzed using the statistical software SAS to test for the relationships and effects of group through linear regression and analysis of variance. 


\subsection{Statistical methods}

Several statistical methods were used to analyze the data obtained from this research project. The statistical method best suiting the comparison at hand was used in each case. Proceeding is a summary of the statistical methods and the applications for which they were used.

When comparing two variables, such as $E_{D}$ vs. $E_{T}$, a simple first order linear regression model was used. Using a simple linear model provided an easy to use prediction equation that fit the data. The format of this equation is as follows:

$$
Y=\beta_{0}+\beta_{1} X
$$

To investigate the possibility of using two independent variables, density and screw withdrawal force, to predict modulus of rupture was performed using a backward method multiple linear regression. This method was used to screen out the interaction effect of density and screw withdrawal force. The format of the equation used was:

$$
Y=\beta_{0}+\beta_{1} X_{1}+\beta_{2} X_{2}+\beta_{3} X_{1} X_{2}
$$


Testing the effect of species or composite groups on the non-destructive testing methods was performed using a general linear model. This procedure tested the interaction effect of species or composite group through the following model:

$$
Y_{i j}=\mu+\alpha_{i}+\left(\beta+\alpha \beta_{i}\right) X+e_{i j}
$$




\section{CHAPTER 3 RESULTS AND DISCUSSION}

During the course of this research approximately one thousand two hundred specimens were evaluated for dynamic modulus of elasticity, true modulus of elasticity, and fastener holding capacity. The replication number of one hundred for each species and composite types ensured robust statistical analyses that could handle the natural variability of wood and wood based composite products. Additionally, the same materials were used to form small clear specimens for modulus of rupture, apparent modulus of elasticity, and fastener holding capacity determinations. The number of replications for these analyses was set to one hundred also. In general, a simple linear regression technique proved to be the most effective tool to describe the relationship between dependent and independent variables. Each subsection contains a table describing the parameters of these regression equations along with the coefficients of determinations $\left(\mathrm{r}^{2}\right)$ and the $\mathrm{P}$ values. Table 3.1 contains the summary statistics of the overall test results. In which the mean, standard deviation, minimum, and maximum values are listed by product type/species. In general, the true MOE values were significantly higher than the apparent MOE as it was expected. However, the percent differences were not consistent between species and composite products. This deviation is attributed to the high variation in shear moduli of wood and wood based products that affect the deflection in a three-point loading scenario. 
Table 3.1 Summary statistics of the overall test results.

\begin{tabular}{|c|c|c|c|c|c|c|c|c|}
\hline Group & Statistics & $\begin{array}{c}\text { Structural size } \\
\text { Dynamic MOE } \\
\text { (psi) }\end{array}$ & $\begin{array}{l}\text { True MOE } \\
\text { (psi) }\end{array}$ & $\begin{array}{l}\text { Density } \\
\left(\mathrm{g} / \mathrm{cm}^{3}\right)\end{array}$ & $\begin{array}{l}\text { MOR } \\
\text { (psi) }\end{array}$ & $\begin{array}{l}\text { Screw withdrawal } \\
\quad \text { force (lbs) }\end{array}$ & $\begin{array}{l}\text { Small specimen } \\
\text { Dynamic MOE } \\
(p s i)\end{array}$ & $\begin{array}{l}\text { Apparent MOE } \\
\text { (psi) }\end{array}$ \\
\hline \multirow[t]{4}{*}{ LVL } & Mean & 2248053 & 1894675 & 0.5530 & 11635 & 500.6 & 2237155 & 1668671 \\
\hline & St.dev. & 79399.5 & 99403.9 & 0.0172 & 854.1 & 66.2 & 151510.6 & 88933.2 \\
\hline & Minimum & 2021895 & 1657302 & 0.5100 & 9219 & 374.9 & 1814121 & 1422669 \\
\hline & Maximum & 2441233 & 2145011 & 0.6030 & 13853 & 745.7 & 2583161 & 1917597 \\
\hline \multirow[t]{4}{*}{ PSL } & Mean & 2729930 & 2067750 & 0.6520 & 10547 & 711.4 & 2735017 & 1790709 \\
\hline & St.dev. & 170365.9 & 108761.4 & 0.0191 & 1224.1 & 97.1 & 187894.4 & 145246.3 \\
\hline & Minimum & 2245478 & 1795990 & 0.5440 & 7760 & 438.6 & 2288025 & 1382388 \\
\hline & Maximum & 3205360 & 2328378 & 0.7010 & 13414 & 913.1 & 3378164 & 2339838 \\
\hline \multirow[t]{4}{*}{ R.O. } & Mean & 2021087 & 1760631 & 0.6948 & 11809 & 928.9 & 2056361 & 1521872 \\
\hline & St.dev. & 326818.3 & 275687.4 & 0.0600 & 2387.3 & 152.5 & 345866.8 & 325010.3 \\
\hline & Minimum & 1057650 & 1065054 & 0.5590 & 3012 & 650.5 & 2161635 & 657862 \\
\hline & Maximum & 2721144 & 2594484 & 0.8730 & 17344 & 1391.2 & 3788471 & 2433183 \\
\hline \multirow[t]{4}{*}{ SPF } & Mean & 1853382 & 1570167 & 0.4977 & 8987 & 527.2 & 1979761 & 1436477 \\
\hline & St.dev. & 286155.6 & 280328.8 & 0.0329 & 2327.9 & 80.8 & 329368.2 & 267967.9 \\
\hline & Minimum & 1138827 & 732015 & 0.3460 & 2705 & 348.8 & 916528 & 724051 \\
\hline & Maximum & 2692390 & 2196628 & 0.5850 & 14757 & 765.6 & 2684085 & 1993143 \\
\hline \multirow[t]{4}{*}{ SYP } & Mean & 1852583 & 1509028 & 0.5569 & 10306 & 688.0 & 2045017 & 1427481 \\
\hline & St.dev. & 488759.5 & 472072.1 & 0.0606 & 2245.4 & 128.4 & 477388.2 & 399176.3 \\
\hline & Minimum & 768307 & 509002 & 0.4070 & 4648 & 364.7 & 699711 & 474106 \\
\hline & Maximum & 3683929 & 3149915 & 0.7980 & 13979.1 & 932.6 & 3017278 & 2367551 \\
\hline \multirow[t]{4}{*}{ Y.P. } & Mean & 1920859 & 1570040 & 0.5476 & 9851.6 & 657.3 & 1863963 & 1429881 \\
\hline & St.dev. & 266023.3 & 287981.8 & 0.0543 & 2677.6 & 141.1 & 300118.2 & 297569.4 \\
\hline & Minimum & 1306108 & 670394 & 0.4120 & 1033 & 335.6 & 1075965 & 436105 \\
\hline & Maximum & 2690951 & 2311986 & 0.6960 & 14418 & 1053.9 & 2534122 & 2133135 \\
\hline
\end{tabular}

${ }^{*}$ For all testing the sample size was 100 except density, for which it was 200. 
Because the critical mechanical property (MOR) is usually described by physical and mechanical attributes, additional three-dimensional mesh plots were developed to visually evaluate the interaction effect of the independent variables on the MOR. However, beyond the applied multiple linear regression technique, development of mathematical models to describe these relationships was beyond the scope of this research.

This chapter discusses the results by structural composites and species in different sub-sections as follows.

\subsection{Results of LVL analyses}

In the first step of the data analysis the experimentally determined dynamic and true moduli of elasticity were compared. Figure 3.1 shows the results for structural size LVL materials. The high coefficients of determination $\left(\mathrm{r}^{2}\right.$ $=0.738)$ and the scatter plot indicated that strong correlation exists between these variables. However, the association between dynamic and apparent MOE is somewhat less pronounced (Figure 3.2). This may be attributed to the fact that the apparent MOE is shear biased and the materials have higher variability in modulus of rigidity $\left(\mathrm{G}_{\mathrm{XY}}\right)$. On the other hand, concerning biological materials the prediction of this linear regression is still acceptable $\left(r^{2}=0.550\right)$. 


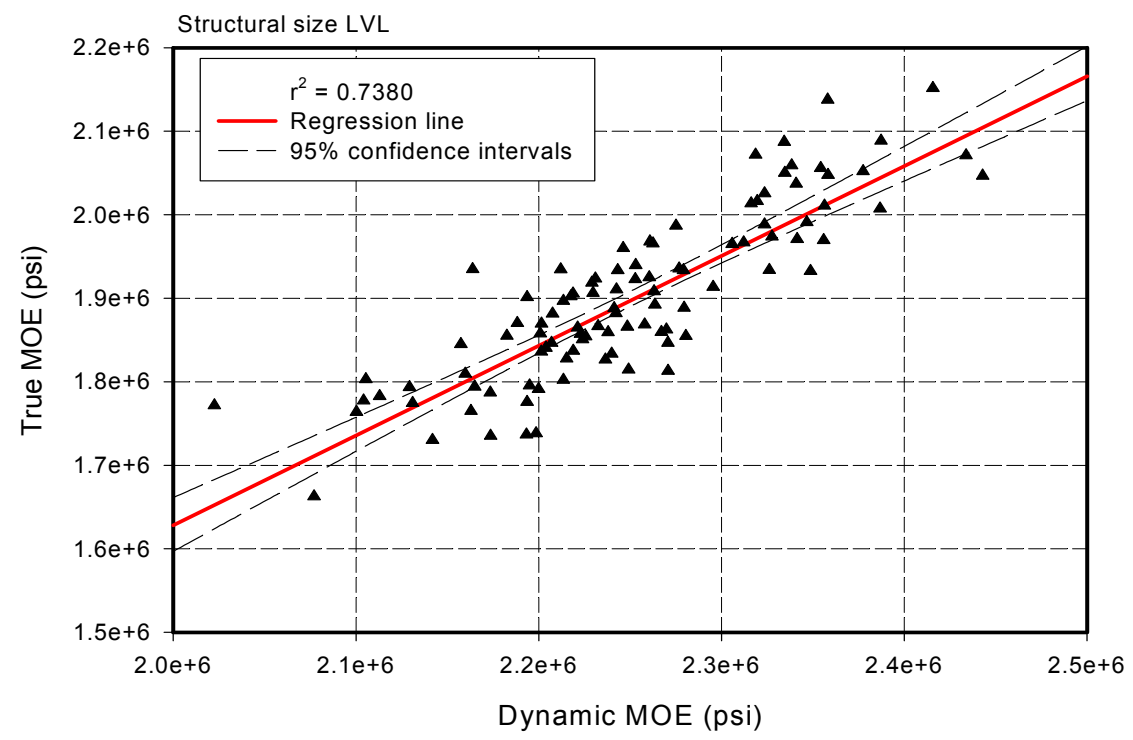

Figure 3.1. - Regression analysis of dynamic vs. true MOE for structural size LVL specimens, $95 \%$ confidence intervals and $\mathrm{r}^{2}$ value are indicated.

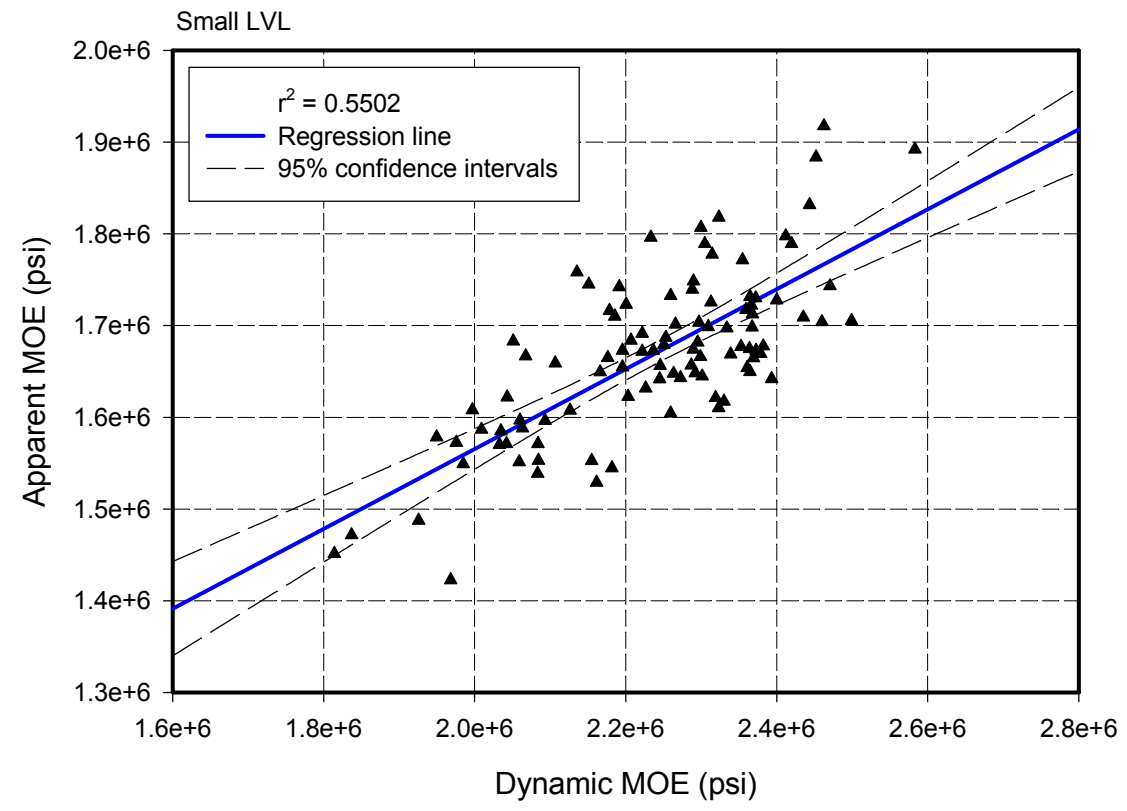

Figure 3.2. - Regression analysis of dynamic vs. apparent MOE for LVL small specimens, $95 \%$ confidence intervals and $\mathrm{r}^{2}$ value are indicated. 
Figure 3.3 indicates acceptable correlation between screw withdrawal resistance and MOR. The model resulted in $r^{2}=0.634$ which indicates that the screw withdrawal resistance of LVL might be a good indicator of true bending strength of the product.

Initially, strong correlation was hypothesized between screw holding capacity and density of the substrate. As demonstrated in Figure 3.4 this is not true for LVL lumber. However, the obtained P value $(<0.0001)$ indicates that the relationship is statistically significant. The weak association between the model (regression line) and the data can be explained by the narrow range of density variation of LVL. Table 3.2 contains the parameters of the regression equations obtained from LVL evaluations.

The combined effect of density and fastener holding capacity of LVL may be studied on Figure 3.5. As the mesh plot indicates, some curvy-linear relationship may exist. However, backwards-stepwise regression revealed that the fastener holing capacity and the density are the best predictors for the bending strength of LVL. In the model the interaction effect was statistically insignificant (Appendix VIII). 


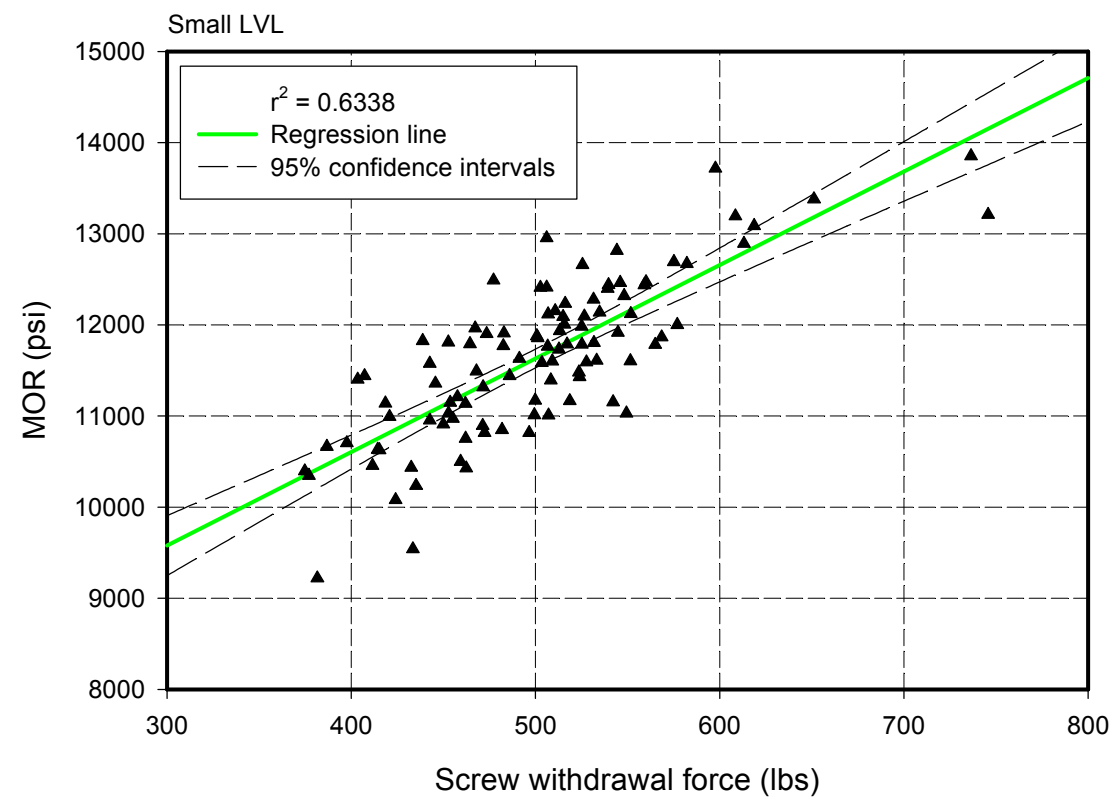

Figure 3.3. - Regression analysis of screw withdrawal force vs. MOR for LVL small specimens, 95\% confidence intervals and $\mathrm{r}^{2}$ value are indicated.

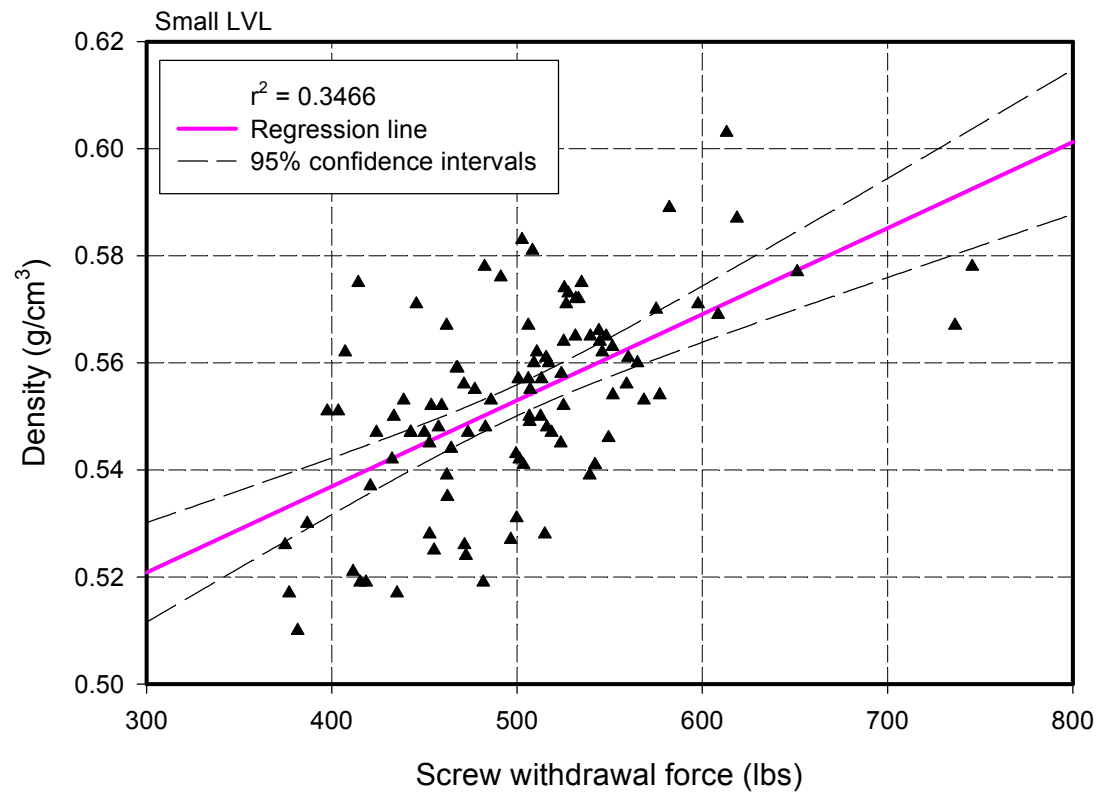

Figure 3.4. - Regression analysis of screw withdrawal force vs. density for LVL small specimens, 95\% confidence intervals and $r^{2}$ value are indicated. 
Table 3.2. - Parameters and statistics of regression analysis for LVL.

\begin{tabular}{ccccccc}
\hline $\begin{array}{c}\text { Dependent } \\
\text { Variable }\end{array}$ & $\beta_{0}$ & $\beta_{1}$ & Variable & $\boldsymbol{r}^{2}$ & $\boldsymbol{P}$ \\
$(\mathrm{Y})$ & & & $(\mathrm{X})$ & & \\
\hline $\mathrm{E}_{\mathrm{T}}$ & -523109 & 1.0755 & $\mathrm{E}_{\mathrm{D}}$ & 0.738 & $<0.0001$ \\
$\mathrm{E}_{\mathrm{A}}$ & 694660 & 0.4354 & $\mathrm{E}_{\mathrm{D}}$ & 0.550 & $<0.0001$ \\
MOR & 6496 & 10.2662 & $\mathrm{SWF}$ & 0.634 & $<0.0001$ \\
Density & 0.4726 & 0.0001609 & SWF & 0.347 & $<0.0001$ \\
\hline
\end{tabular}




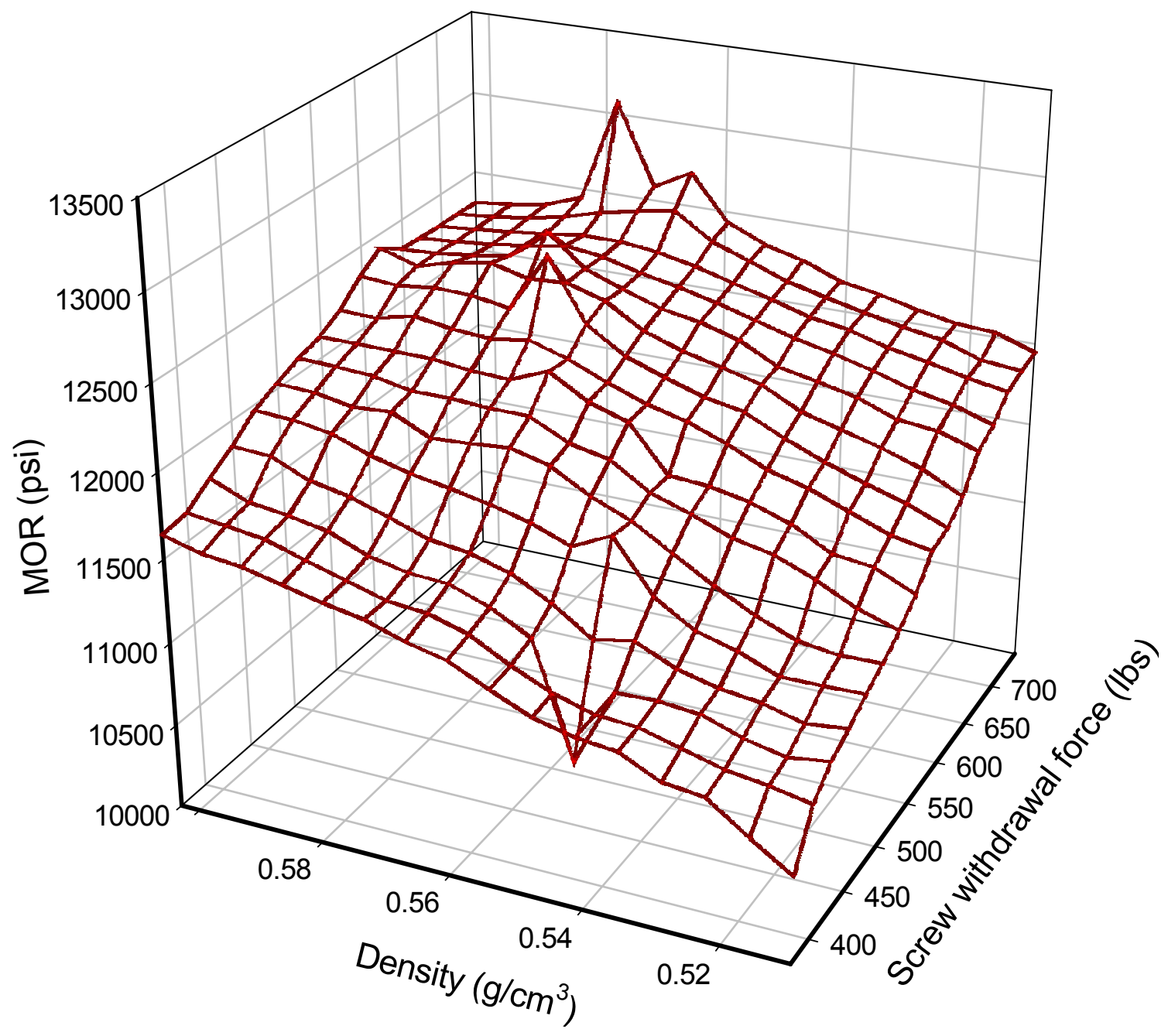

Figure 3.5. - Three-dimensional mesh plot of screw withdrawal force, density, and MOR for LVL. 


\subsection{Prediction of the properties of PSL}

Figure 3.6 shows the relationship between dynamic and true MOE of PSL. Similarly the regression analysis proved that statistically significant correlation exists between these properties $\left(r^{2}=0.622\right)$. As it was observed for $L V L$, the dynamic MOE is less effective in prediction of the apparent MOE for PSL (Figure 3.7).

Screw retention strength of PSL samples proved to be good predictors for MOR, as demonstrated in Figure 3.8. The regression analysis on the relationship between screw withdrawal strength and density resulted in comparatively low $r^{2}$ value discouraging the use of screw withdrawal force as a predictor of density. However, as in the case of LVL the correlation between the variables were statically significant according to the obtained $\mathrm{P}$ value (Figure 3.9). Table 3.3 lists the parameters and statistics of these regression analyses.

Figure 3.10 demonstrates the visual evaluation of the interaction effect of density and fastener holding capacity on the MOR. The chart shows sharp peak drops in MOR at certain locations and the interaction effect does appear to be linear. On the other hand, the linear regression analysis eliminated the interaction in the model between these two variables. The best predictor of MOR for PSL turned out to be fastener-holding capacity alone (Appendix VIII). The random occurrence in changes in MOR may be explained by the random voids in the PSL product and the inherent natural variability of the yellow-poplar species. 


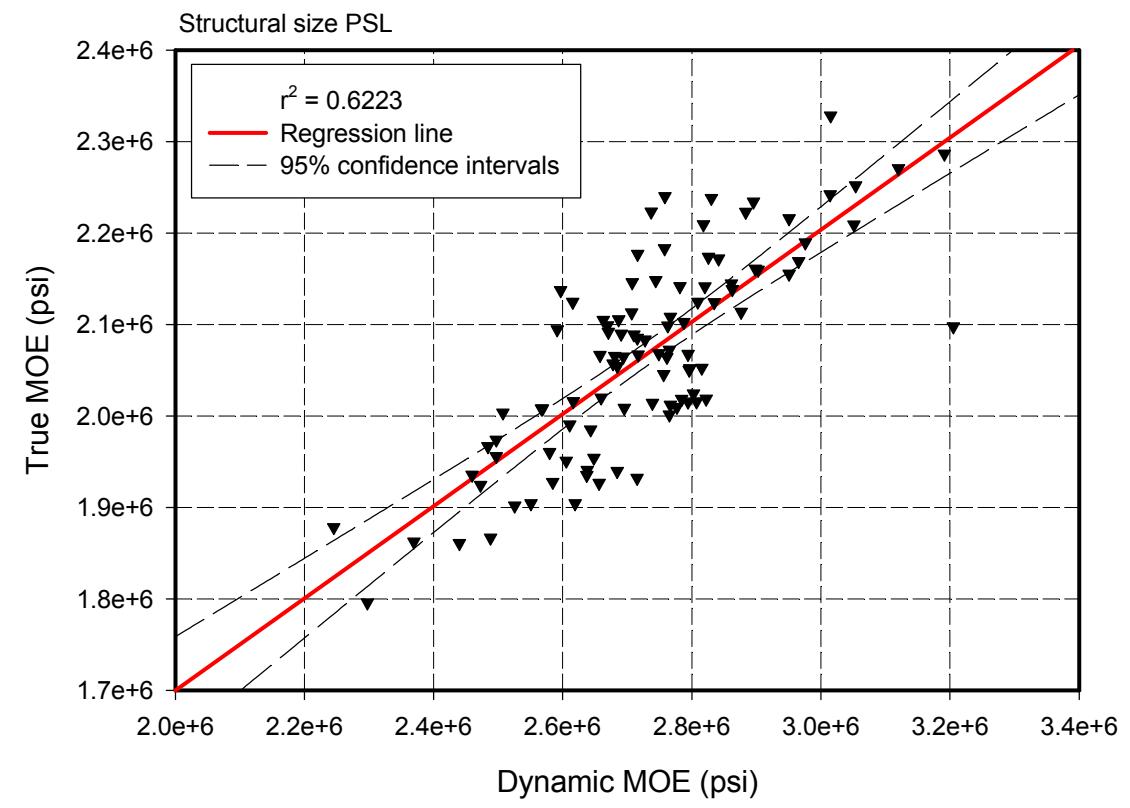

Figure 3.6. - Regression analysis of dynamic vs. true MOE for structural size PSL specimens, $95 \%$ confidence intervals and $\mathrm{r}^{2}$ value are indicated.

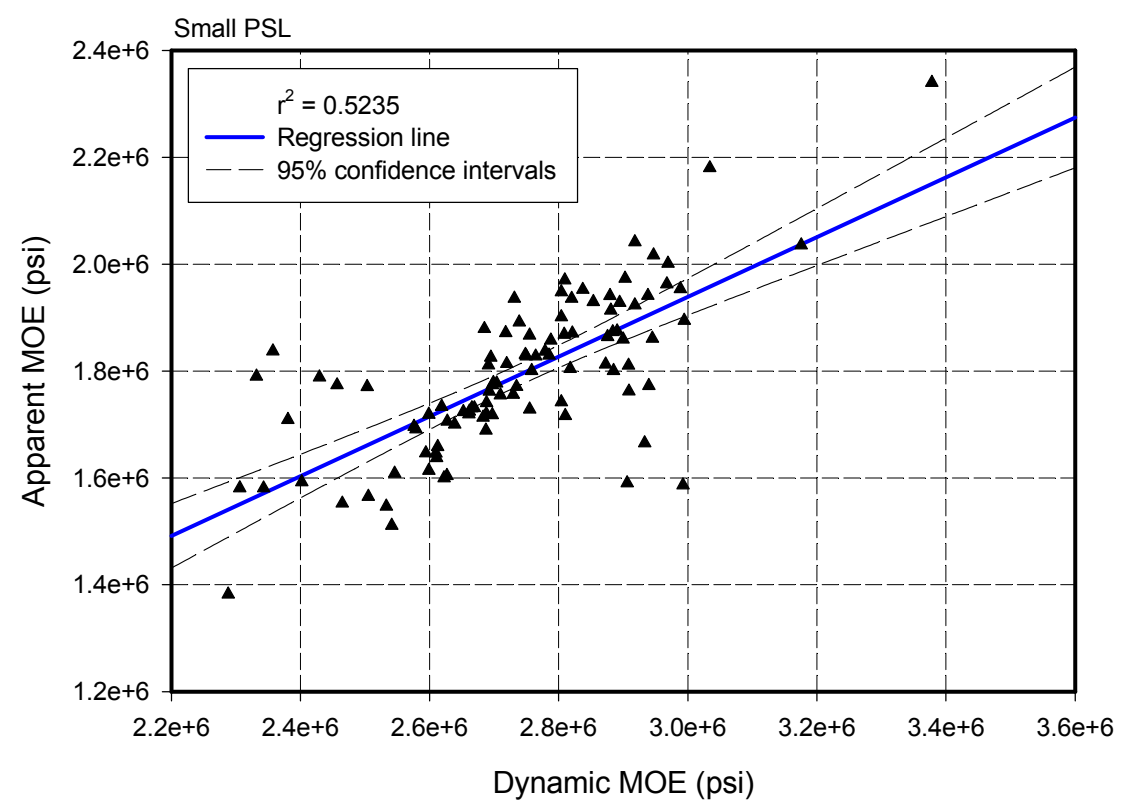

Figure 3.7. - Regression analysis of dynamic vs. apparent MOE for small size PSL specimens, 95\% confidence intervals and $r^{2}$ value are indicated. 


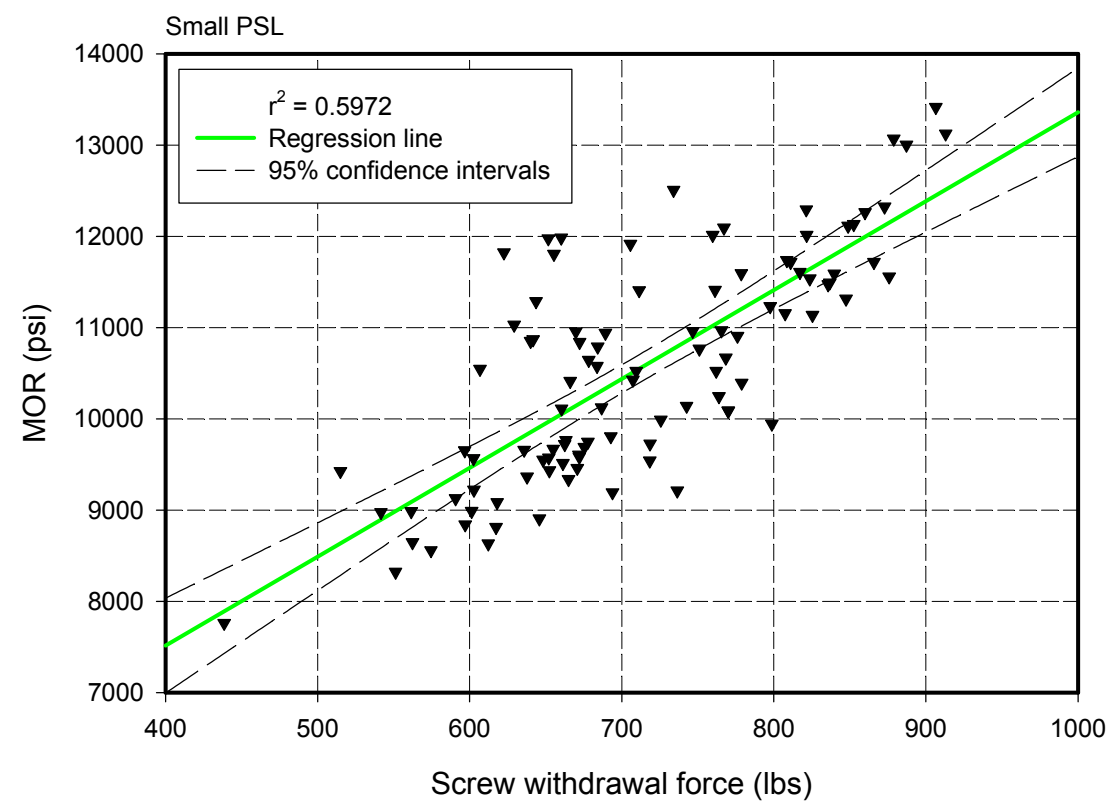

Figure 3.8. - Regression analysis of screw withdrawal force vs. MOR for small PSL specimens, 95\% confidence intervals and $\mathrm{r}^{2}$ value are indicated.

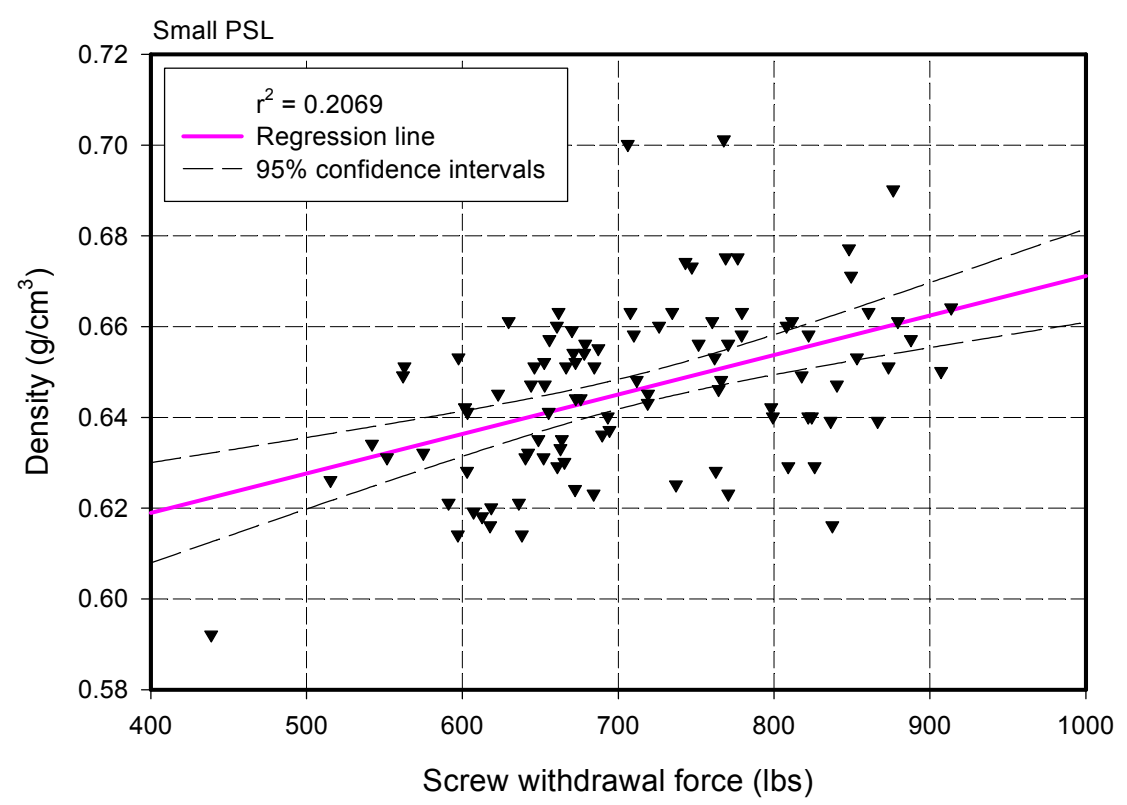

Figure 3.9. - Regression analysis of screw withdrawal force vs. density for small PSL specimens, 95\% confidence intervals and $\mathrm{r}^{2}$ value are indicated. 
Table 3.3. - Parameters and statistics of regression analysis for PSL.

\begin{tabular}{ccccccc}
\hline $\begin{array}{c}\text { Dependent } \\
\text { Variable }\end{array}$ & $\beta_{0}$ & $\beta_{1}$ & $\begin{array}{c}\text { Independent } \\
\text { Variable }\end{array}$ & $\boldsymbol{r}^{2}$ & $\boldsymbol{P}$ \\
$(\mathrm{Y})$ & & & $(\mathrm{X})$ & & \\
\hline $\mathrm{E}_{\mathrm{T}}$ & 692925 & 0.5036 & $\mathrm{E}_{\mathrm{D}}$ & 0.622 & $<0.0001$ \\
$\mathrm{E}_{\mathrm{A}}$ & 261036 & 0.5593 & $\mathrm{E}_{\mathrm{D}}$ & 0.524 & $<0.0001$ \\
MOR & 3618 & 9.7392 & $\mathrm{SWF}$ & 0.597 & $<0.0001$ \\
Density & 0.5841 & 0.00008699 & $\mathrm{SWF}$ & 0.207 & $<0.0001$ \\
\hline
\end{tabular}




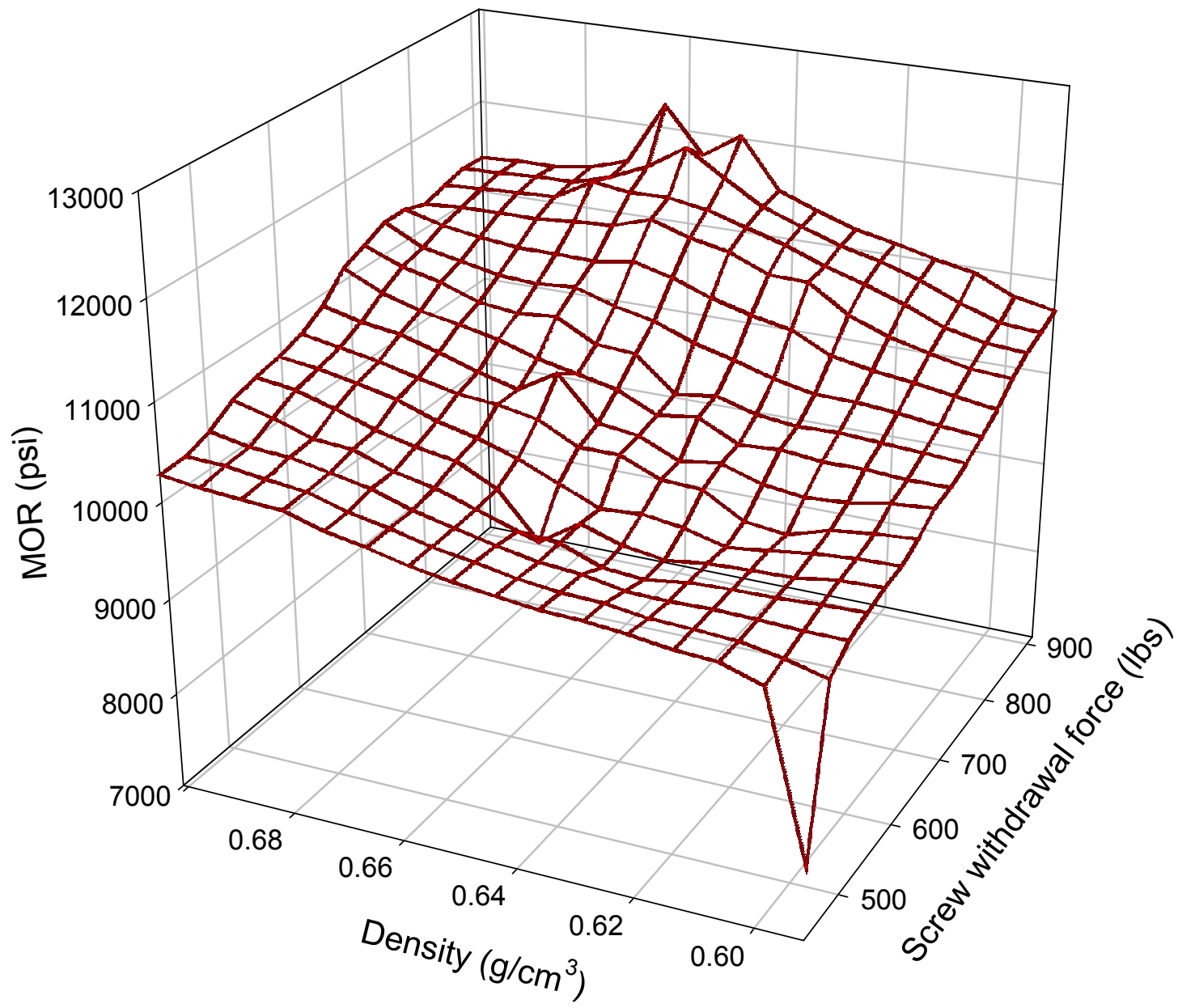

Figure 3.10. - Three-dimensional plot between screw withdrawal force, density, and MOR for PSL. 


\subsection{Regression results for red oak data}

Experimental results demonstrated statistically significant relationship between dynamic and true MOE of red oak lumber. However, due to the high variability of this species in mechanical properties, several outliers were observed as shown in Figure 3.11. Computed statistics including $\mathrm{r}^{2}$ and $\mathrm{P}$ values confirmed that for red oak the dynamic MOE is a good predictor regarding the true MOE. When the dynamic MOE was used to predict the apparent MOE the quality of the prediction declined. However, both the correlation coefficient and P value remained on acceptable levels (Figure 3.12).

The comparison of screw retention capacity and MOR for red oak lumber yielded several outliers also. The association between these variables proved to be statistically significant. Figure 3.13 shows the results of this analysis where a few outliers can be observed in the lower screw withdrawal force region.

It can be stated that the screw withdrawal force may be used to predict the density of red oak as demonstrated on Figure 3.14. Table 3.4 contains the parameters and the regression statistics for red oak lumber. The interaction between density and fastener holding capacity in the prediction of bending strength of red oak can be estimated as linear (Figure 3.15). Although, the stepwise regression analysis demonstrated that the effect of interaction on the MOR prediction was statistically negligible. Positive peaks as outliers may bias this estimation. Refined statistical analysis is necessary to establish reliable prediction models. 


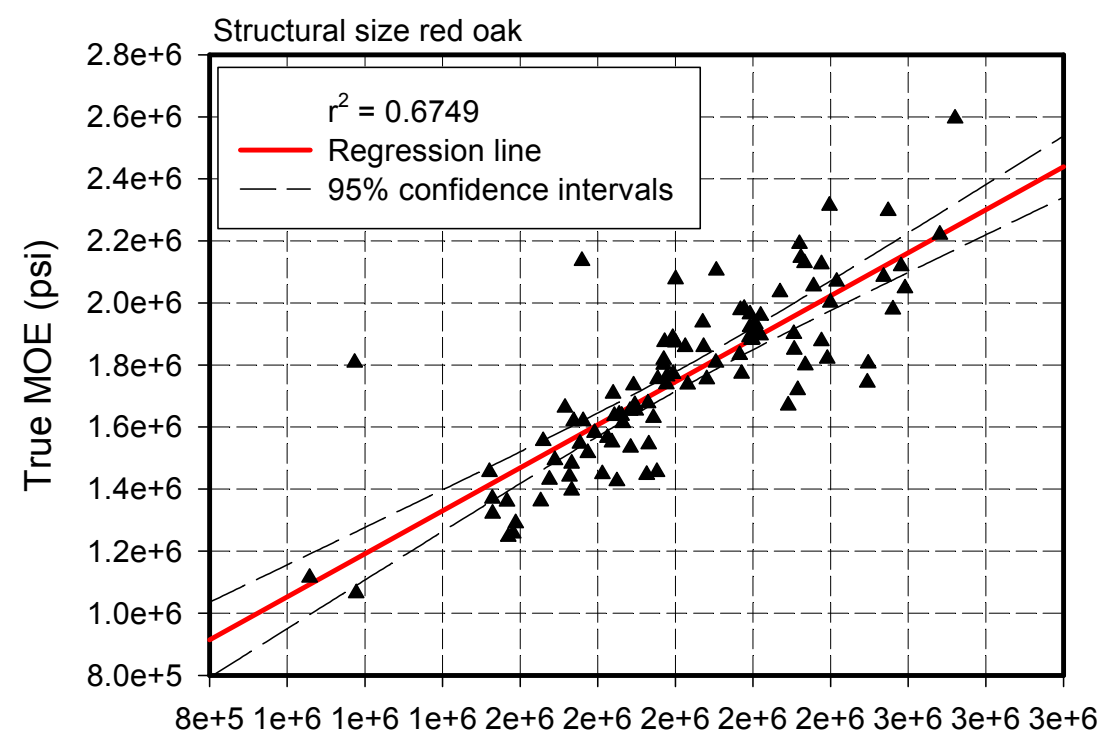

Dynamic MOE (psi)

Figure 3.11. - Regression analysis of dynamic vs. true MOE for red oak specimens, $95 \%$ confidence intervals and $\mathrm{r}^{2}$ value are indicated.

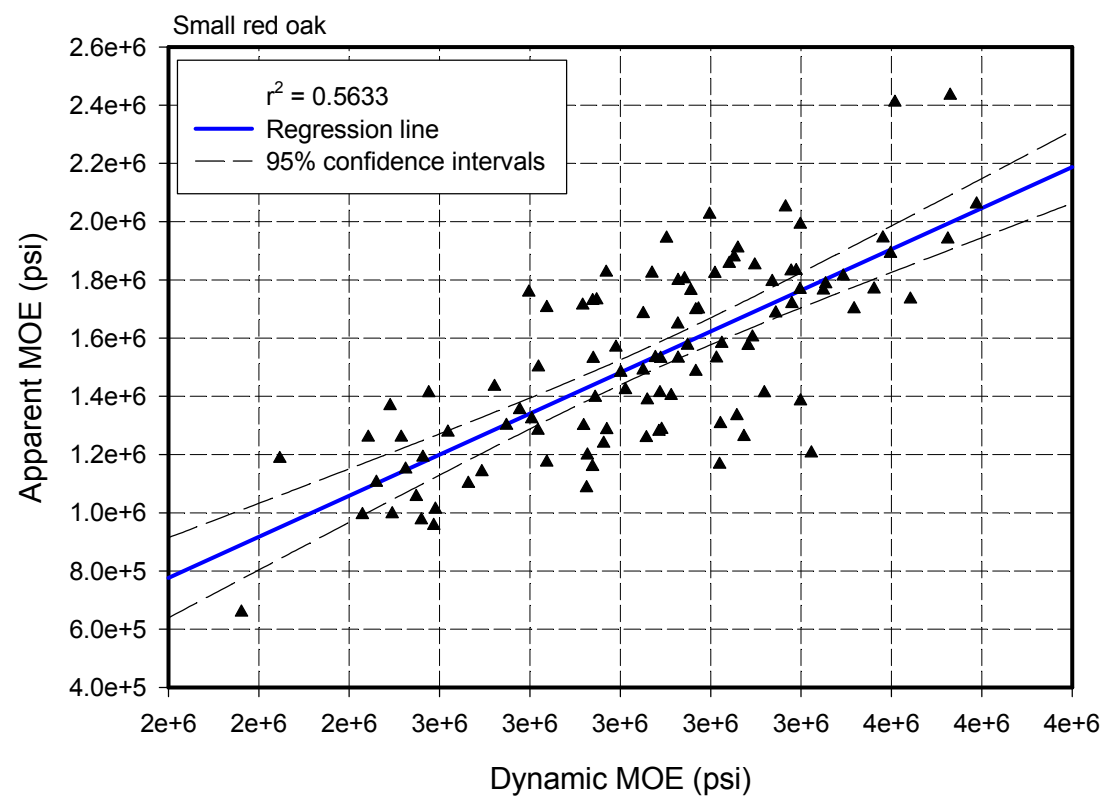

Figure 3.12. - Regression analysis of dynamic vs. apparent MOE for small red oak specimens, $95 \%$ confidence intervals and $\mathrm{r}^{2}$ value are indicated. 


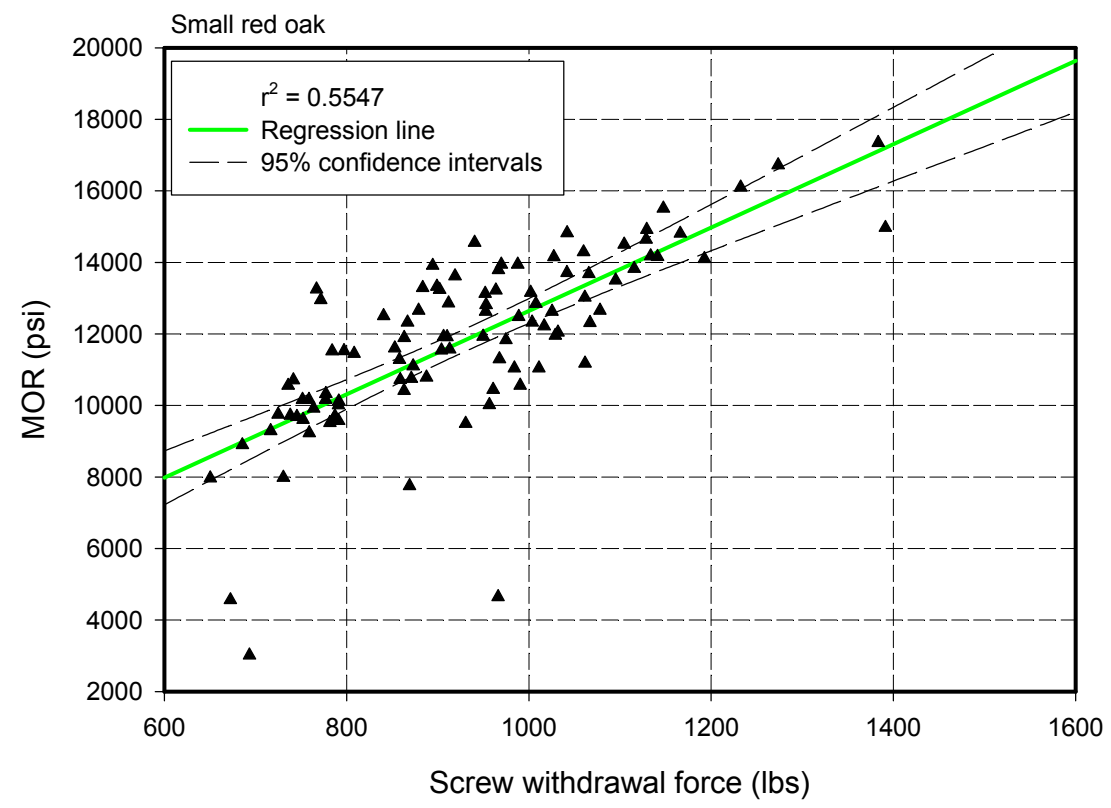

Figure 3.13. - Regression analysis of screw withdrawal force vs. MOR for small red oak specimens, 95\% confidence intervals and $r^{2}$ value are indicated.

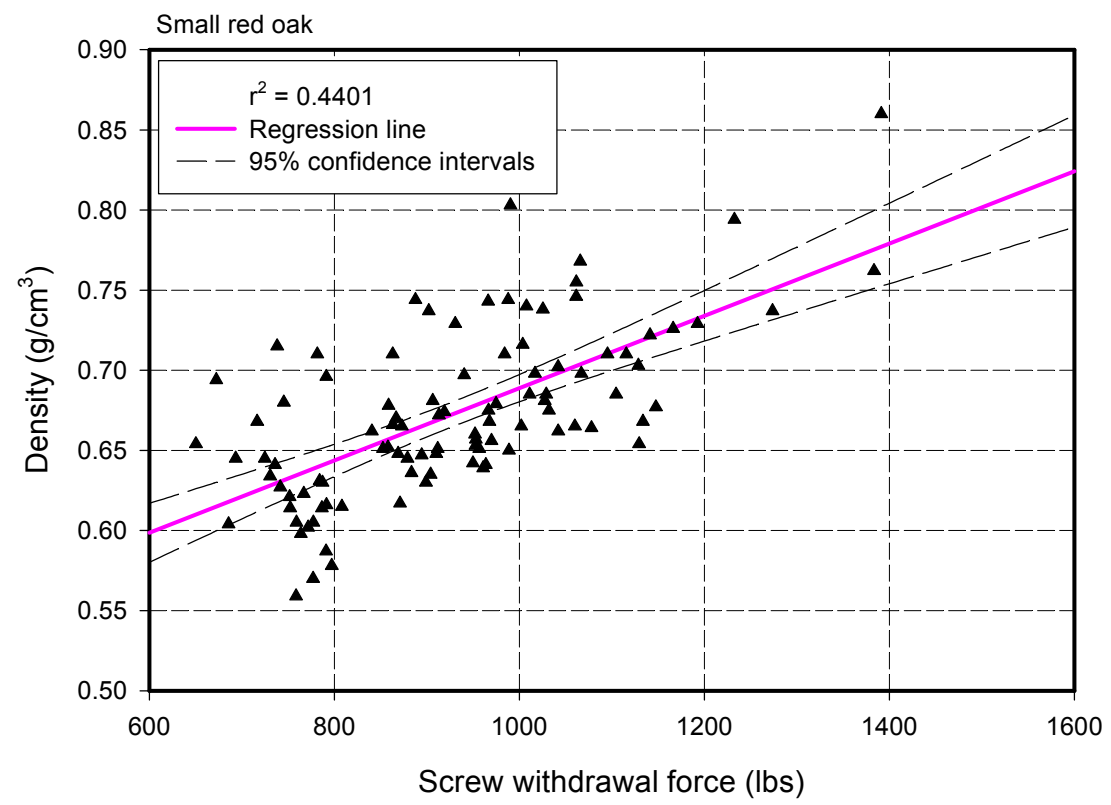

Figure 3.14. - Regression analysis of screw withdrawal force vs. density of small red oak specimens, 95\% confidence intervals and $\mathrm{r}^{2}$ value are indicated. 
Table 3.4. - Parameters and statistics of regression analysis for red oak.

\begin{tabular}{ccccccc}
\hline $\begin{array}{c}\text { Dependent } \\
\text { Variable }\end{array}$ & $\beta_{0}$ & $\beta_{1}$ & $\begin{array}{c}\text { Independent } \\
\text { Variable }\end{array}$ & $\boldsymbol{r}^{2}$ & $\boldsymbol{P}$ \\
$(\mathrm{Y})$ & & & $(\mathrm{X})$ & & \\
\hline $\mathrm{E}_{\mathrm{T}}$ & 360042 & .6930 & $\mathrm{E}_{\mathrm{D}}$ & 0.675 & $<0.0001$ \\
$\mathrm{E}_{\mathrm{A}}$ & -633648 & 0.7053 & $\mathrm{E}_{\mathrm{D}}$ & 0.563 & $<0.0001$ \\
MOR & 978 & 11.6560 & $\mathrm{SWF}$ & 0.555 & $<0.0001$ \\
Density & 0.4631 & 0.0002257 & $\mathrm{SWF}$ & 0.440 & $<0.0001$ \\
\hline
\end{tabular}




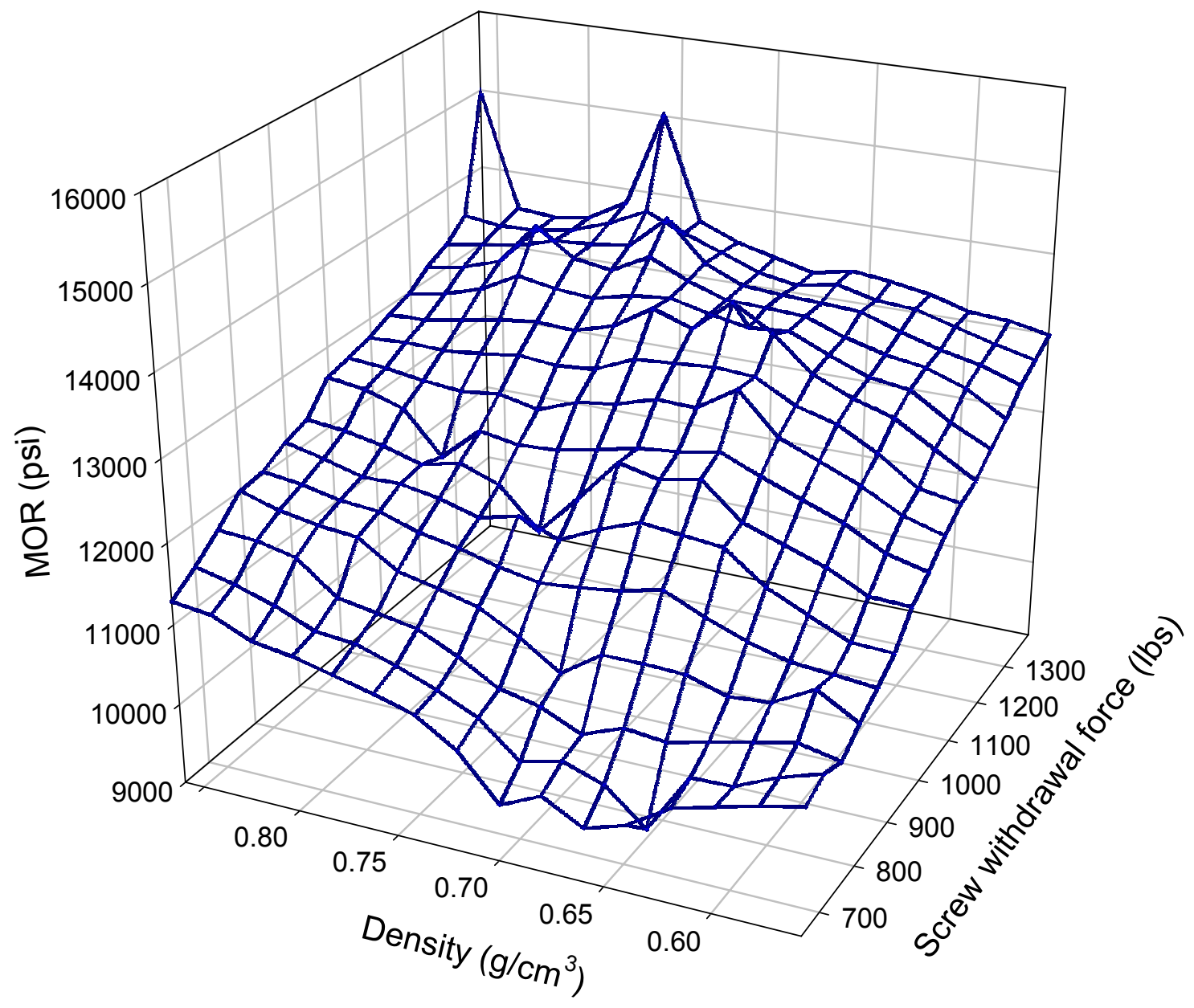

Figure 3.15. - Three-dimensional mesh plot between screw withdrawal force, density, and MOR for red oak. 


\subsection{Evaluation of data obtained on yellow-poplar}

Results of the regression analysis comparing dynamic and true MOE for the yellow poplar species indicated that a statistically significant relationship exists between these properties $\left(r^{2}=0.602\right)$. As can be seen in Figure 3.16, the yellow poplar species produced less outliers than did the red oak species. This may be attributed to the difference in natural variability between ring-porous and diffuse-porous species. Using dynamic MOE as a predictor of the apparent MOE yielded a lower correlation, as with the previously mentioned groups. However, it can be seen in Figure 3.17, that the relationship between the two variables is still acceptable $\left(r^{2}=0.571\right)$.

Using screw withdrawal force as a predictor of MOR for the yellow-poplar species proved to be statistically significant $\left(r^{2}=0.642\right)$. From Figure 3.18 it can be seen that several outliers exist, primarily in the lower range of MOR values. Density prediction using screw retention strength similarly yielded lower than expected results for the yellow-poplar species (Figure 3.19). Although the coefficient of determination was low $\left(r^{2}=0.296\right)$, the $P$ value obtained from the analysis indicates that the relationship is still statistically significant. The statistics and parameters of the yellow-poplar species are contained in Table 3.5.

Visual evaluation concerning the interaction effect of density and screw withdrawal force on MOR is demonstrated in Figure 3.20. The chart shows that some sharp peak drops exist at certain locations, however the effect does appear 
to be linear, and statistically in-significant according to the backwards stepwise analysis (Appendix VIII). 


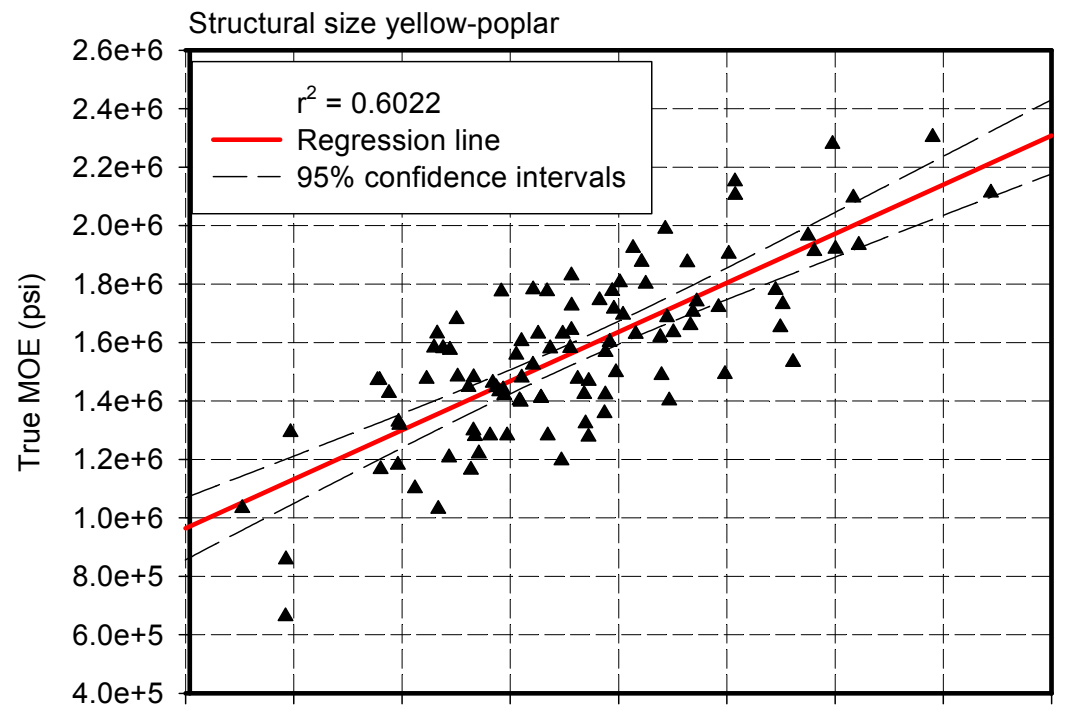

$\begin{array}{lllllllllll}1.2 e+6 & 1.4 e+6 & 1.6 e+6 & 1.8 e+6 & 2.0 e+6 & 2.2 e+6 & 2.4 e+6 & 2.6 e+6 & 2.8 e+6\end{array}$

Dynamic MOE (psi)

Figure 3.16. - Regression analysis of dynamic vs. true MOE for structural size yellow-poplar, 95\% confidence intervals and $r^{2}$ value are indicated.

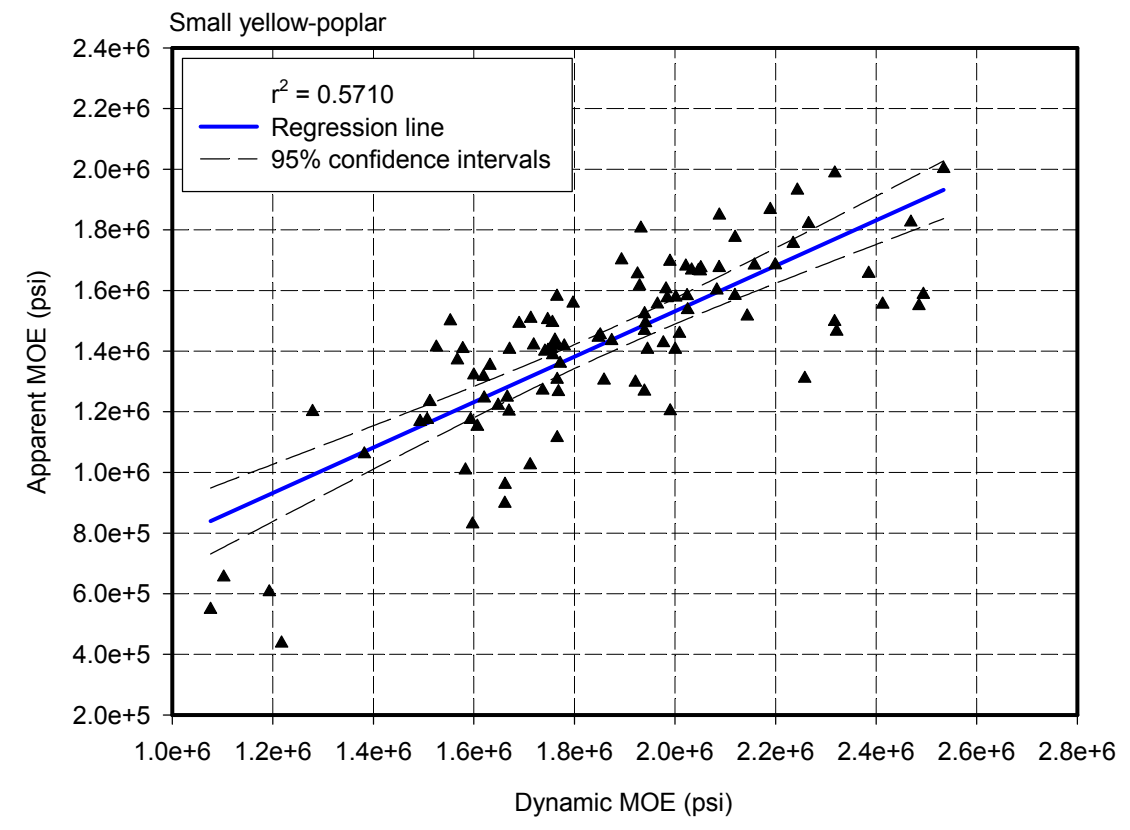

Figure 3.17. - Regression analysis of dynamic vs. apparent MOE for small yellow-poplar specimens, $95 \%$ confidence intervals and $r^{2}$ value are indicated. 


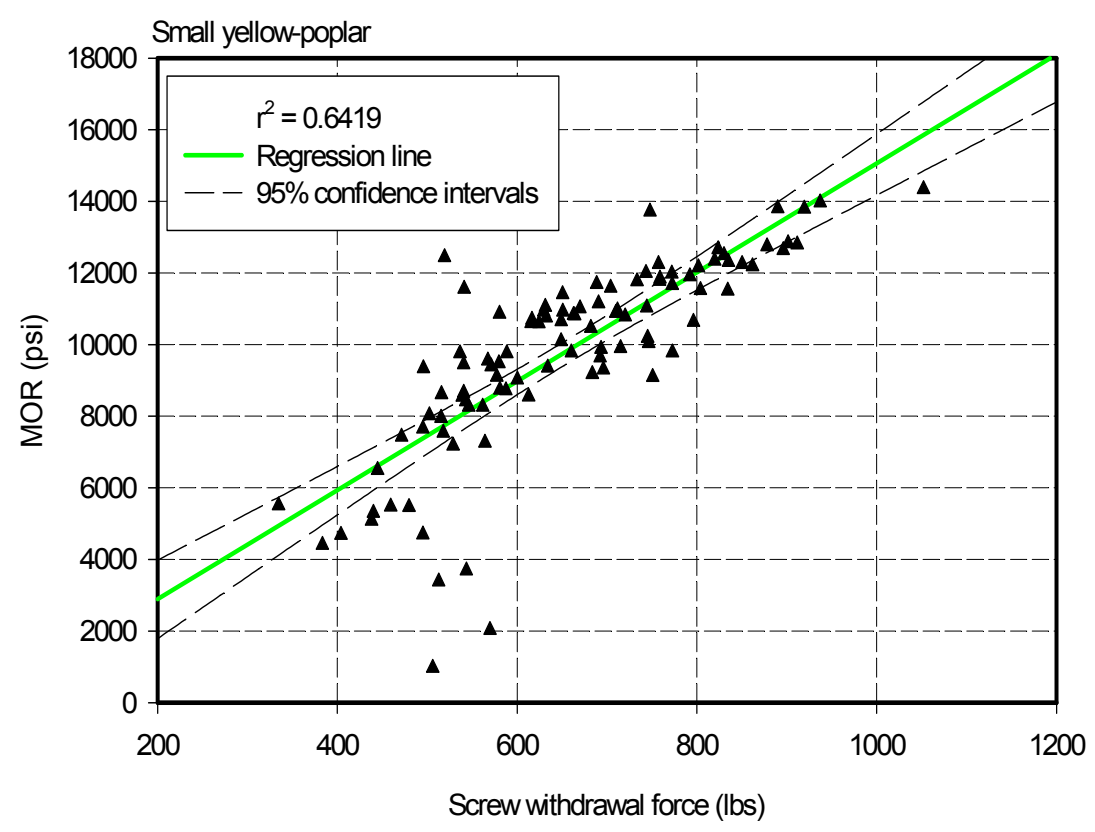

Figure 3.18. - Regression analysis of screw withdrawal force vs. MOR for small yellow-poplar specimens, $95 \%$ confidence intervals and $\mathrm{r}^{2}$ value are indicated.

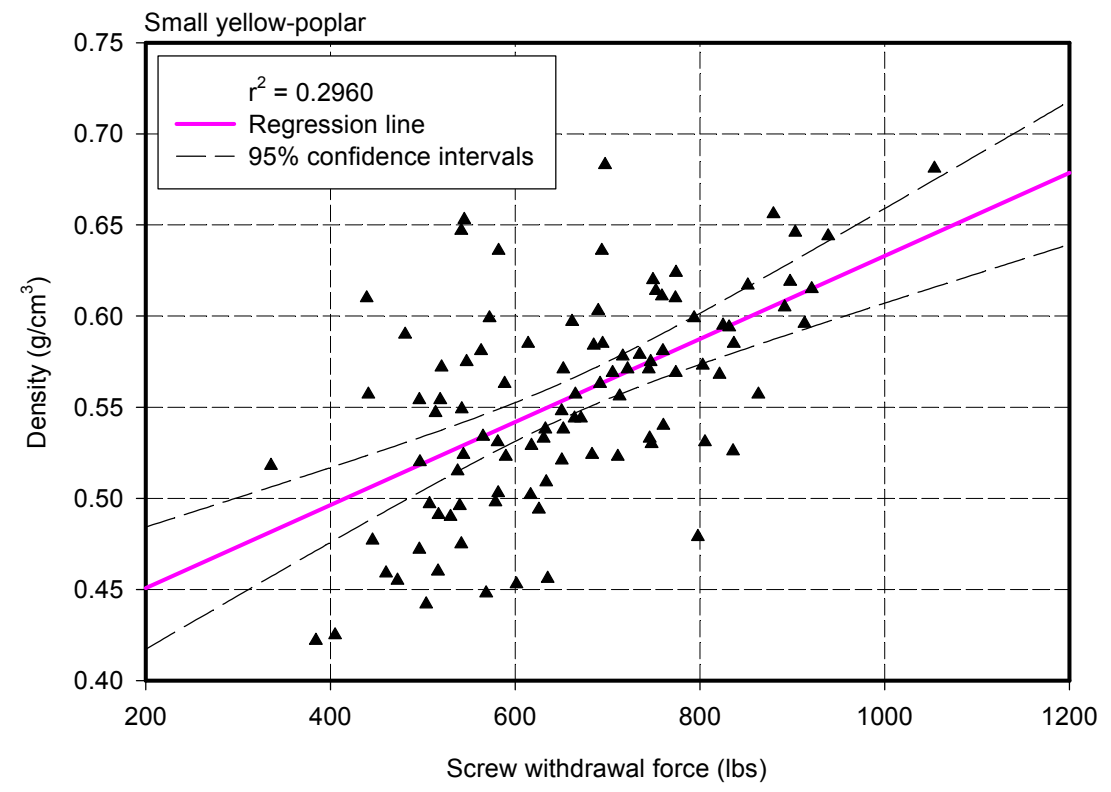

Figure 3.19. - Regression analysis of screw withdrawal force vs. density for small yellow-poplar specimens, $95 \%$ confidence intervals and $r^{2}$ value are indicated. 
Table 3.5. - Parameters and statistics of regression analysis for yellow-poplar.

\begin{tabular}{ccccccc}
\hline $\begin{array}{c}\text { Dependent } \\
\text { Variable }\end{array}$ & $\beta_{0}$ & $\beta_{1}$ & $\begin{array}{c}\text { Independent } \\
\text { Variable }\end{array}$ & $\boldsymbol{r}^{2}$ & $\boldsymbol{P}$ \\
$(Y)$ & & & $(\mathrm{X})$ & & \\
\hline $\mathrm{E}_{\mathrm{T}}$ & -43642 & 0.8401 & $\mathrm{E}_{\mathrm{D}}$ & 0.602 & $<0.0001$ \\
$\mathrm{E}_{\mathrm{A}}$ & 33387 & 0.7492 & $\mathrm{E}_{\mathrm{D}}$ & 0.571 & $<0.0001$ \\
MOR & -144 & 15.2087 & $\mathrm{SWF}$ & 0.642 & $<0.0001$ \\
Density & 0.4051 & 0.0002279 & $\mathrm{SWF}$ & 0.296 & $<0.0001$ \\
\hline
\end{tabular}




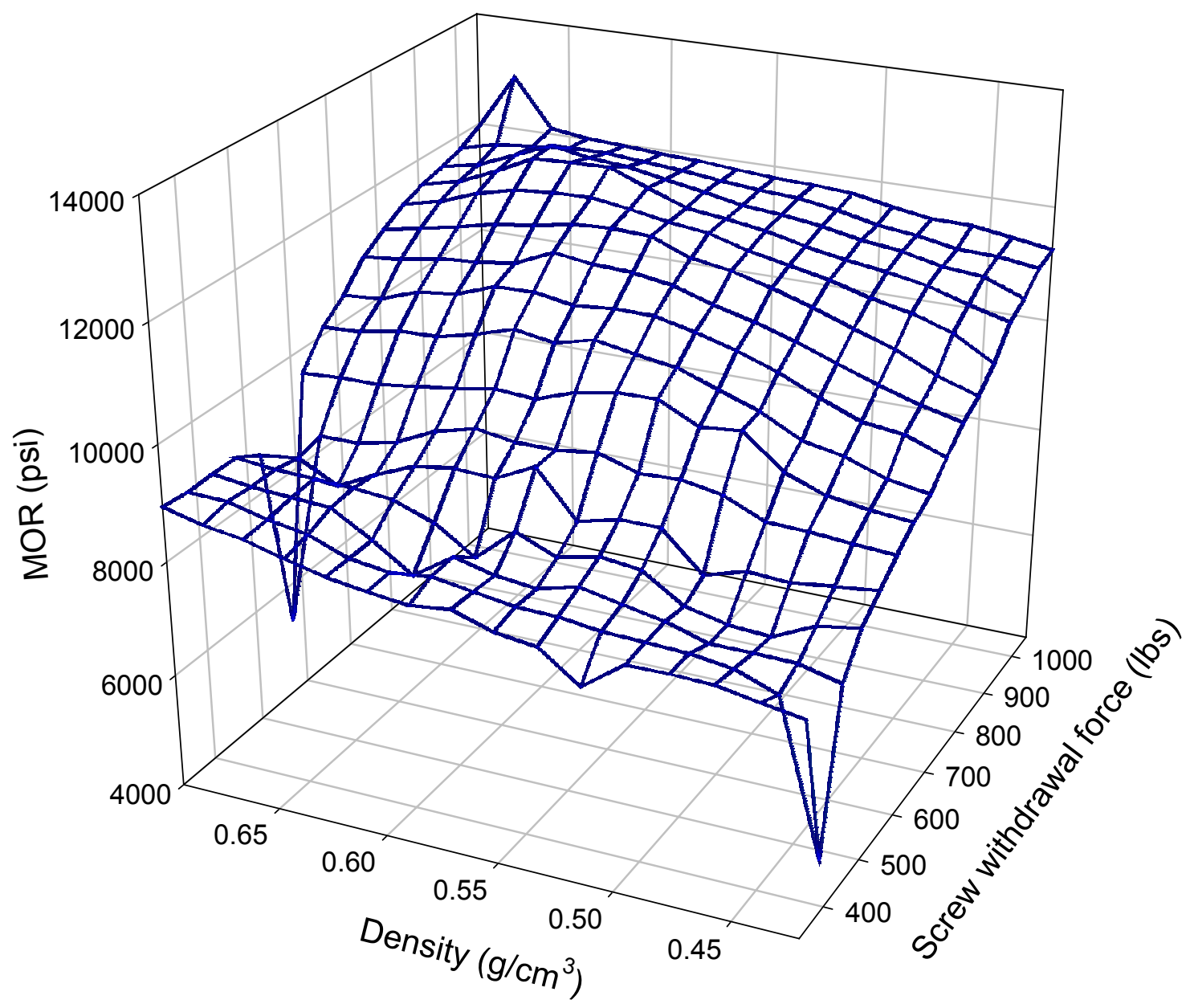

Figure 3.20. - Three-dimensional mesh plot between screw withdrawal force, density, and MOR for yellow-poplar. 


\subsection{Results of regression analysis for SPF}

The data from the SPF group was analyzed statistically to determine if dynamic MOE was a suitable predictor of the true MOE for the SPF group. Figure 3.21 , along with the high $r^{2}$ value $\left(r^{2}=0.774\right)$, demonstrated that dynamic MOE is in fact a good predictor of the true MOE of these species. The magnitude of variation between the dynamic and true MOE was considerably lower for the SPF group as it was for the yellow-poplar species. This may be attributed to the difference between hardwood and soft wood species. Investigation of using dynamic MOE as a predictor of apparent MOE resulted in somewhat less pronounced results $\left(r^{2}=0.619\right)$. As can be seen in Figure 3.22 , a few outliers exist in this comparison, which may bias the results of this analysis.

Statistical analysis proved that the correlation between the screw withdrawal force and MOR variables was acceptable $\left(r^{2}=0.6016\right)$ for the SPF species group. Figure 3.23 demonstrates that although some outliers exist, screw-holding capacity is a good indicator of the true bending strength for SPF. The comparison between screw withdrawal resistance and density resulted in a low coefficient of determination $\left(r^{2}=0.188\right.$, Figure 3.24). However, the P value obtained from the analysis indicated that the regression model is still statistically acceptable $(\mathrm{P}=<0.0001)$. The variation in fastener holding capacity may be attributed to the natural variation among the species that composes the SPF 


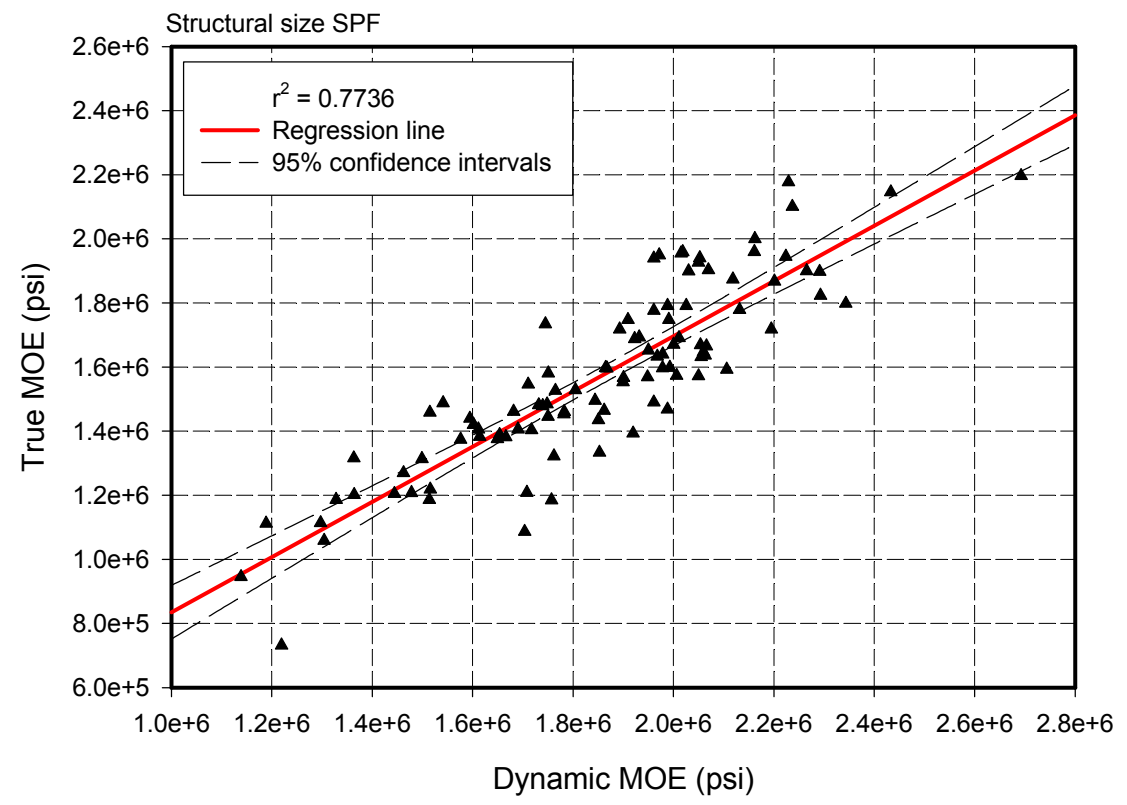

Figure 3.21. - Regression analysis of dynamic vs. true MOE for structural size SPF specimens, 95\% confidence intervals and $r^{2}$ value are indicated.

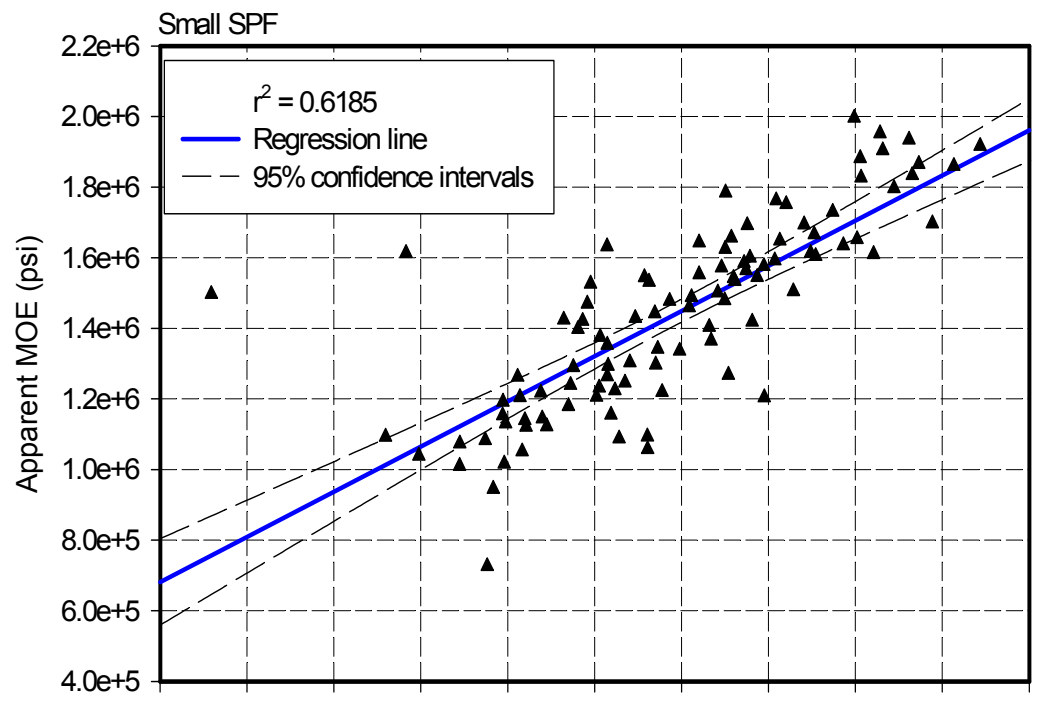

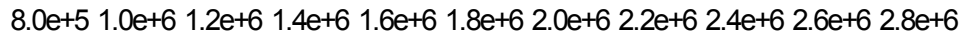

Dynamic MOE (psi)

Figure 3.22. - Regression analysis of dynamic vs. apparent MOE for small SPF specimens, $95 \%$ confidence intervals and $\mathrm{r}^{2}$ value are indicated. 


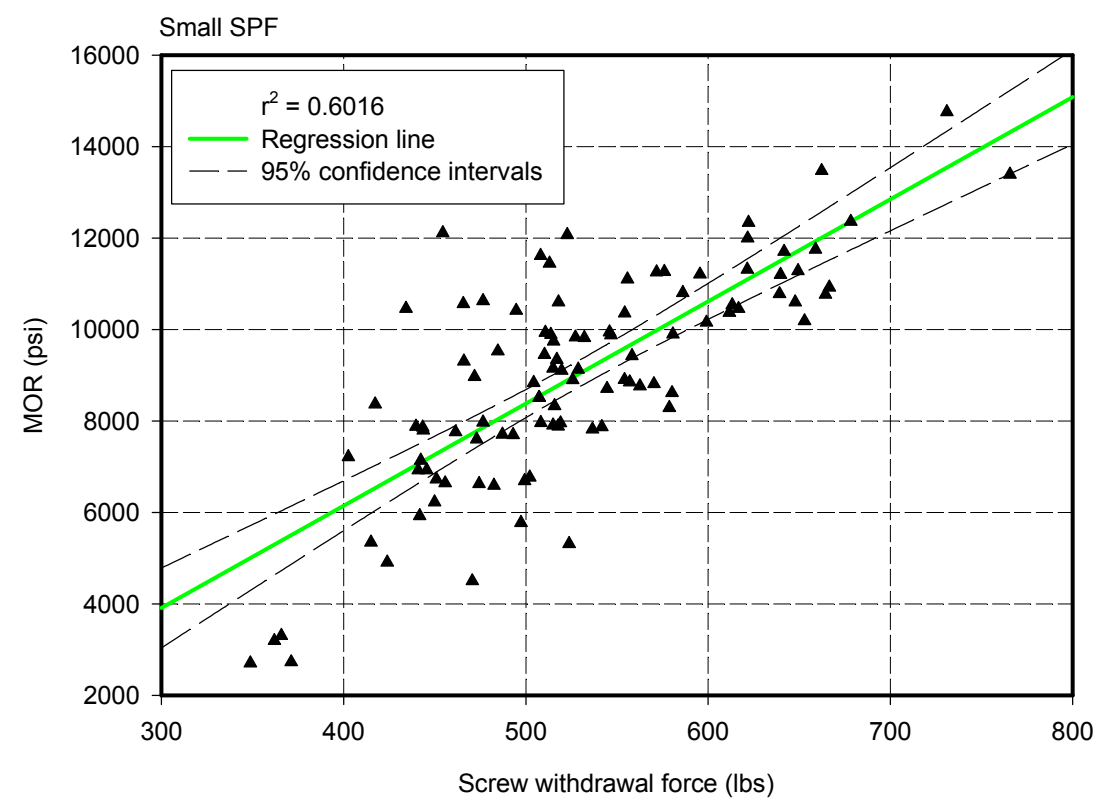

Figure 3.23. - Regression analysis of screw withdrawal force vs. MOR for small SPF specimens, 95\% confidence intervals and $r^{2}$ value are indicated.

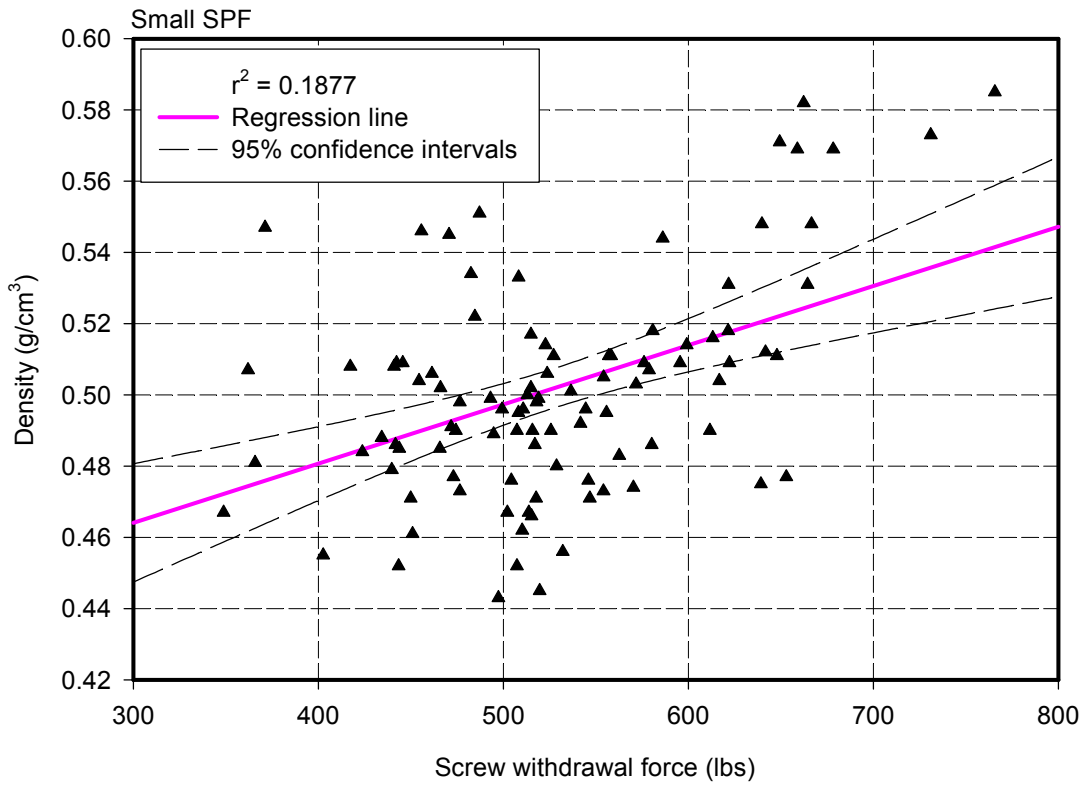

Figure 3.24. - Regression analysis of screw withdrawal force vs. density for small SPF specimens, $95 \%$ confidence intervals and $r^{2}$ value are indicated. 
lumber group. Table 3.6 contains the parameters and regression equations obtained from the SPF group.

From Figure 3.25 the combined effect of density and screw withdrawal resistance on the modulus of rupture may be studied. The three-dimensional mesh plot indicates that some curvy-linear relationship may exist between these variables. The regression analysis resulted in a model containing density and the interaction between density and SWF as predicting variables (Appendix VIII). This somewhat inconclusive result may be explained by the high variability in the SPF group, as discussed earlier.

Table 3.6. - Parameters and statistics of regression analysis for SPF.

\begin{tabular}{ccccccc}
\hline $\begin{array}{c}\text { Dependent } \\
\text { Variable }\end{array}$ & $\beta_{0}$ & $\beta_{1}$ & $\begin{array}{c}\text { Independent } \\
\text { Variable }\end{array}$ & $\boldsymbol{r}^{2}$ & $\boldsymbol{P}$ \\
$(\mathrm{Y})$ & & & $(\mathrm{X})$ & & \\
\hline $\mathrm{E}_{\mathrm{T}}$ & -26751 & 0.8616 & $\mathrm{E}_{\mathrm{D}}$ & 0.774 & $<0.0001$ \\
$\mathrm{E}_{\mathrm{A}}$ & 169741 & 0.6398 & $\mathrm{E}_{\mathrm{D}}$ & 0.619 & $<0.0001$ \\
MOR & -2788 & 22.3356 & $\mathrm{SWF}$ & 0.602 & $<0.0001$ \\
Density & 0.4142 & 0.0001662 & $\mathrm{SWF}$ & 0.188 & $<0.0001$ \\
\hline
\end{tabular}




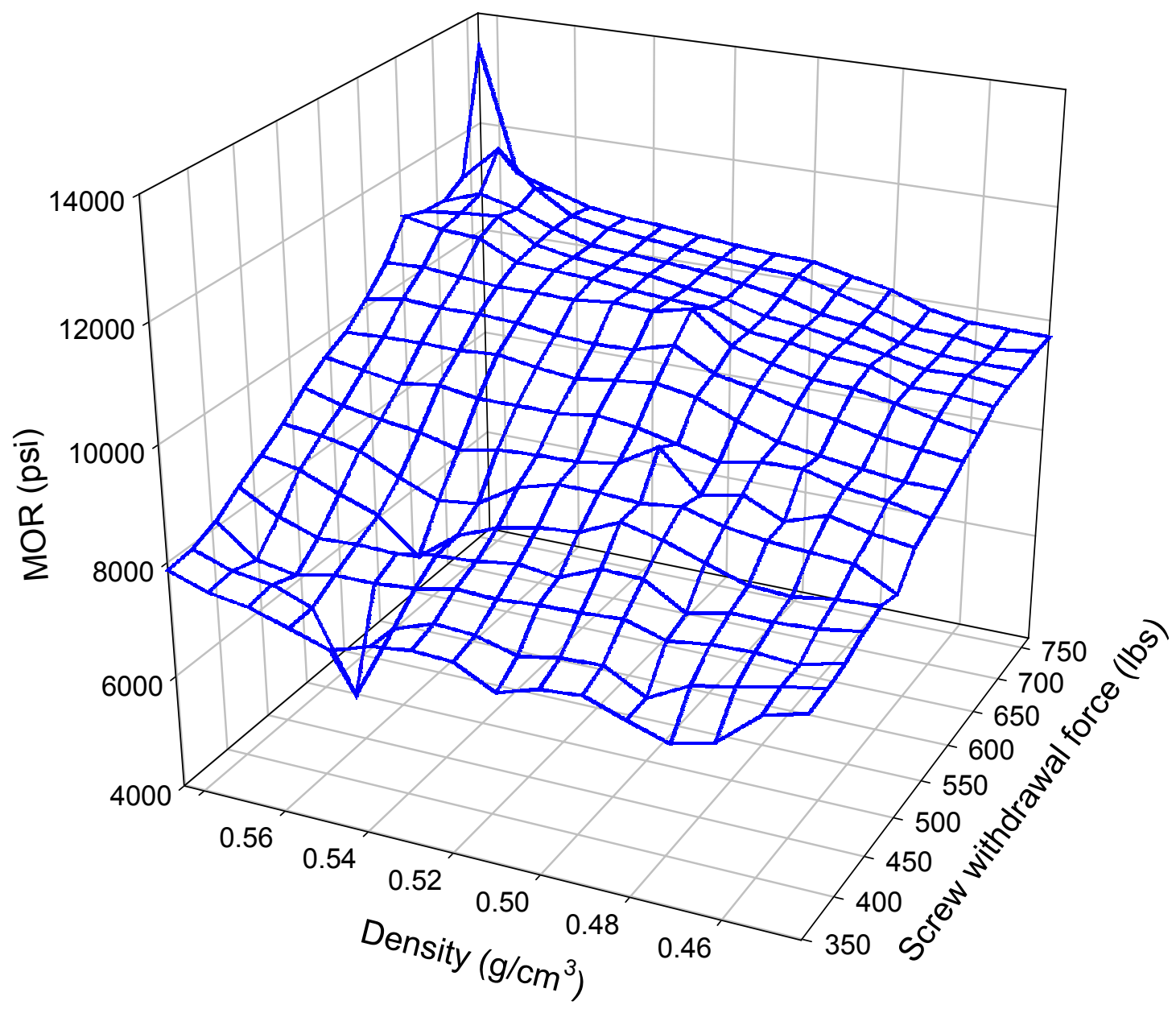

Figure 3.25. - Three-dimensional plot of screw withdrawal force, density, and MOR for SPF. 


\subsection{Investigation findings of SYP}

Experimental results indicate a statistically significant relationship between dynamic and true MOE of the SYP species group. The coefficient of determination for this species group was among the highest obtained in this investigation $\left(r^{2}=0.820\right)$. Figure 3.26 indicates that the high correlation may be attributed to the low variability and very few outliers obtained from the testing of this species group. Ability for dynamic MOE to predict the true MOE of SYP proved to be somewhat less pronounced than that of predicting true MOE. While the $r^{2}$ value was slightly lower for predicting apparent MOE than true MOE $\left(r^{2}=\right.$ 0.802), it was the strongest correlation between the two variables obtained through this research. Figure 3.27 demonstrates the high correlation between dynamic and apparent MOE.

Analysis of the SYP species group also yielded the highest relationship between screw withdrawal force and MOR $\left(r^{2}=0.727\right)$. Figure 3.28 illustrates the association between these variables. The ability of screw withdrawal resistance to predict the density of the SYP group proved to be significant $\left(\mathrm{r}^{2}=\right.$ 0.461). Although the coefficient of determination is somewhat low, the obtained $P$ value $(\mathrm{P}=<0.0001)$ indicates that screw withdrawal force is a significant predictor of density for the SYP group (Figure 3.29). The regression parameters and statistics are presented in Table 3.7. 


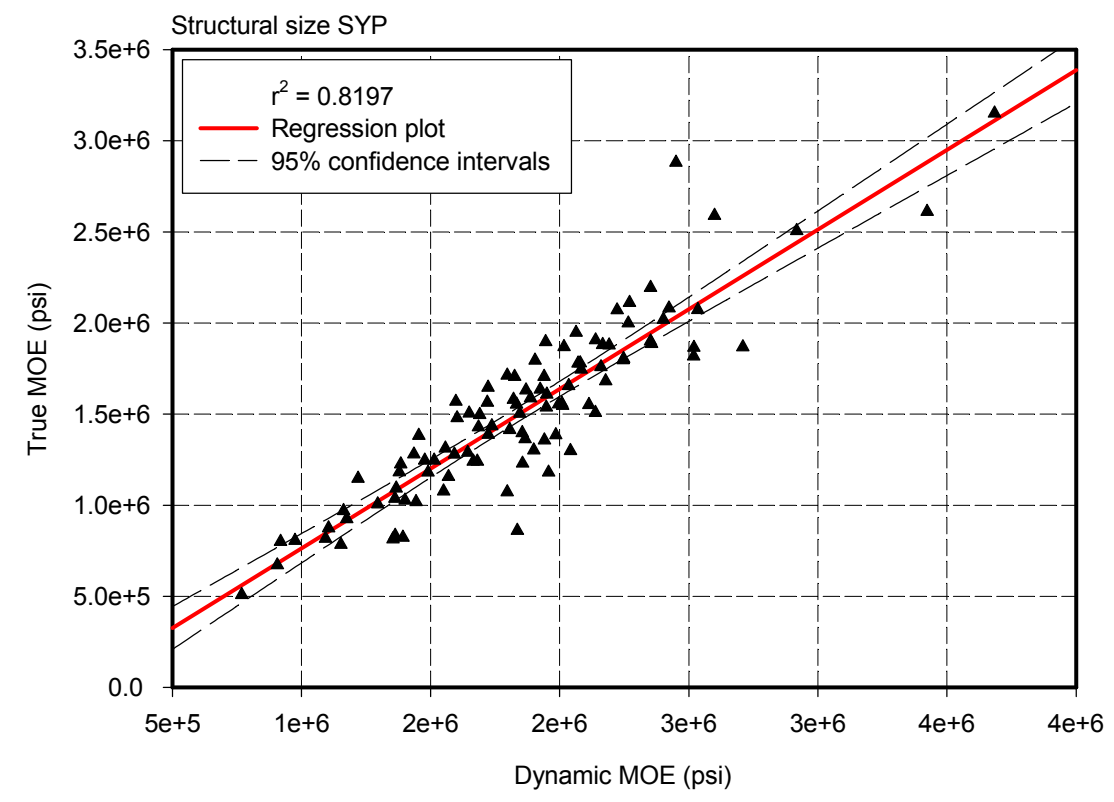

Figure 3.26. - Regression analysis of dynamic vs. true MOE for structural size SYP specimens, $95 \%$ confidence intervals and $\mathrm{r}^{2}$ value are indicated.

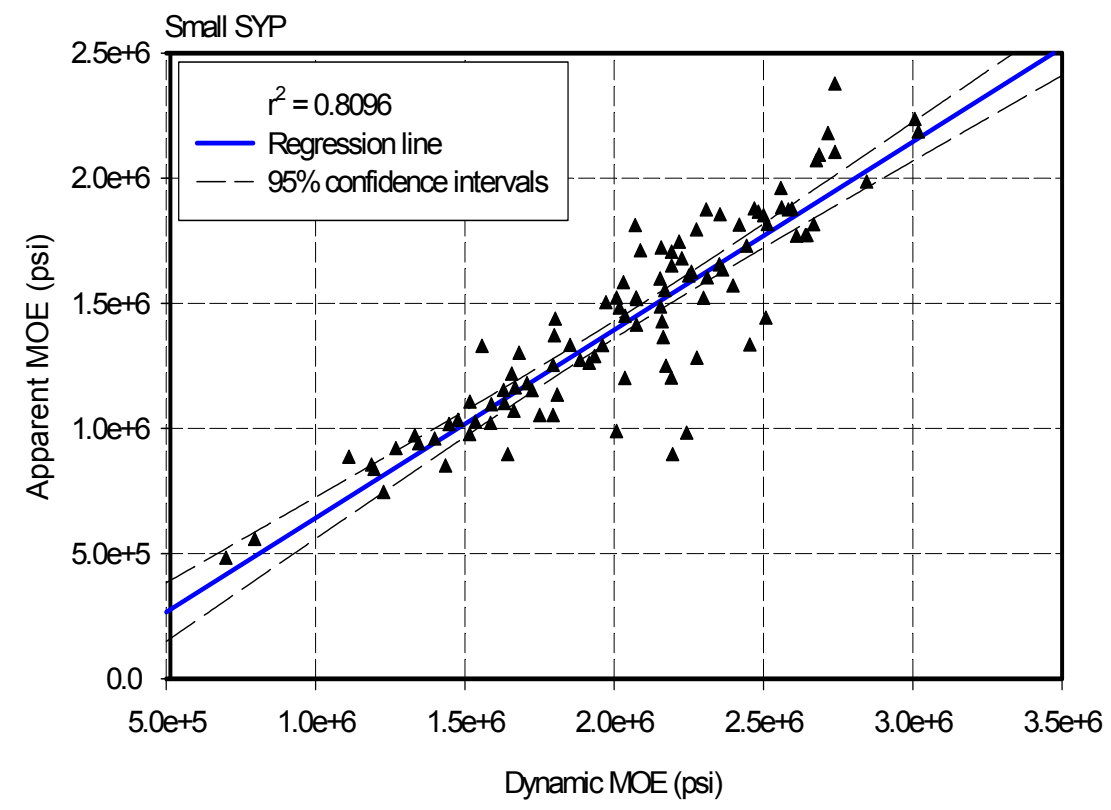

Figure 3.27. - Regression analysis of dynamic vs. apparent MOE for small SYP specimens, $95 \%$ confidence intervals and $\mathrm{r}^{2}$ value are indicated. 


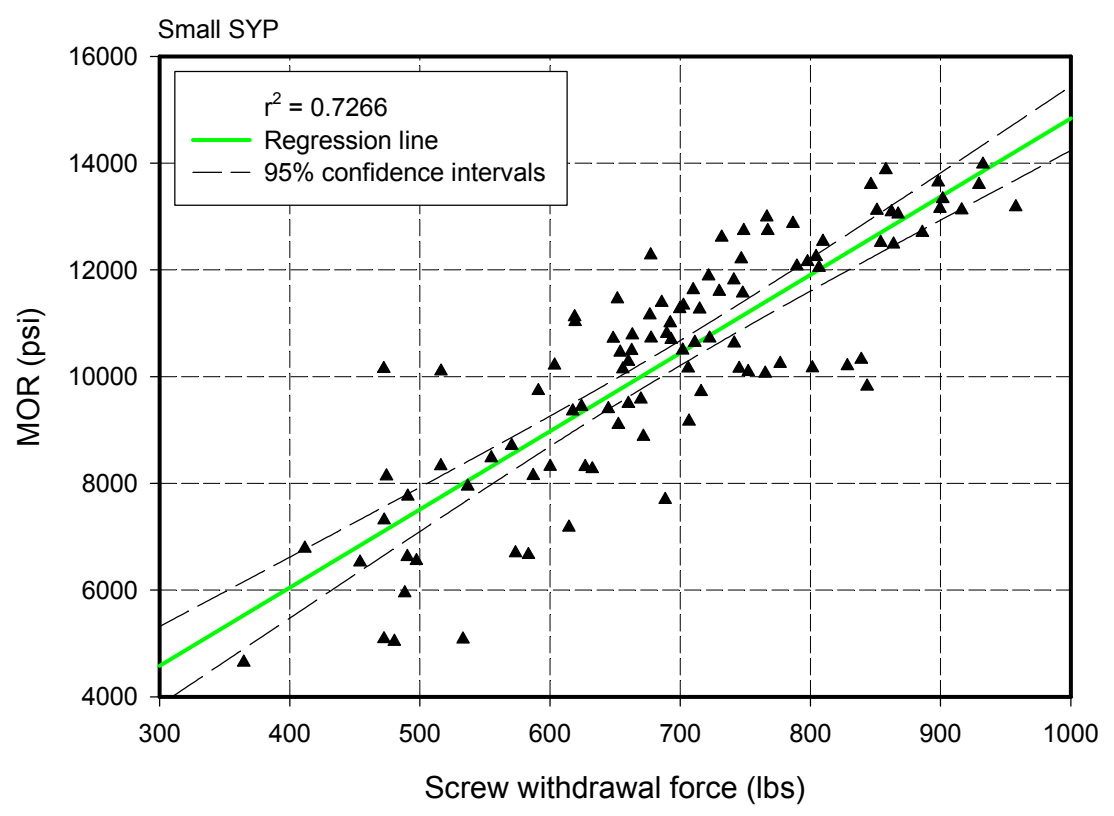

Figure 3.28. - Regression analysis of screw withdrawal force vs. MOR for small SYP specimens, 95\% confidence intervals and $r^{2}$ values are indicated.

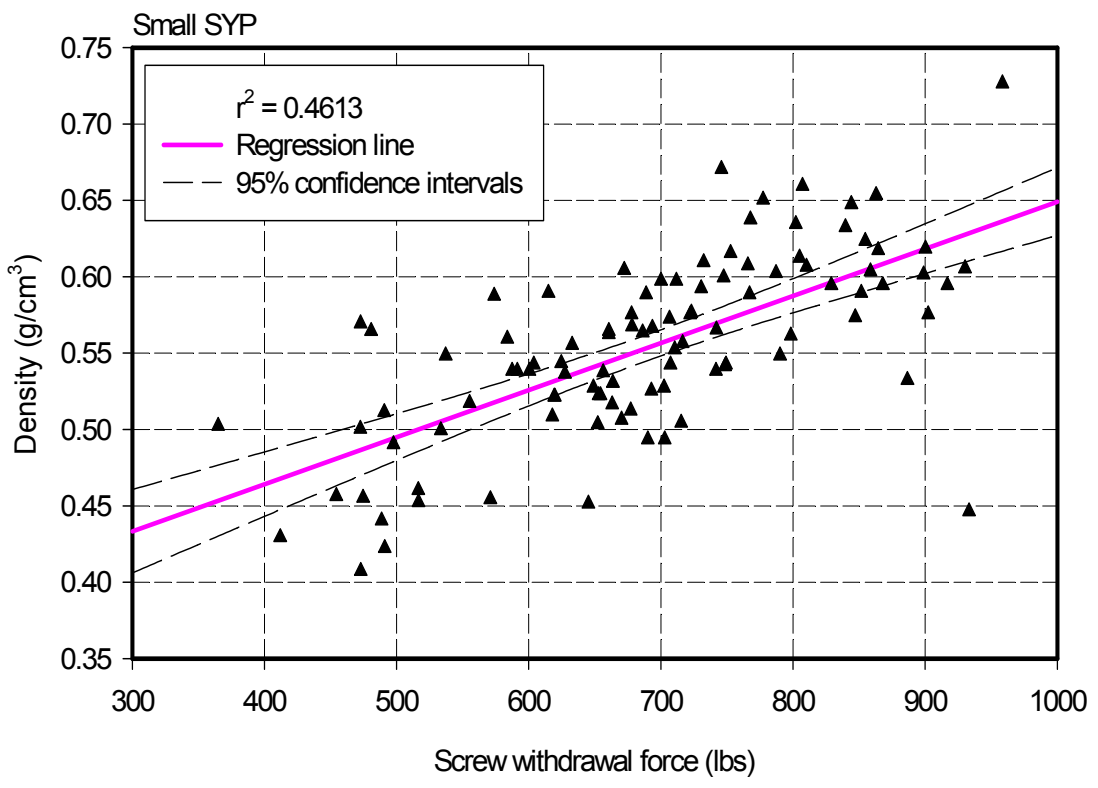

Figure 3.29. - Regression analysis of screw withdrawal force vs. density for small SYP specimens, $95 \%$ confidence intervals and $\mathrm{r}^{2}$ value are indicated. 
Table 3.7. - Parameters and statistics of regression analysis for SYP.

\begin{tabular}{ccccccc}
\hline $\begin{array}{c}\text { Dependent } \\
\text { Variable }\end{array}$ & $\beta_{0}$ & $\beta_{1}$ & $\begin{array}{c}\text { Independent } \\
\text { Variable }\end{array}$ & $\boldsymbol{r}^{2}$ & $\boldsymbol{P}$ \\
$(\mathrm{Y})$ & & & $(\mathrm{X})$ & & \\
\hline $\mathrm{E}_{\mathrm{T}}$ & -111000 & 0.8745 & $\mathrm{E}_{\mathrm{D}}$ & 0.820 & $<0.0001$ \\
$\mathrm{E}_{\mathrm{A}}$ & -109674 & 0.7517 & $\mathrm{E}_{\mathrm{D}}$ & 0.802 & $<0.0001$ \\
MOR & 182 & 14.6568 & $\mathrm{SWF}$ & 0.727 & $<0.0001$ \\
Density & 0.3408 & 0.0003082 & $\mathrm{SWF}$ & 0.461 & $<0.0001$ \\
\hline
\end{tabular}


The three-dimensional mesh plot (Figure 3.30) indicates that some curvylinear relationship between MOR, density, and screw withdrawal resistance may exist for the SYP group. The few sharp peaks, which are present in this figure, may be explained by the natural variability within each species that comprises the SYP lumber group. No significant interaction effect on the prediction was detected by regression analysis, and the model included both SWF and density as best predictors (Appendix VIII).

In general, the density as a physical property is strongly correlated to the fastener holding capacity of the products. Consequently, when both are used for predicting the MOR, due to their co-linearity, usually the regression analysis eliminates their interaction effect. It does appear that using both variables may increase the quality of MOR predictions however, the in-situ determination of the density of a member is not viable. Thus as a compromise, the fastener holding capacity may be used as a single independent variable to estimate the bending strength of the member. Furthermore, this single variable (SWF) can be used successfully to estimate the density, which is an input parameter for dynamic MOE estimation. 


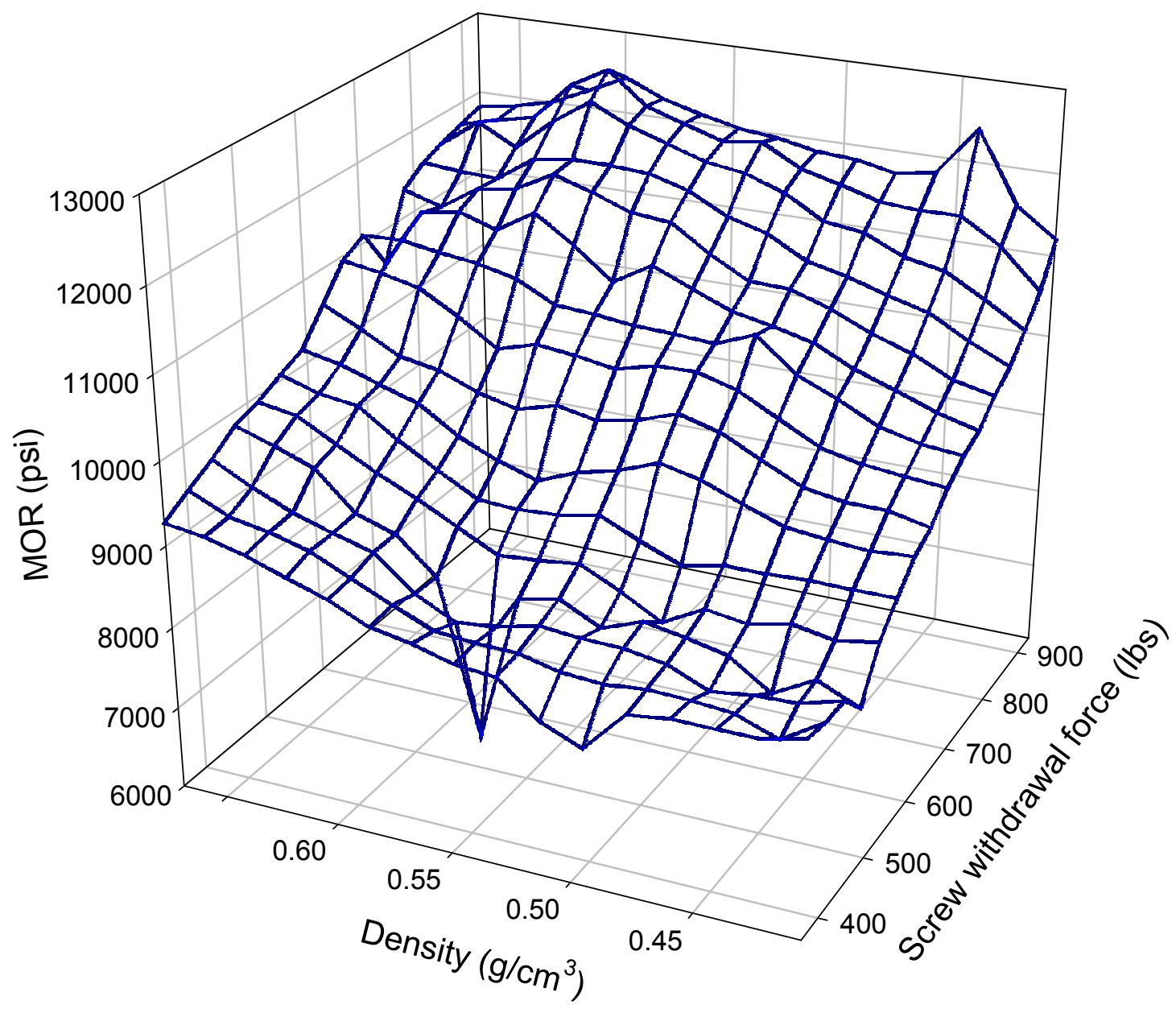

Figure 3.30. - Three-dimensional mesh plot between screw withdrawal force, density, and MOR for SYP. 


\subsection{Statistical evaluations concerning all groups combined}

A general linear model was used to test the interaction of species or composite groups in prediction of true MOE by dynamic MOE. Result of this model indicated that species or composite groups have statistically significant effects $(\mathrm{P}=<0.0001)$ on the dependent variable, thus separate prediction equations should be used when testing among different species or composite products. A comparison of the dynamic and true MOE for all groups combined (Figure 3.31), revealed a strong relationship $\left(r^{2}=0.779\right)$ between the two variables.

Similarly, a GLM procedure was used to test the effect of species or composite group in prediction of apparent MOE using dynamic counterpart. This model proved that species or composite groups do have statistically significant effects $(\mathrm{P}=0.0267)$ on the outcome. Figure 3.32 illustrates a regression comparison between dynamic and apparent MOE for all groups combined. The low coefficient of determination $\left(r^{2}=0.389\right)$ indicates a poor relationship between the two variables when all groups are combined, further confirming the previously observed relationship. 


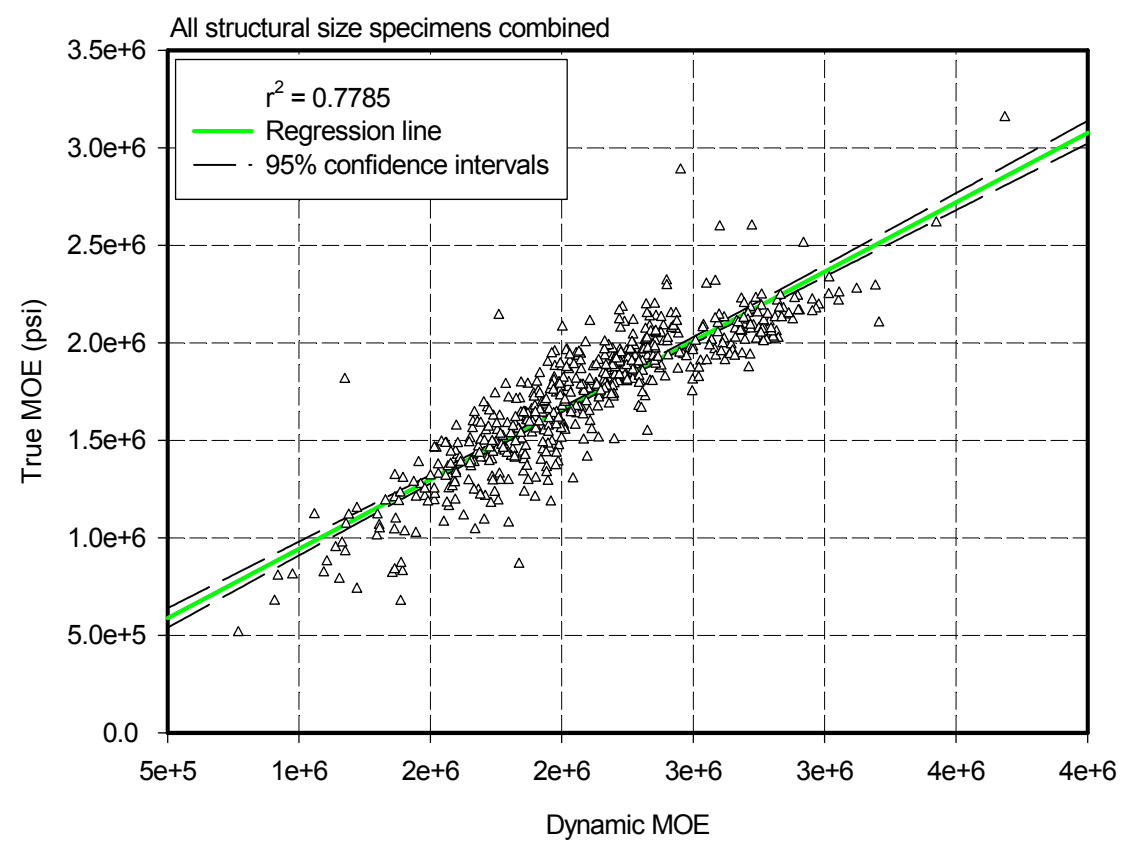

Figure 3.31. - Regression analysis of $E_{D}$ vs. $E_{T}$ for all groups combined, $95 \%$ confidence intervals and $\mathrm{r}^{2}$ value are indicated.

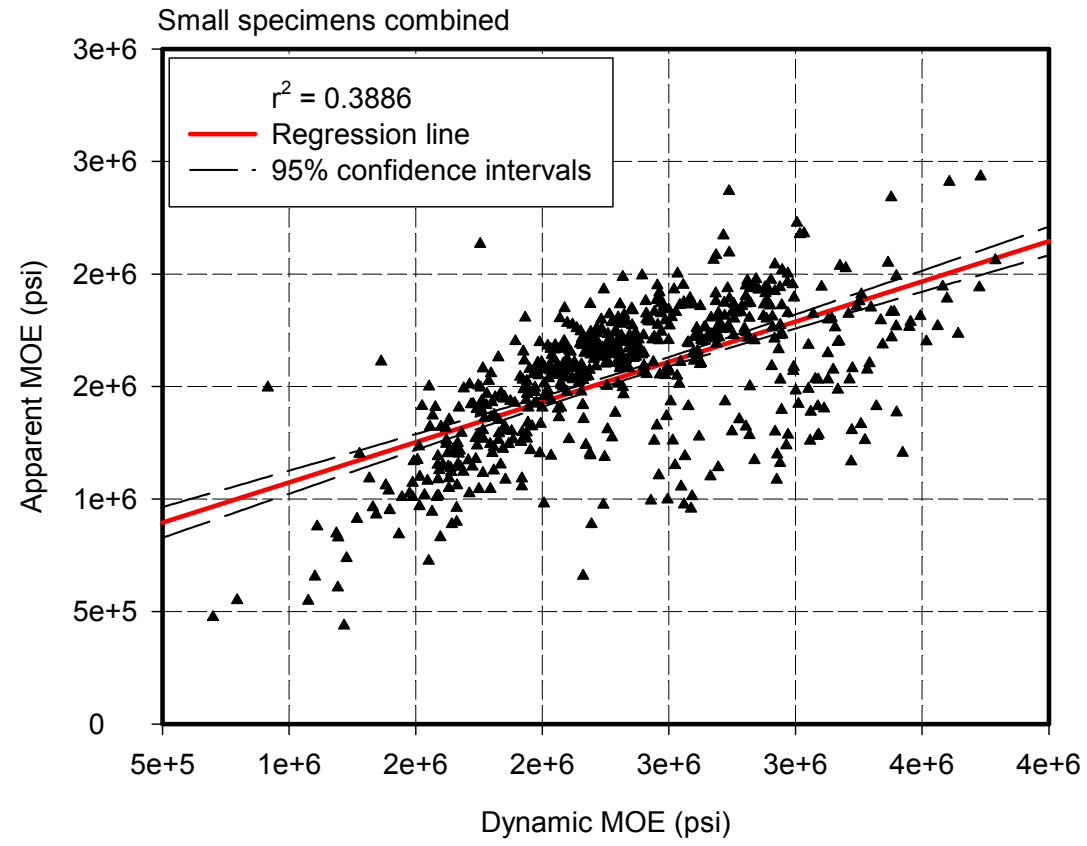

Figure 3.32. - Regression analysis of $E_{D}$ vs. $E_{A}$ for all groups combined, $95 \%$ confidence intervals and $\mathrm{r}^{2}$ value are indicated. 
The effect of species or composite groups on the ability of screw withdrawal resistance to predict the bending strength was tested using a similar GLM procedure. Result of this analysis indicated that species or composite groups do have a significant effects $(\mathrm{P}=<0.0001)$ at $95 \%$ confidence level in predicting MOR. A regression analysis performed on the combined screw withdrawal force and MOR data for all species and composite groups (Figure 3.33) resulted in a low coefficient of determination $\left(r^{2}=0.348\right)$, indicating that further analyses should be done by species group.

Furthermore, the interaction of species or composite groups on using screw withdrawal force to predict density was analyzed using a GLM procedure. Result of this analysis indicated that species or composite groups do have a statistically significant effect $(P<0.0001)$ on the dependent variable. This further confirms that when using screw withdrawal force to predict density, separate prediction equations should be used. Regression comparison of screw withdrawal force and density for all groups combined (Figure 3.34) resulted in an acceptable coefficient of determination $\left(r^{2}=0.560\right)$.

The next chapter contains a brief summary of this research along with the conclusions, which may be drawn from the results. Furthermore, some indications for further research are also included. 


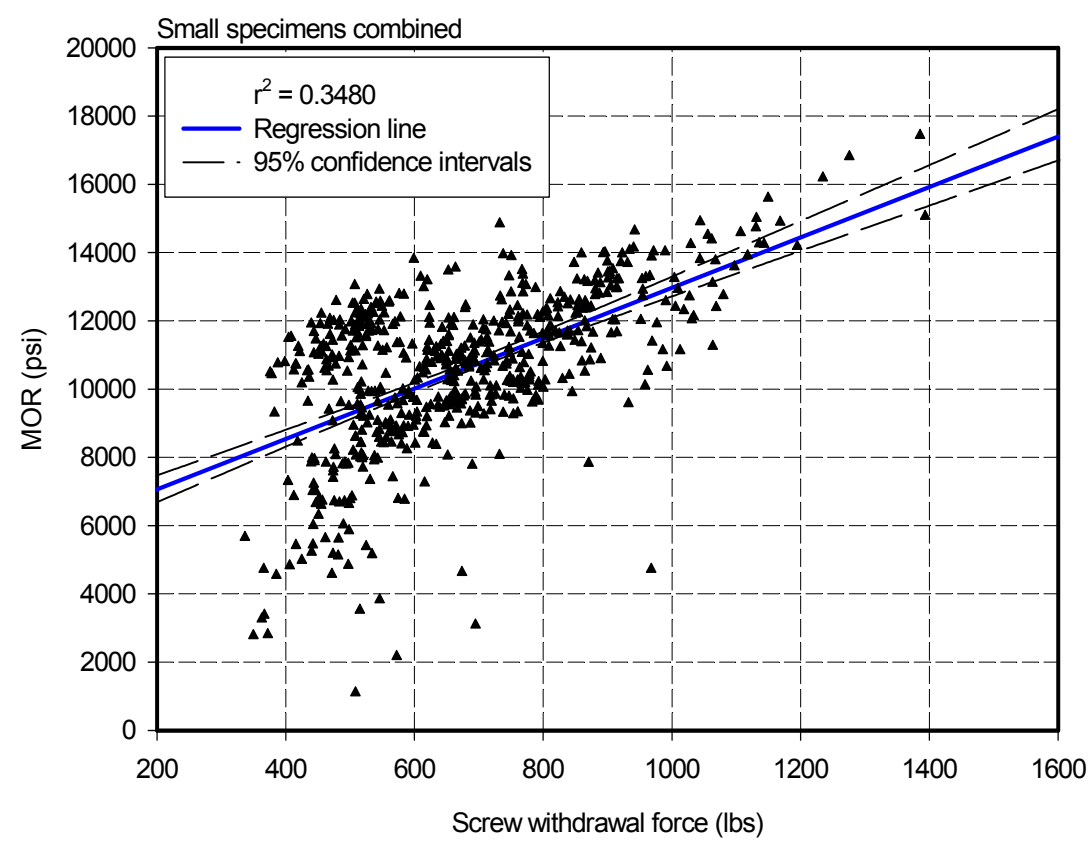

Figure 3.33. - Regression analysis of SWF vs. MOR for all groups combined, $95 \%$ confidence intervals and $r^{2}$ value are indicated.

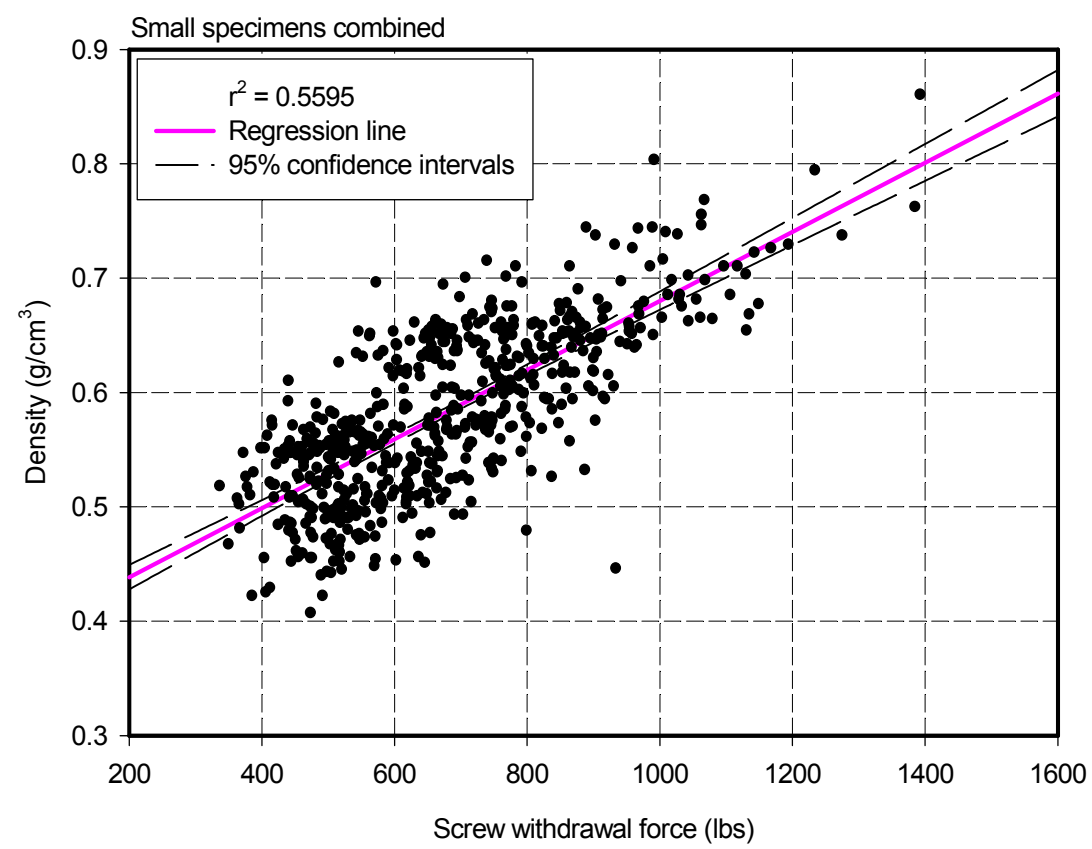

Figure 3.34. - Regression analysis of SWF vs. density for all groups combined, $95 \%$ confidence intervals and $\mathrm{r}^{2}$ value are indicated. 


\section{CHAPTER 4 - SUMMARY AND CONCLUSIONS}

\subsection{Summary}

The primary objective of this research was to evaluate the performance of existing non-destructive testing methods for prediction accuracy of physical and mechanical properties of structural solid wood and composite products. Techniques included stress wave timing for dynamic MOE determination and fastener withdrawal force measurements. These measuring techniques can be easily performed on built-in structural wood members in building that may require retrofitting, remodeling, or the structural material may be used as recycled load supporting elements. Standard ASTM testing procedures were used to compare predicted and actual strength and stiffness values.

The research intended to cover the evaluation of most commonly used wood species and load bearing composite products. Additionally, two locally important species, yellow-poplar, red oak, were also involved in the analyses. The well-known natural variability of wood and wood-base composites forced us to use minimum one hundred samples for each type of evaluation.

The selected statistical procedures included first order linear regression, general linear model development, and multiple linear regression (backward stepwise method). All statistical analyses were performed at $95 \%$ confidence 
level $(\alpha=0.05)$. The analytical work resulted in thirty-six simple linear models that may be used for further research purposes.

This research is the first phase of a comprehensive project aimed at to develop a field-testing protocol for non-destructive evaluation of built-in wooden members regarding their strength and stiffness. To further proceed with this long-term goal, the effect of moisture content on stress wave timing was briefly investigated. Additionally, the effect of treatment (creosote) was also evaluated on the strength and stiffness properties of PSL. Currently, the monitoring of a creosote treated PSL bridge deck is in progress, which is the first application of the findings of this research. The above mentioned two side studies are discussed briefly in chapters 5 and 6 of this thesis, respectively. Based on the results and discussion presented in the previous chapter, the conclusions of this research are provided in the next section.

\subsection{Conclusions}

The performed statistical evaluations provided confidence to draw some conclusions from the results of this research. Besides the high number of replications for each measurement, standard statistics confirmed that the majority of the developed regression equations can be used reliably to predict at least three mechanical properties and the density of the examined species and products. The specific conclusions may be stated as follows: 
- Stress wave timing and its result, the dynamic MOE, is a good predictor of the true MOE of all species and products;

- When the same technique is used for predicting the apparent MOE the quality of the prediction declined; however, still remained on statistically significant level;

- The best in situ predictor of MOR is the screw withdrawal resistance of the member. However, further refinement is necessary to obtain the design value $\left(\mathrm{F}_{\mathrm{b}}\right)$;

- The density of the examined species and composite products can be predicted using the screw withdrawal resistance. This process can alleviate any difficulties in in situ density assessment;

- As an overall conclusion, separate prediction equations are necessary for each species or composite products tested because no reliable general equation could be developed.

Several influencing factors, variables, were kept constant during these investigations. These variables that may have significant effects on strength and stiffness properties include temperature, different treatments (CCA, Borate), etc. The author wishes to draw attention of the readers that findings of this research have no universal value. Care should be take to interpret results obtained from experiments and materials other than described in this thesis. 


\subsection{Recommendations for further research}

Through out the course of this research a few items for further investigation have come about. One item that is recommended for further investigation is the effect of impact force on the wave velocity. In the testing method described, the sound wave is sent through the specimen by striking the transmitter with a small hammer. However, the effect of impact force with the transmitter is unknown.

Another factor worthy of investigation is the effect of distance between the transmitter and receiver on the dynamic MOE. The distance in which the sound wave travels through the specimen could have an effect on its ability to predict the true or apparent MOE. This research assumed that the longest distance possible would provide the best results by subjecting the wave to most of the specimen and hence most of the defects. However, if there is an optimal testing distance for sound wave propagation time to predict the true or apparent MOE remains to be validated.

One last area that the researcher feels important enough for a closer look is the effect of the depth of pilot and screw insertion on the ability to predict MOR and density using screw withdrawal force. The depth of the pilot hole and insertion of screw was held constant throughout this research. While good correlations were related for most groups and properties, higher correlations may be possible through different combinations of depth of pilot holes and screw insertion. A standard test procedure should be developed. 


\section{CHAPTER 5 - EFFECT OF CREOSOTE TREATMENT ON SCREW WITHDRAWAL FORCE AND DYNAMIC MOE}

\subsection{Abstract}

The high mechanical properties of wood make it desirable in building construction, including exterior uses. In exterior applications, chemically treated lumber is often used to retard fungal growth and decay. However, the effect that chemical treatment has on the stress wave propagation time, dynamic modulus of elasticity (MOE), and screw withdrawal force is uncertain. Our study focused on determining what effect, if any, pressure treatment with creosote has on screw withdrawal force and stress wave velocity. For this experiment we compared the results from the non-destructive tests for both treated and non-treated PSL specimens. We found that when using screw withdrawal force to predict density, the effect of creosote treatment did not have a significant effect. However, our results indicate that when using screw withdrawal force to predict modulus of rupture (MOR), and dynamic MOE to predict the true MOE, that treatment with creosote did have a significant effect. These results indicated that when using stress wave velocity to predict MOE or screw withdrawal force to predict MOR, separate prediction equations for treated and non-treated PSL elements are desired. 


\subsection{Introduction}

Wood is used world wide in many exterior applications such as bridge construction, boat building, and residential deck construction. In exterior use, wood is exposed to many harsh conditions such as insect attack, weathering, and excessive moisture leading to fungal attack and decay. Because only a few species of wood are naturally decay resistant the wood industry has developed many methods of treating the wood to combat this undesirable state of decay. One of the most widely used methods is pressure treating. Pressure treatment consists of placing a quantity of wood in a large cylinder and cycling through a vacuum/pressure schedule to drive the treating chemical into the wood cells.

Creosote is one of the most commonly used preservatives on the market. Once driven into the wood cells this preservative fixates to the cell walls, retarding fungal growth and hence decays. However one question came to mind while doing this study. What effect does creosote treatment have on stress wave timing and the dynamic MOE? Emerson et al. (1999) performed a study using sound wave propagation time to detect decay in creosote treated timber bridges. Results from their study found that heavy creosote treatment decreased wave velocity, as does decay. They suggest that prudence be used to determine if velocity was reduced due to decay or just heavy treatment. 
The objective of this side study was to determine what, if any, effect creosote treatment has on the two non-destructive evaluation techniques being developed, screw withdrawal force and dynamic MOE.

\subsection{Materials and methods}

This study consisted of thirty-five creosote pressure treated PSL specimens. The specimens were cut to approximate dimensions of 2 in. $x 2$ in. $x$ 30 in. prior to treatment. Specimens were placed in the conditioning chamber mentioned in methods section 2.1.1 and allowed to equalize. Measurements were then performed for stress wave time, mass, length, width, and thickness. The devices and methods used for these measurements were the same as mentioned in the methods sections 2.2.2. All calculations for density, volume, moment of inertia, section modulus, and dynamic MOE were the same as presented in section 2.2.1.

After the stress wave timing, measurements were attained, the specimens were tested in four-point static bending for the true MOE and MOR. Finally the specimens were tested for screw withdrawal force. The four point static bending and screw withdrawal force testing followed the same methods and calculations as presented in section 2.2.1 and 2.2.2.

Analysis of variance and regression analysis were then performed between the treated PSL specimens and the non-treated PSL specimens 
previously tested to compare the effect that the creosote treatment may have had on the dynamic MOE or the screw withdrawal force. All statistical analyses were performed at a $95 \%$ confidence level $(\alpha=0.05)$.

\subsection{Results and discussion}

The results from the regression analysis revealed that screw withdrawal force is a suitable predictor of MOR for both the treated PSL and the non-treated PSL specimens. Figure 5.1 is a fitted line regression plot $\left(r^{2}=0.5972, P=\right.$ $<0.0001$ ) of screw withdrawal force vs. MOR for the non-treated PSL specimens. A fitted line regression plot for the screw withdrawal force vs. MOR for the treated PSL specimens can be found in Figure $5.2\left(\mathrm{r}^{2}=0.6696, \mathrm{P}=<0.0001\right)$. Both plots reveal a good relationship between the screw withdrawal force and the MOR. Analysis of variance was used to test for differences in the relationship between screw withdrawal force and MOR among groups. This revealed that at the $\alpha=$ 0.05 level, group has a significant effect on MOR $(\mathrm{P}=0.2561)$. When screw withdrawal force is used to predict the MOR of a specimen, a separate regression equation must be used for treated and non-treated PSL specimens. 


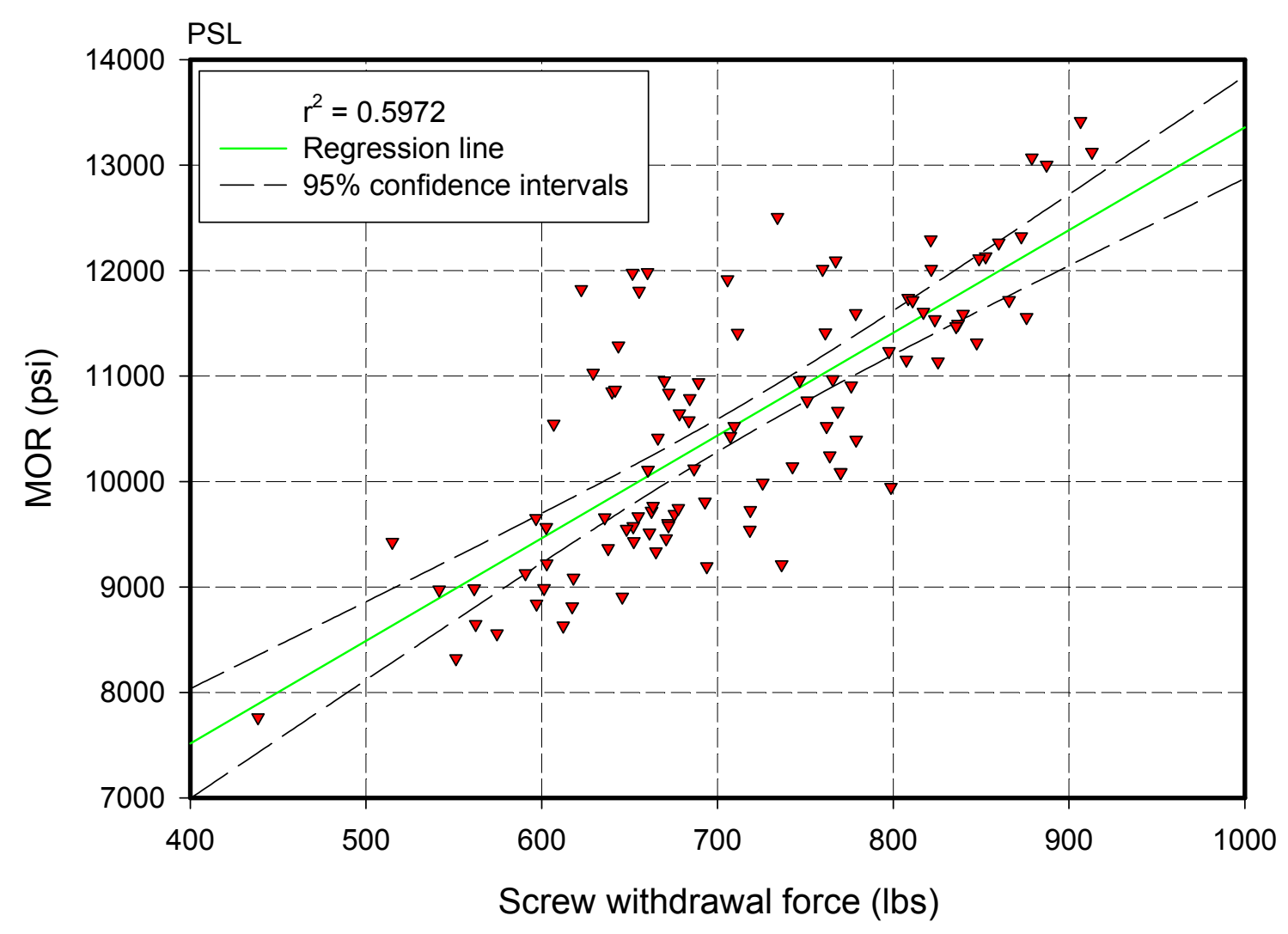

Figure 5.1. - Regression analysis of screw withdrawal force vs. modulus of rupture for PSL specimens, 95\% confidence intervals and $\mathrm{r}^{2}$ value are indicated. 


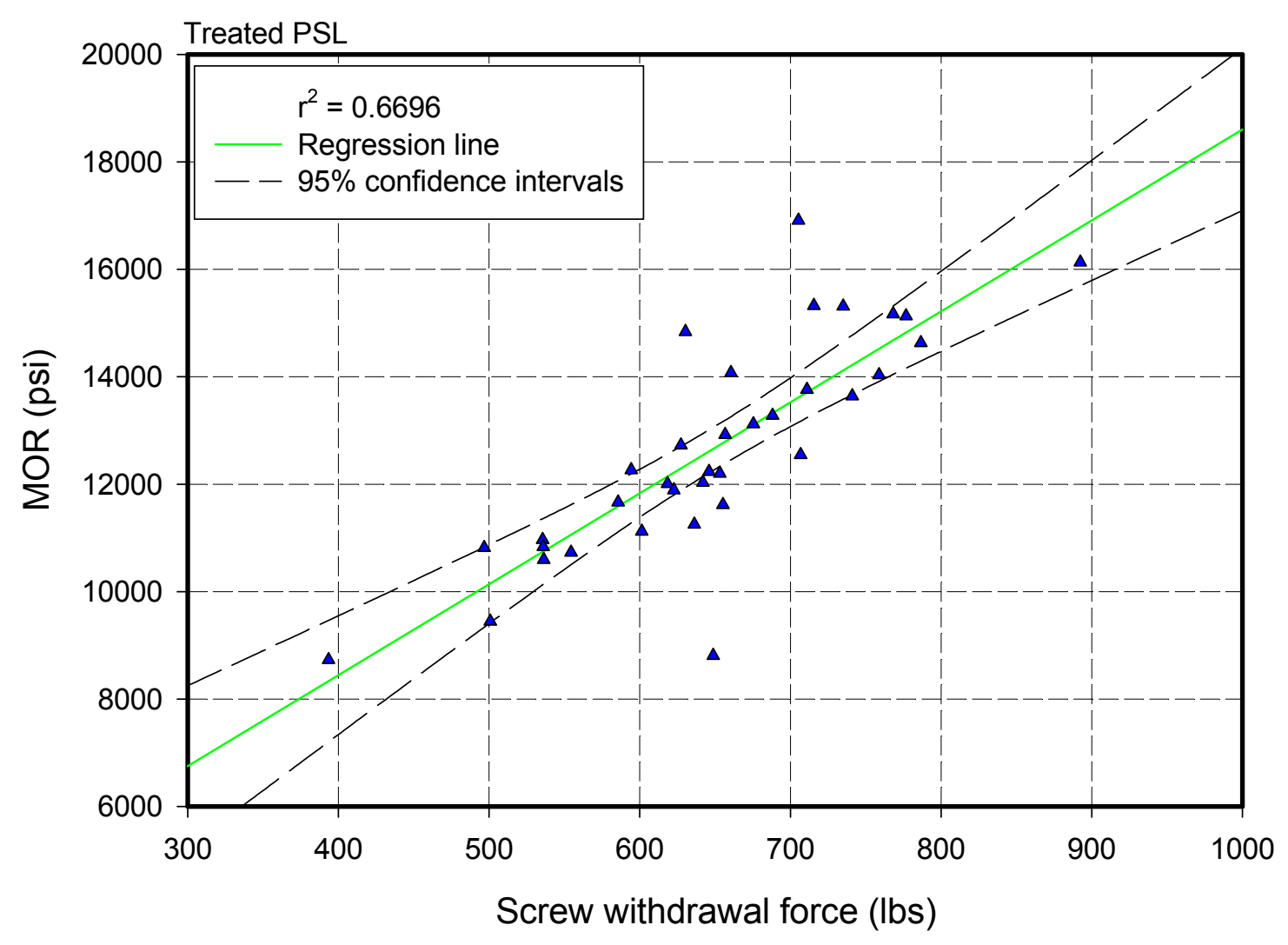

Figure 5.2. - Regression analysis of screw withdrawal force vs. modulus of rupture for treated PSL specimens, 95\% confidence intervals and $r^{2}$ value are indicated. 
Regression analysis revealed that screw withdrawal force is a good predictor of density, at the $95 \%$.. confidence level, for the non-treated PSL specimens as can be seen in Figure $5.3\left(r^{2}=0.2069, P=<0.0001\right)$. Screw withdrawal force was found to not be a statistically significant predictor of density for the treated PSL specimens, Figure $5.4\left(r^{2}=0.1102, P=0.0514\right)$ at the $\alpha=0.05$ level. The analysis of variance revealed that the effect of creosote treatment did not have an effect on using screw withdrawal force as a predictor of density $(\mathrm{P}=$ $<0.0001)$.

Looking at a three dimensional mesh plot of the density screw withdrawal force vs. density vs. MOR for the non-treated PSL specimens (Figure 5.5) one can see that the relationship between the three is linear. However, when looking at a plot of the same variables for the treated PSL specimens (Figure 5.6) it can be seen that the relationship is not as smooth. This difference is attributed to the variability in using screw withdrawal force as a predictor of density between the two groups. Since screw withdrawal force is a much better predictor of density for the non-treated PSL specimens the relationship between the three is likewise much better.

Regression analysis determined that the dynamic MOE explained a significant amount of variation in true MOE at the $95 \%$ confidence level. This relationship between dynamic MOE and true MOE can be seen in Figure $5.7\left(\mathrm{r}^{2}=\right.$ 0.6223, $\mathrm{P}=<0.0001)$ for the non-treated PSL specimens and in Figure $5.8\left(\mathrm{r}^{2}=\right.$ $0.7328, \mathrm{P}=<0.0001)$ for the treated PSL specimens. Analysis of variance was used to test for differences in the relationship between dynamic and true MOE 
among groups. This analysis revealed that creosote treatment has a statistically significant effect $(\mathrm{P}=<0.0003)$ on the dynamic MOE at the $\alpha=0.005$ level, indicating that separate regression equations are required when predicting the true MOE from dynamic MOE between treated and non-treated PSL specimens. Table 5.1 contains the regression formulas developed during this analysis for the treated PSL specimens.

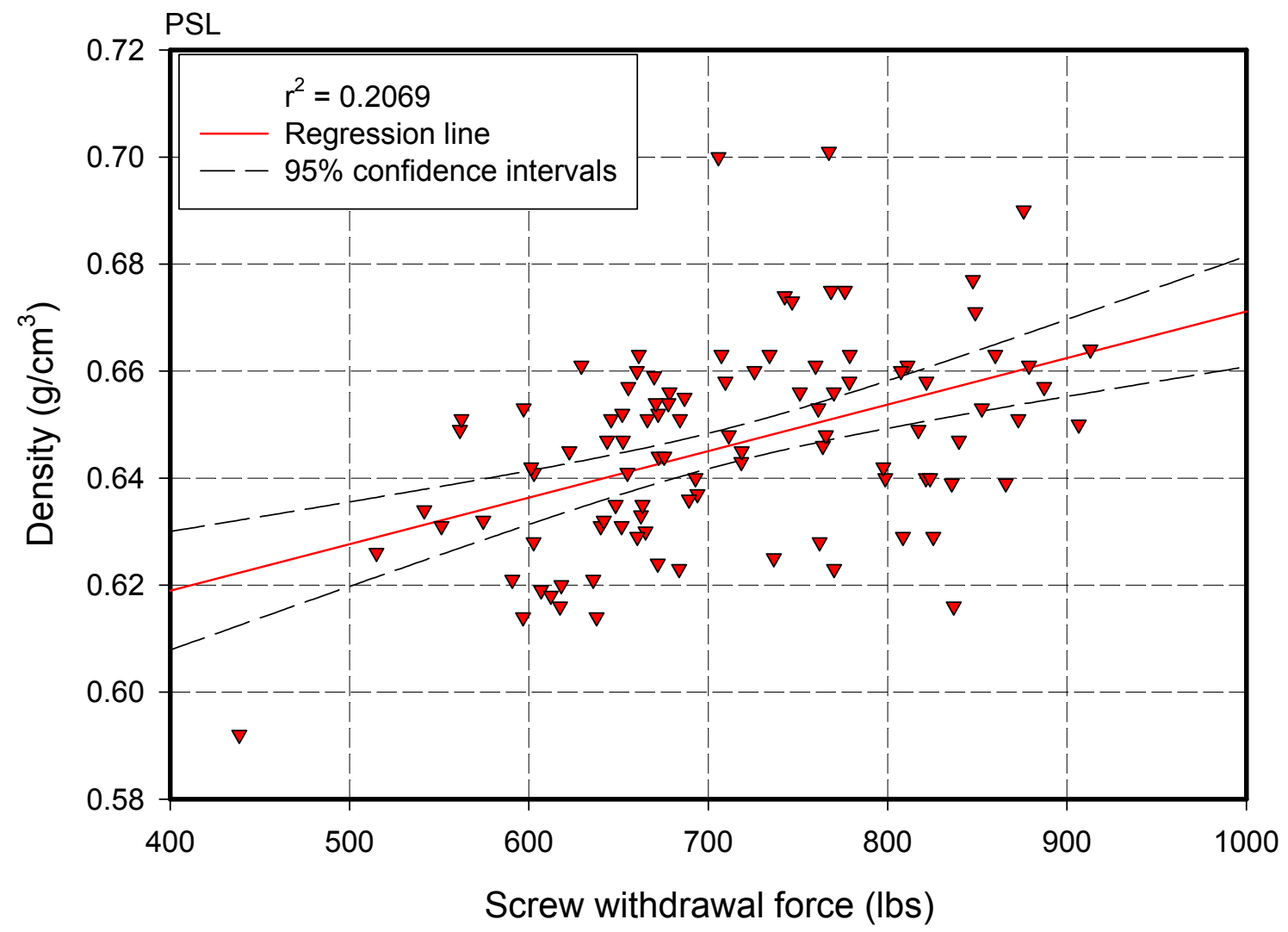

Figure 5.3. - Regression analysis of screw withdrawal force vs. density for PSL specimens, $95 \%$ confidence intervals and $\mathrm{r}^{2}$ value are indicated. 


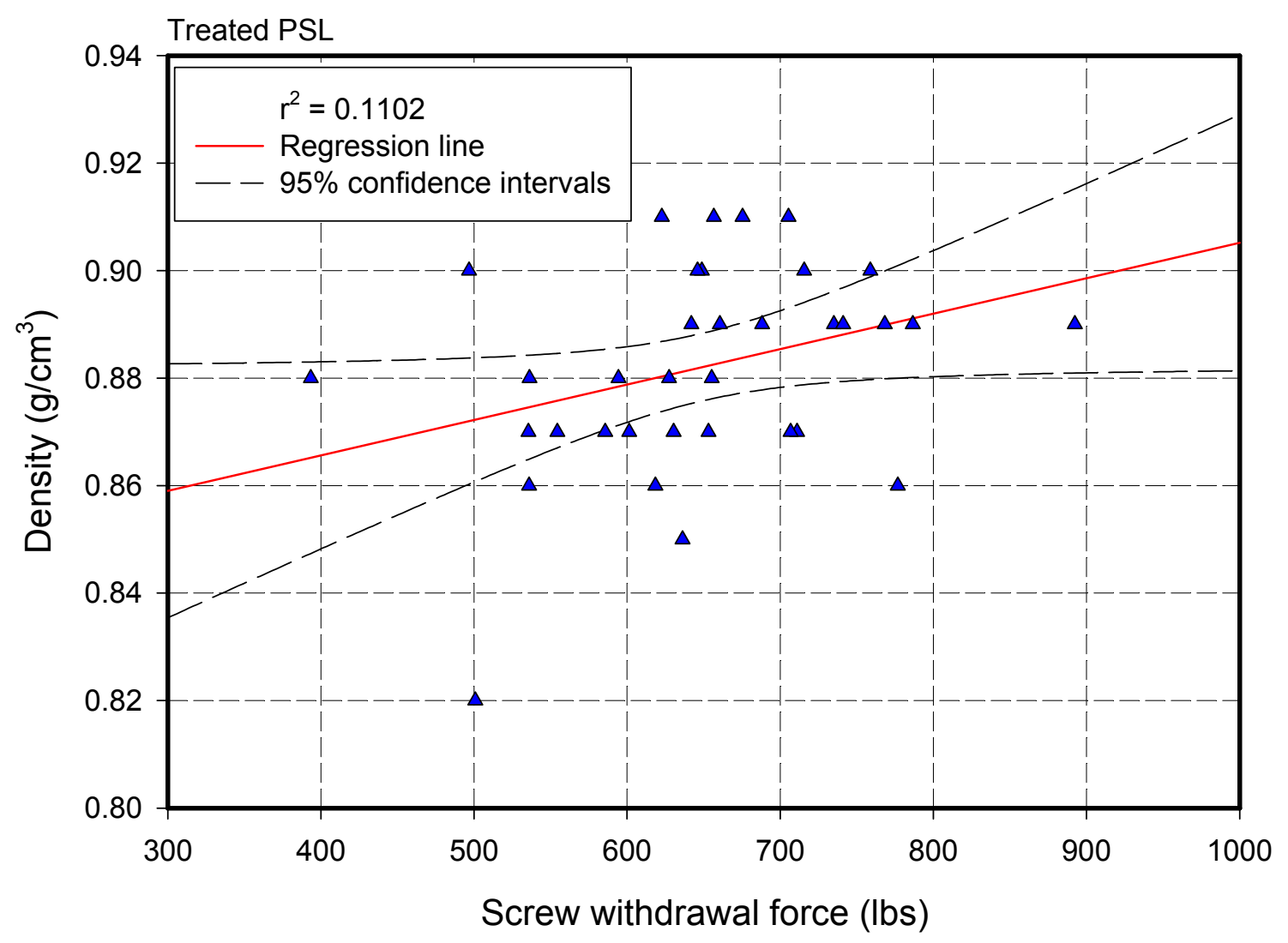

Figure 5.4. - Regression analysis of screw withdrawal force vs. density for treated PSL specimens, 95\% confidence intervals and $r^{2}$ value are indicated. 


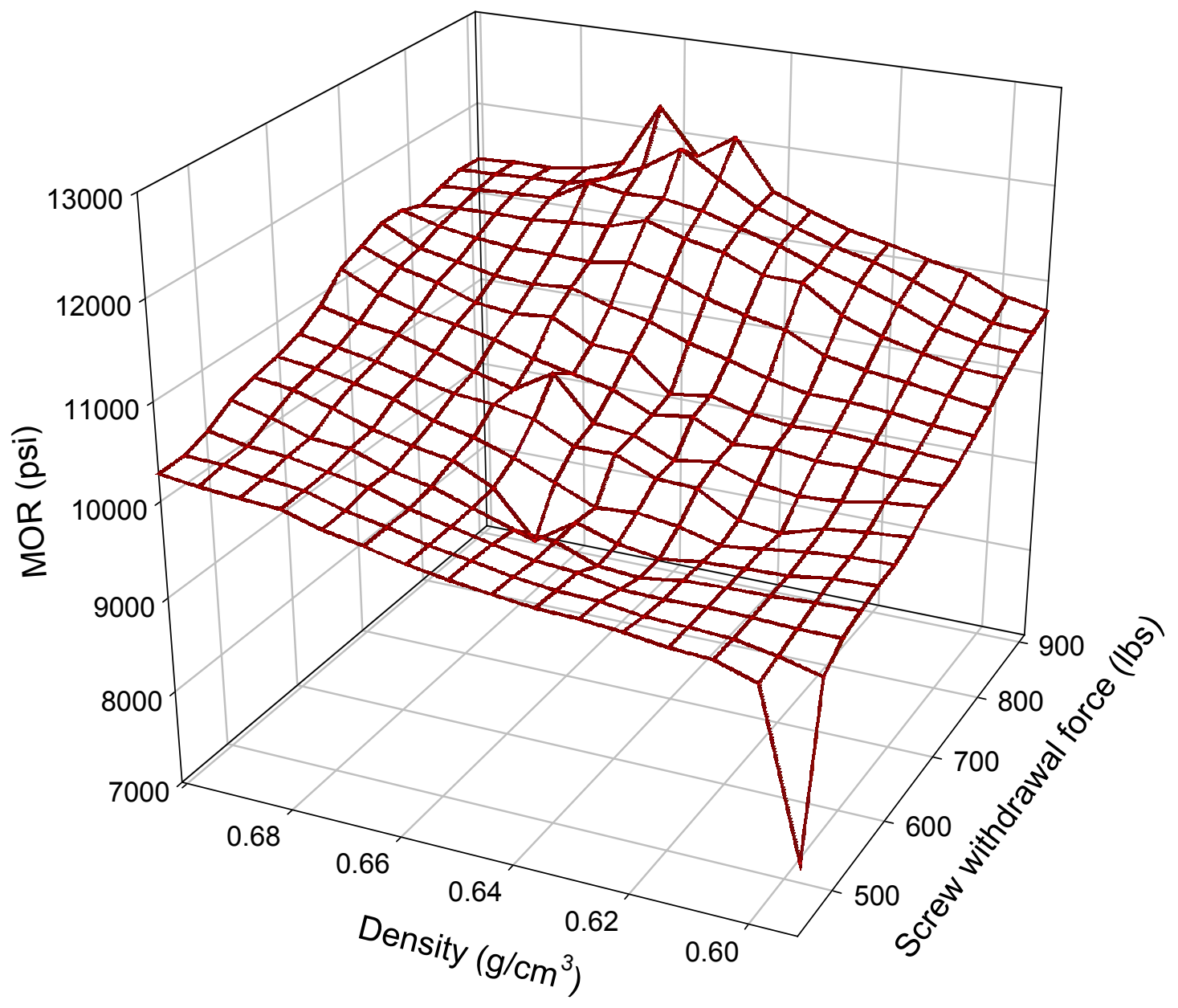

Figure 5.5. - 3D mesh plot of screw withdrawal force, density, and MOR for PSL specimens. 


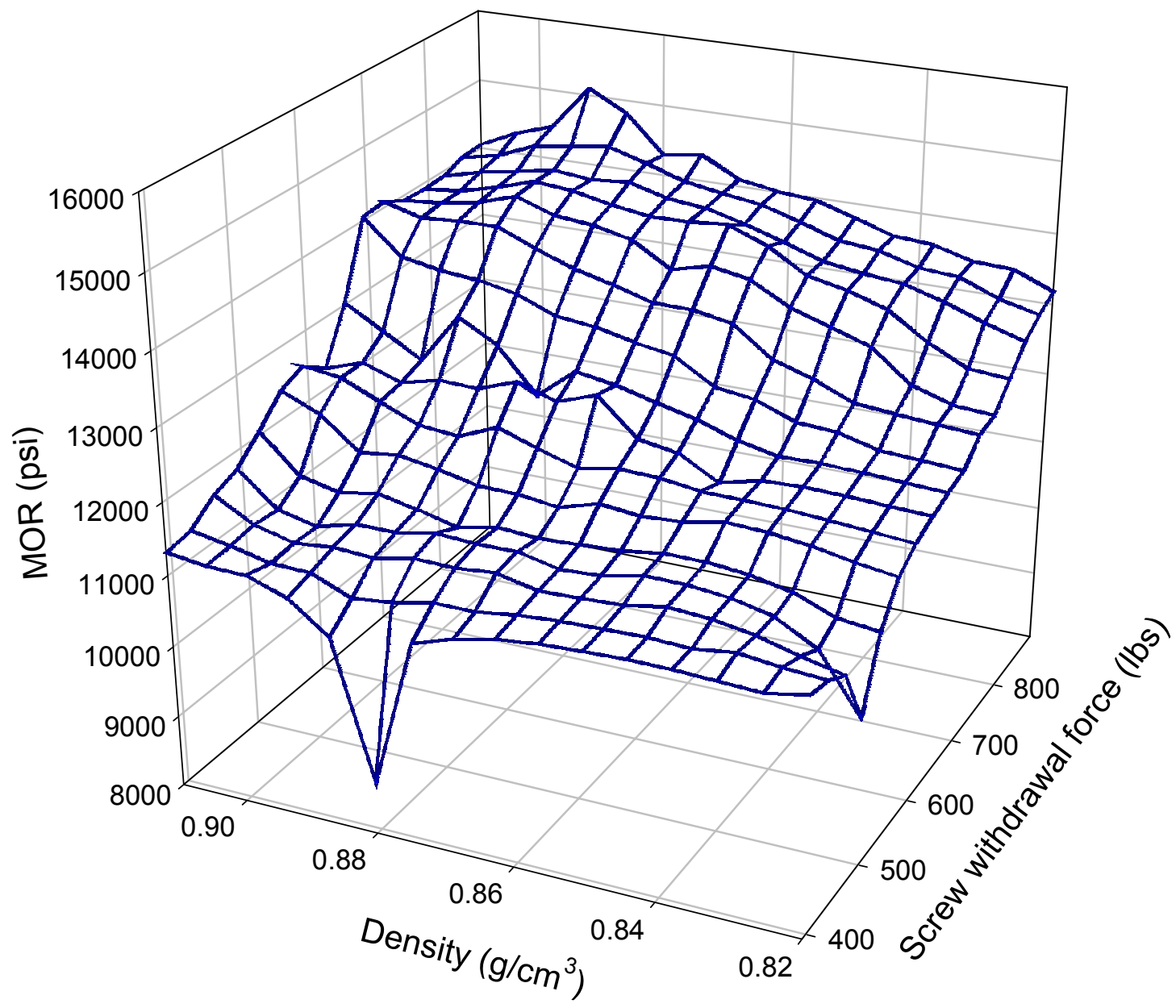

Figure 5.6. - 3D plot of screw withdrawal force, density, and MOR for treated PSL specimens. 


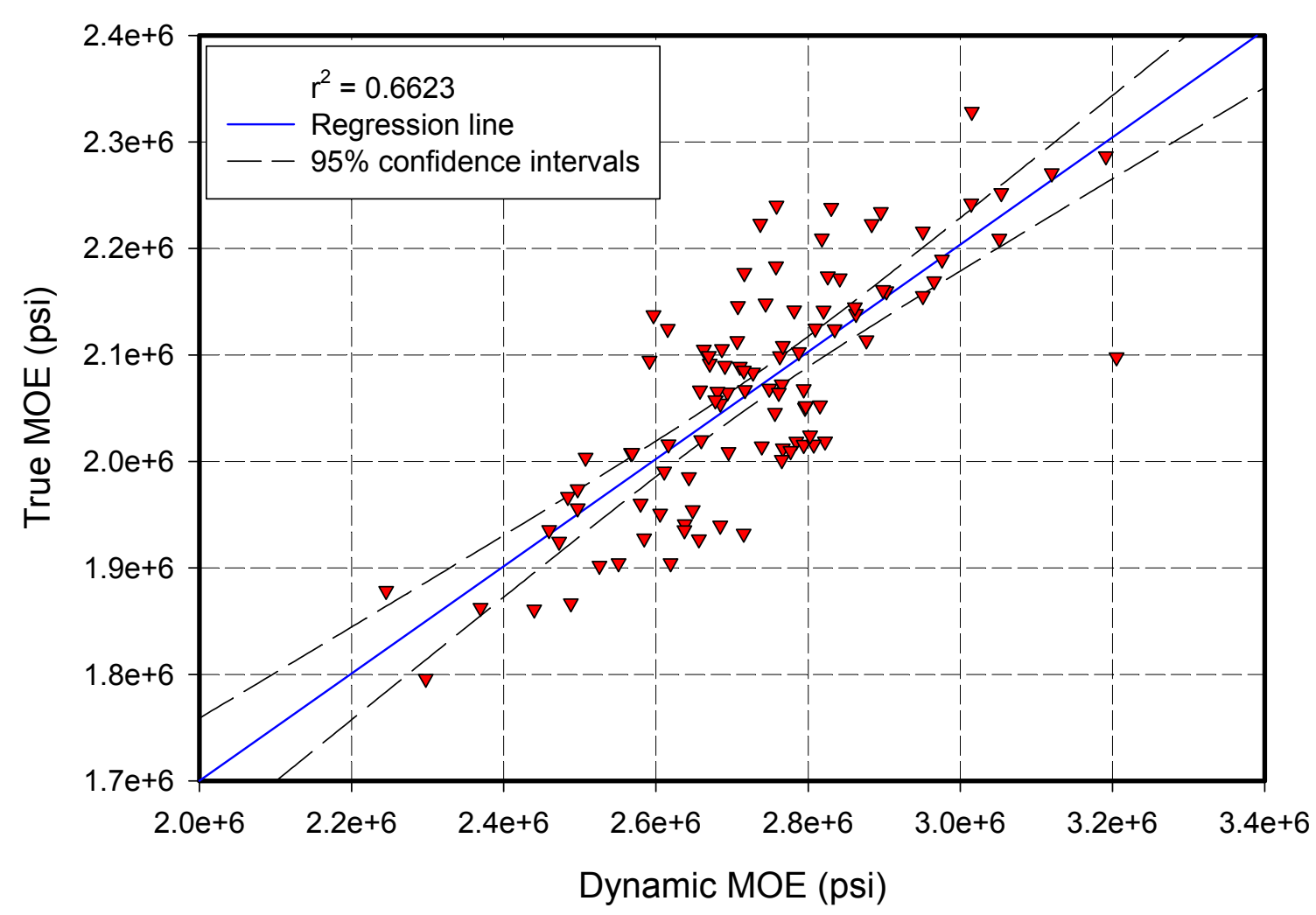

Figure 5.7. - Regression analysis of dynamic vs. true modulus of elasticity for PSL specimens, 95\% confidence intervals and $\mathrm{r}^{2}$ value are indicated. 


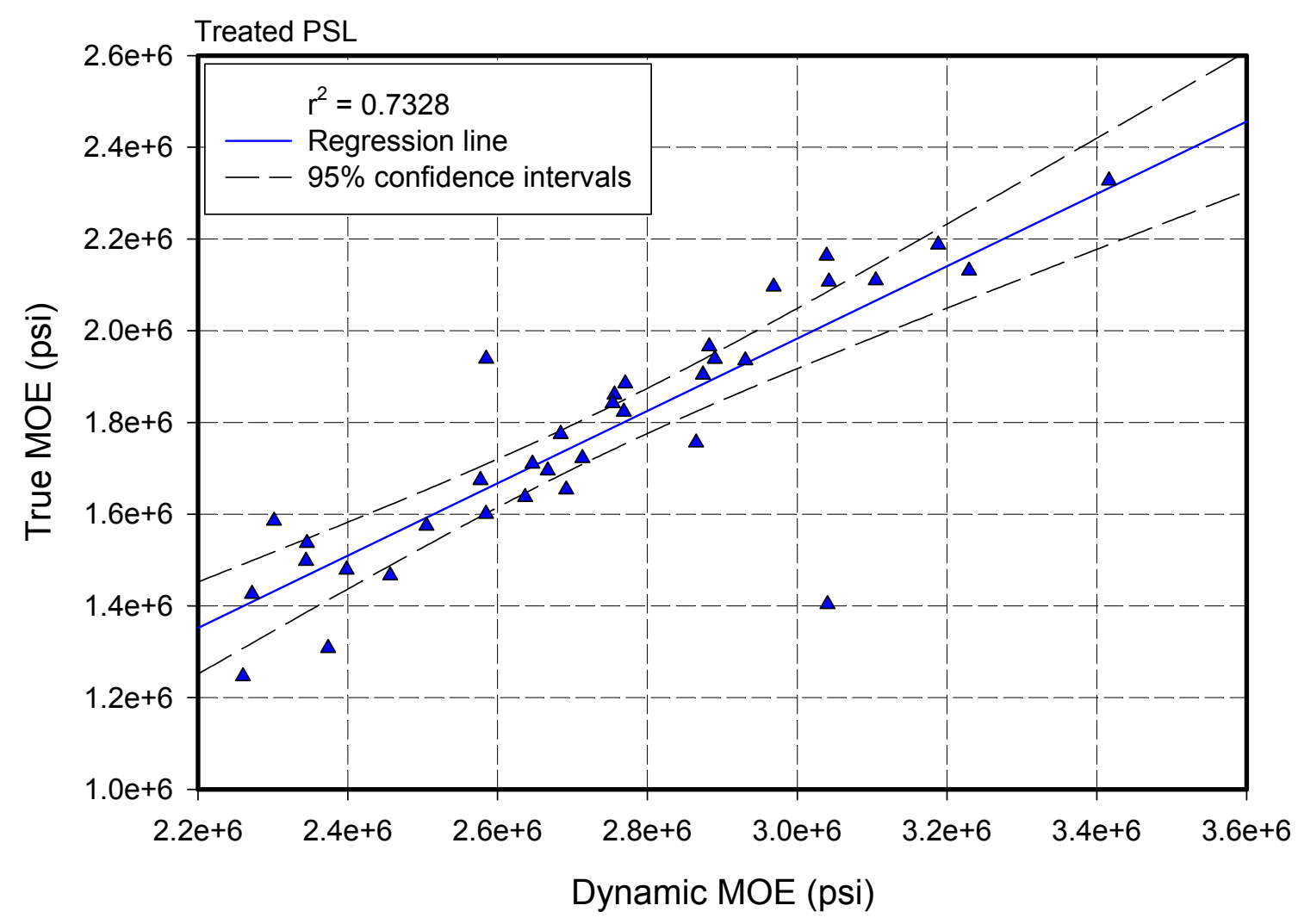

Figure 5.8. - Regression analysis of dynamic vs. true modulus of elasticity for treated PSL specimens, 95\% confidence intervals and $r^{2}$ value are indicated. 
Table 5.1. - Parameters and statistics of regression analysis for treated PSL.

\begin{tabular}{cccccc}
\hline \hline $\begin{array}{c}\text { Dependent } \\
\text { variable } \\
(\mathrm{Y})\end{array}$ & $\beta_{0}$ & $\beta_{1}$ & $\begin{array}{c}\text { Independent } \\
\text { variable } \\
(X)\end{array}$ & $r^{2}$ & $P$ \\
\hline \hline $\mathrm{E}_{\mathrm{T}}$ & -384163 & 0.7891 & $\mathrm{E}_{\mathrm{D}}$ & 0.733 & $<0.0001$ \\
$\mathrm{MOR}$ & 1671 & 16.9306 & $\mathrm{SWF}$ & 0.670 & $<0.0001$ \\
Density & 0.8393 & 0.00006592 & $\mathrm{SWF}$ & 0.110 & 0.0514 \\
\hline
\end{tabular}

\subsection{Conclusions}

Through the use of the equations presented in Tables 5.1 and 3.2, one is capable of non-destructively evaluating the modulus of rupture, density, and modulus of elasticity of treated or non-treated PSL specimens. A high correlation between the dependent and the independent variables allows these predictions of the mechanical properties to be performed at a high degree of certainty. However, using screw withdrawal force to predict the density of a specimen does not have as high of a degree of confidence as does the others.

Analysis of variance was used to test for the effect of group (treatment) on the testing methods investigated. The results reveal that treatment does have a significant effect on the ability of the non-destructive testing methods to predict the mechanical properties of specimens, the exception being density prediction. It was found that while the average dynamic MOE was almost identical for the treated and non-treated specimens alike, the average true MOE was 900,000 psi 
lower for the treated PSL specimens. The difference between the dynamic and true MOE was considered significant, thus treatment has a significant effect. The average screw withdrawal force was also found to be on average 90 lbs less for the treated PSL specimens although the MOR was approximately 2000 psi higher and the density was $0.2 \mathrm{~g} / \mathrm{cm}^{3}$ higher. Since the screw withdrawal force dropped while the density and MOR increased this also caused the effect of treatment to be statistically significant.

The results of this study are in close agreement with the conclusions found by Emerson et al. (1999). Their study indicated that treatment with creosote would slow the wave velocity time, hence lowering the dynamic MOE. Our study determined that the effect of creosote treatment on screw withdrawal force and stress wave velocity is significant enough that when using any of these non-destructive test methods one must use separated prediction equations for both treated and non-treated PSL specimens. 


\section{CHAPTER 6 - EFFECT OF MOISTURE}

\subsection{Abstract}

Wood is a hygroscopic material, having the ability to gain and loose moisture in conjunction with the surrounding environment. However, the moisture content of a specimen is also one of many factors having a significant impact on the mechanical properties. The exact impact moisture content has on the stress wave propagation is not known. The objective of this side study was to determine what, if any, effect moisture content has on the stress wave velocity.

Results of this study revealed a statistically significant relationship between moisture content and average wave time, moisture content and density, along with moisture content and dynamic MOE. The effect of these relationships are significant enough to suggest that the moisture content be taken into consideration when performing the non-destructive evaluation described by this research. 


\subsection{Introduction}

Moisture content is one of many factors that have an important impact on the mechanical properties of wood. Studies of solid wood indicated that MOE in bending and compressive strength, both parallel and perpendicular to the grain, increases linearly with drying below fiber saturation point (Green and Kretschmann 1994). However, some research indicates that mechanical properties do not always increase with decreasing moisture content. Kretschmann and Green (1996) indicated that ultimate tensile strength increases as moisture content decreases, reaching it's maximum at about $10-12 \%$. However, they also note that the ultimate tensile strength then decreases with additional drying below $10 \%$.

Exactly what effect does moisture content have on sound wave propagation? The Forest Products Laboratory (1999) noted that the speed of sound decreases with increasing moisture content. It was also noticed that the decrease is proportional with the influence that moisture content has on the modulus of elasticity and density. Wu (1999) states that stress wave velocity decreased by about $1 \%$ per moisture content percent increase. This previous research led us to this related study of trying to determine the extent to which moisture content affected the stress wave velocity. 


\subsection{Materials and methods}

This study consisted of four specimens of yellow poplar (Liriodendron tulipifera) cut to target dimensions of $2 \times 2 \times 30$ inches. Specimens were chosen to be free of any defects, such as sloping grain and knots, and to reduce any other form of variation that may occur. At the start of the study, specimens were at a green moisture content of above $30 \%$, as measured with a hand held moisture meter with species correction. The specimens were stored in a conditioning chamber in which the temperature and relative humidity were set to provide moisture content conditions of $10 \%$. Measurements were performed daily for average dimensions, mass, moisture content, and stress wave time. Once the specimens air-dried down to $10 \%$ moisture content, the study was concluded. Devices and procedures used to attain these measurements are the same as described in the materials section 2.2. Using the measurements it was possible to track the density, average wave time, and dynamic MOE throughout the declining changes in moisture content.

\subsection{Results and discussion}

The relationship between moisture content and wave propagation time, moisture content and density, and moisture content and dynamic MOE were investigated. All regression analysis performed used a 95\% confidence interval 
$(\alpha=0.05)$. We found that a linear relationship existed between moisture content and wave propagation time $\left(r^{2}=0.72\right)$, Figure 6.1. A quadratic relationship was found to exist between moisture content and density $\left(r^{2}=0.78\right)$, Figure 6.2. Results also conclude that a quadratic relationship exists between moisture content and the dynamic MOE $\left(r^{2}=0.54\right)$, Figure 6.3. Figure 6.4 is a threedimensional plot of moisture content, density, and dynamic MOE. This plot helps to illustrate the relationship between the three variables. A three-dimensional parabolic regression line was fitted to the moisture content, density, and dynamic MOE data (Figure 6.5), revealing a high relationship between the three variables $\left(r^{2}=0.84\right)$. 


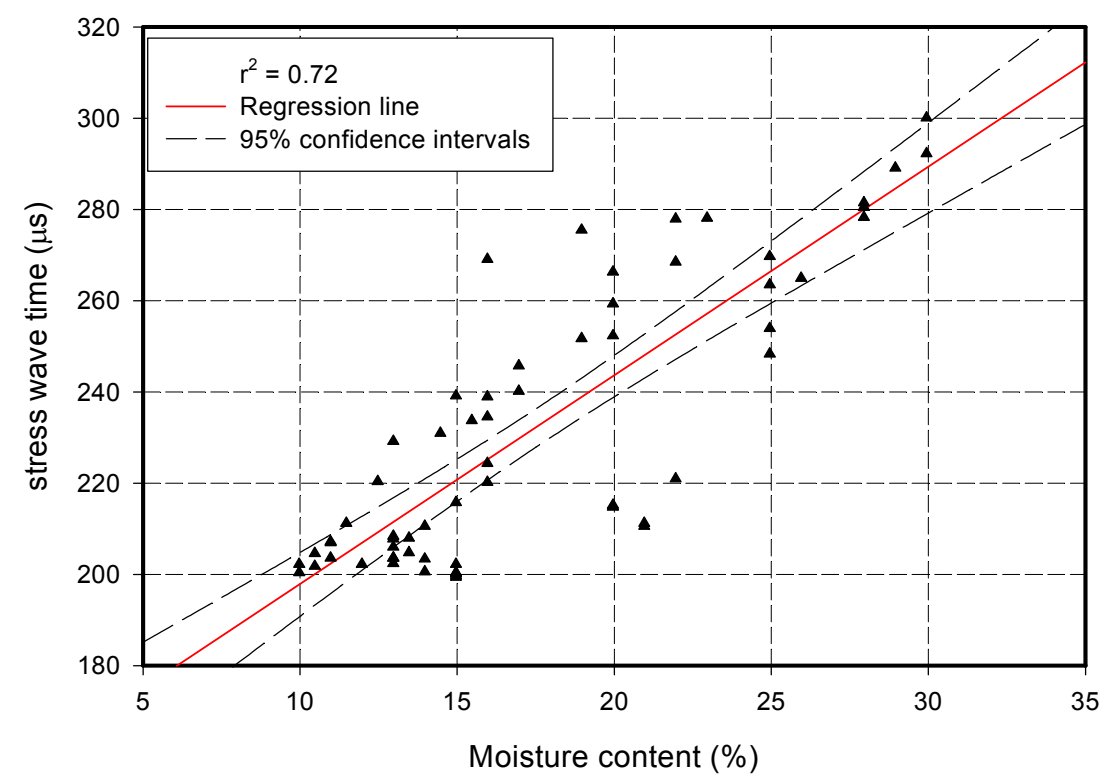

Figure 6.1. - Regression Analysis between moisture content and velocity, 95\% confidence intervals and $\mathrm{r}^{2}$ value are indicated.

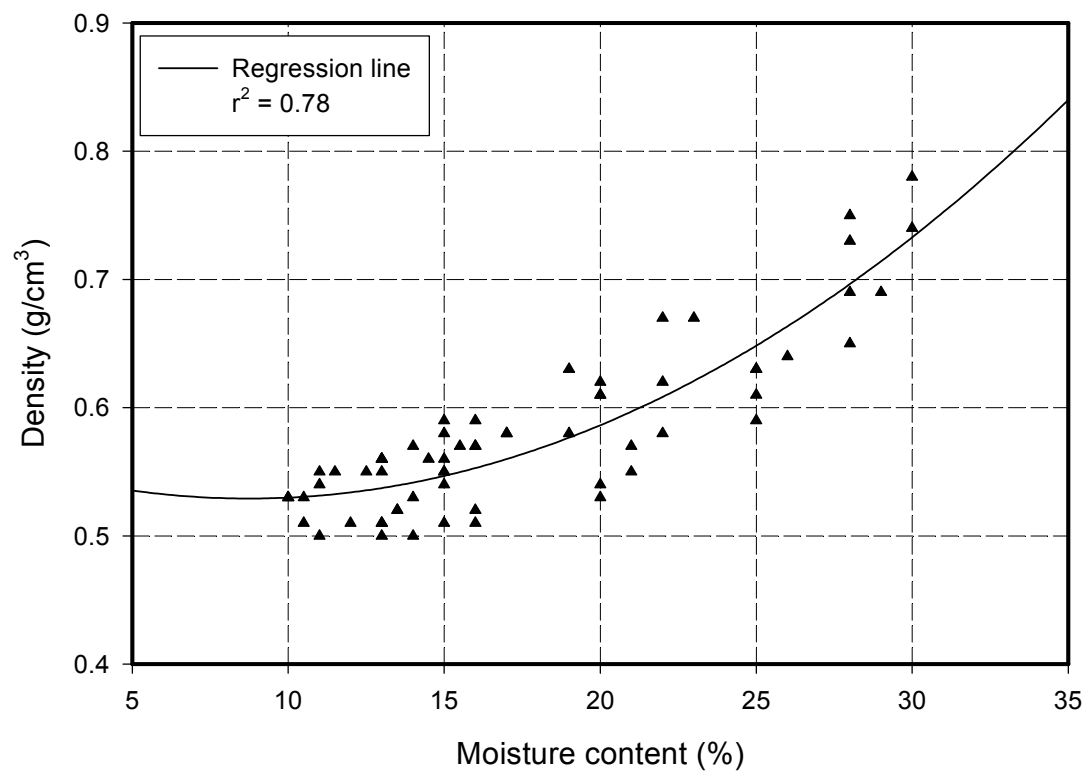

Figure 6.2. - Regression plot between moisture content and density, $\mathrm{r}^{2}$ value indicated. 


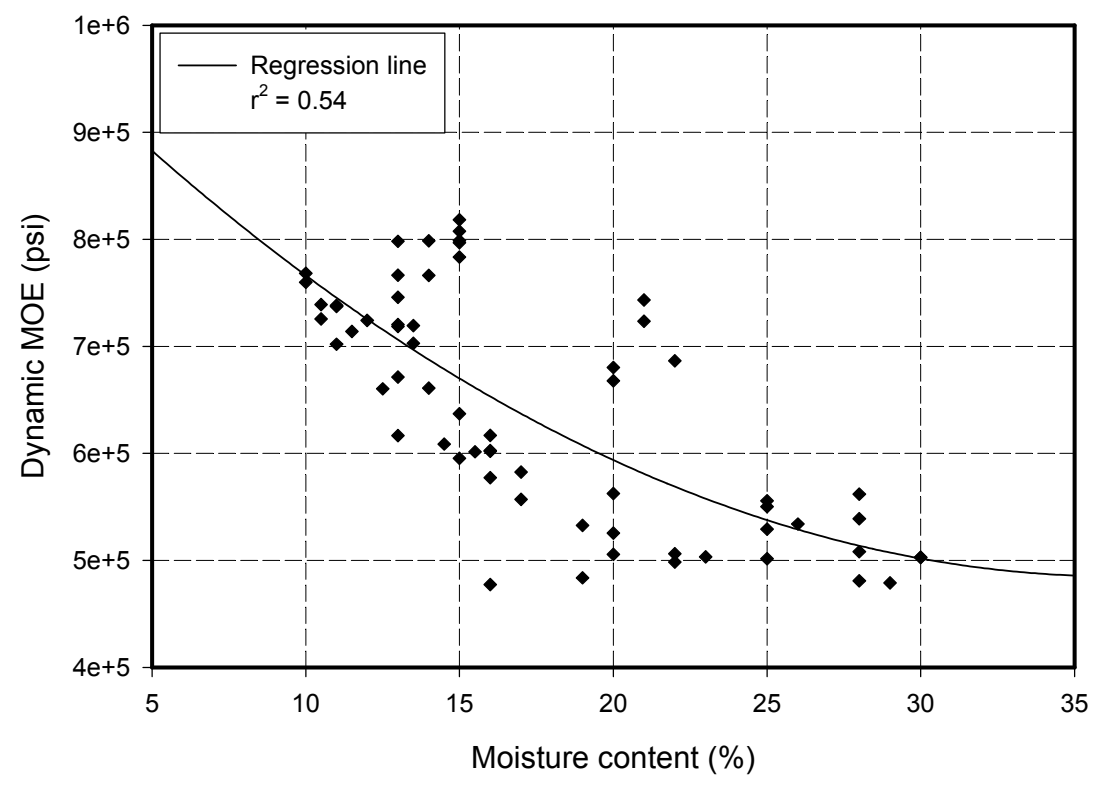

Figure 6.3. - Regression plot between moisture content and dynamic MOE, $\mathrm{r}^{2}$ value indicated.

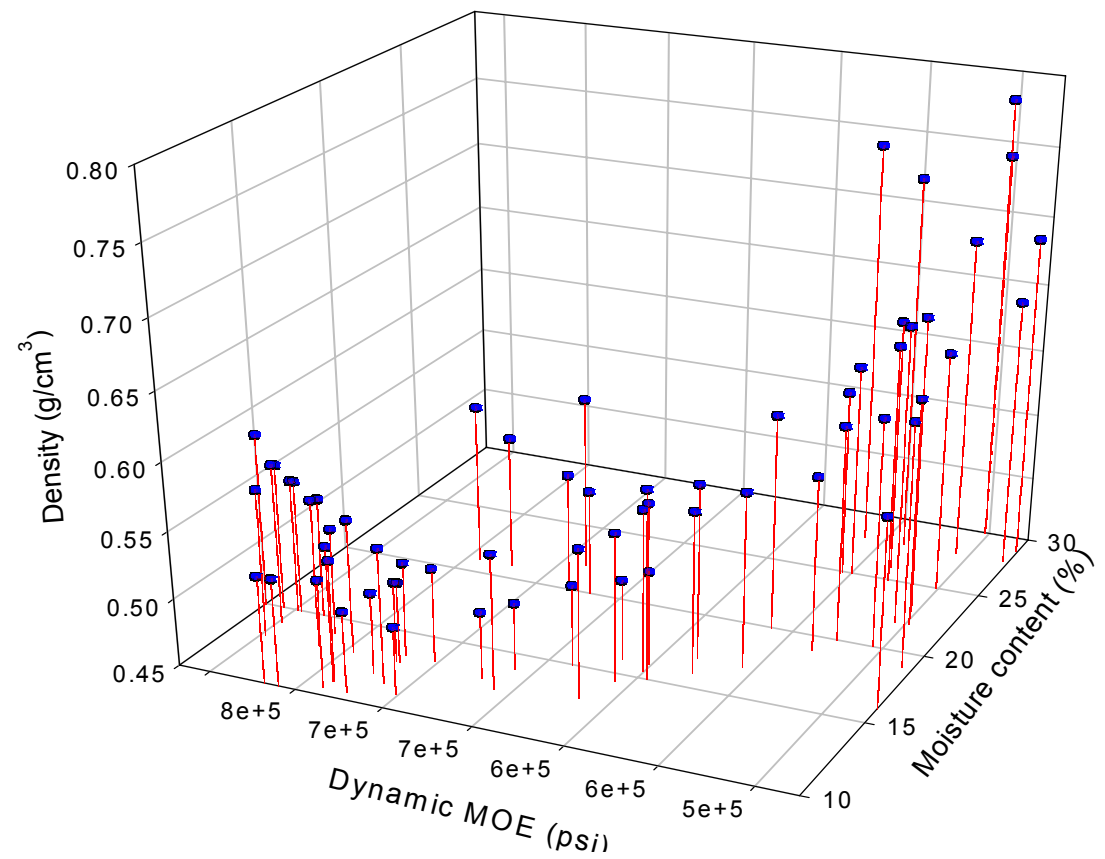

Figure 6.4. - Three-dimensional plot between density, dynamic MOE, and moisture content. 


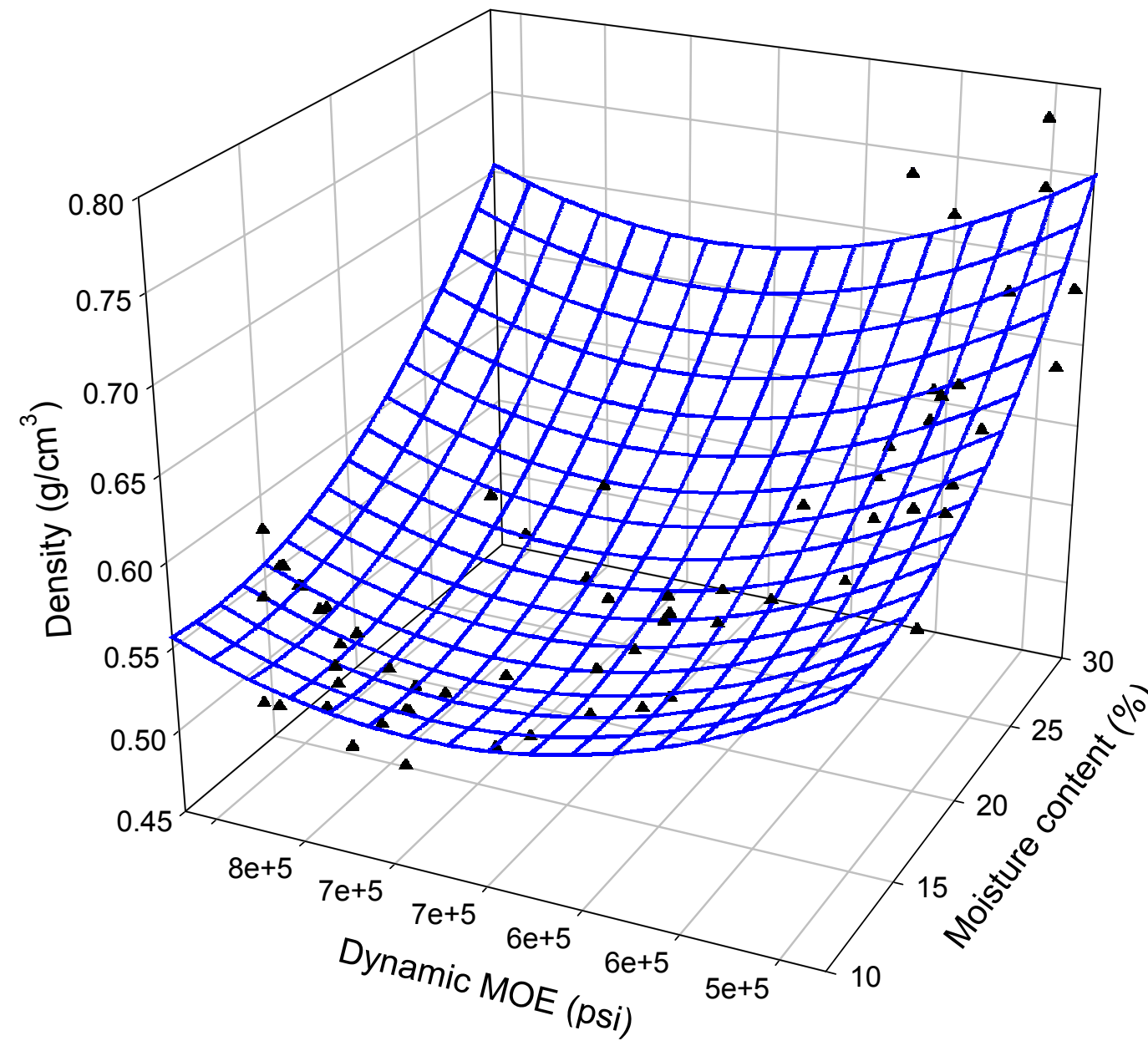

Figure 6.5. - Three-dimensional regression plot between density, dynamic MOE, and moisture content, $\mathrm{r}^{2}$ value indicated. 
The formula fitted to the moisture content $\underline{\text { vs. }}$ wave propagation time data by the linear regression analysis was $\mathrm{Y}=152.2+4.57 \mathrm{x}$, using wave propagation time as $\mathrm{Y}$ and moisture content as $\mathrm{X}$. This indicates that for every one - percent increase in moisture content, wave propagation time increases by approximately $2 \%$. Wu (1999) found an increase in wave propagation time of approximately $1 \%$ per one-percent increase in moisture content. The slight difference between Wu's results and ours could possibly be accounted by species density of the specimens.

Non-linear regression analysis proved the relationship between the moisture content and density using the quadratic formula $Y=y 0+a x+b x^{2}$. This non-linear relationship is consistent with the shrinkage characteristics of wood. As wood loses water, below the fiber saturation point, the initial shrinkage is large. However, as more water is lost and the moisture content approaches $10-$ $12 \%$ the dimensional loss becomes smaller.

Moisture content and dynamic MOE also proved to have a non-linear, quadratic, relationship. This was proved through regression analysis using the formula $Y=y 0+a x+b x^{2}$. The increase in dynamic MOE between the fiber saturation point and approximately $21 \%$ moisture content is small. However, once below $21 \%$ moisture content the increase in dynamic MOE becomes more significant with every decrease of one percent in moisture content. 


\subsection{Conclusions}

The results from this study indicated that moisture content directly affects the non-destructive testing method being investigated in this study. Moisture content appears to affect dynamic modulus of elasticity in the same manner that it affects the true modulus of elasticity, determined statically. When performing the in situ, nondestructive, evaluation described in this research one must take into account the moisture content of the wooden element in question. Failure to take moisture content of the specimen into consideration could contribute to false evaluations. 


\section{List of References}

American Society for Testing and Materials. 1983. Standard test methods for testing small clear specimens of timber ASTM D 143. ASTM, West Conshohocken, PA.

American Society for Testing and Materials. 1995. Standard test methods for mechanical fasteners in wood ASTM D 1761-88. ASTM, West Conshohocken, PA.

American Society for Testing and Materials. 1995. Standard test methods for structural size lumber ASTM D 198-94. ASTM, West Conshohocken, PA.

American Society for Testing Materials. 1983. Standard test methods for direct moisture content measurement of wood and wood-based materials. ASTM D 4442-92. ASTM, West Conshohocken, PA.

Anderson, R.B., J. Wiedenbeck, and R. Ross. 1997. Nondestructive evaluation for detection of honeycomb in the sawmill: an economic analysis. Forest Products Journal 47(6): 53-59. 
Armstrong, J., D. Patterson, and J. Sneckenberger. 1991. Comparison of three equations for predicting stress wave velocity as a function of grain angle. Wood and Fiber Science 23(1): 32-43.

Brashaw, B., R. Ross, and R. Pellerin. 1997. Stress wave nondestructive evaluation of green veneer: southern yellow pine and Douglas fir. International Society for Optical Engineering 2944: 296-306.

Cai, Z., M. Hunt, R. Ross, and L. Soltis. 2000. Static and vibration moduli of elasticity of salvaged and new joists. Forest Products Journal 50(2): 35-40.

Carll, C., and T. Highley. 1999. Decay of wood and wood-based products above ground in buildings. Journal of Testing and Evaluation 27(2): 150-158.

De Groot, R., R. Ross, and W. Nelson. 1998. Non-destructive assessment of wood decay and termite attack in southern pine sapwood. Wood Protection 3(2): 25-34.

Divos, F., I. Daniel, and L. Bejo. 2001. Defect detection in timber by stress wave time and amplitude. Journal of Nondestructive Testing 6(3). 
Divos, F., L. Nemeth, and L. Bejo. 1998. Evaluation of the wooden structure of a Baroque palace in Papa, Hungry. $11^{\text {th }}$ International Symposium on Nondestructive Testing of Wood, September 9-11, Madison, WI. pp.153-160.

Emerson, R., D. Pollock, J. Kainz, K. Fridley, D. McLean, and R. Ross. 1999. Nondestructive evaluation techniques for timber bridges. $5^{\text {th }}$ World Conference on Timber Engineering, August 17-20, Montreux, Switzerland. pp. 670-677.

Emerson, R., D. Pollock, D. McLean, K. Fridley, R. Ross, and R. Pellerin. 1999. Nondestructive testing of large bridge timbers. $11^{\text {th }}$ International Symposium on Nondestructive Testing of Wood. September 9-11, Madison, WI. pp.175-184.

Falk, R., D. Green, D. Rammer, and S. Lantz. 2000. Engineering evaluation of 55-year-old timber columns recycled from an industrial military building. Forest Products Journal 50(4): 71-76.

Forest Products Laboratory. 1999. Wood Handbook: Wood as an engineering material. FPL-GTR-113. USDA Forest Products Laboratory, Madison, WI. 
Fuller, J. R. Ross, and J. Dramm. 1994. Honeycomb and surface check detection using ultrasonic nondestructive evaluation. FPL-RN-0261. USDA Forest Products Laboratory, Madison, WI.

Gerhards, C.C. 1975. Stress wave speed and MOE of sweetgum ranging from 10-15 percent MC. Forest Products Journal 25(4): 51-57.

Green, D. and D. Kretschmann. 1994. Moisture content and the properties of clear southern pine. FPL-RP-531. USDA Forest Products Laboratory, Madison, WI.

Green, D., D. Kretschmann, M. Wolcott, and R. Ross. 1996. Mechanical grading of timbers for transportation industry. FPL-GTR-94. USDA Forest Products Laboratory, Madison, WI.

Green, D., R. Ross, and K. McDonald. 1994. Production of hardwood machine stress rated lumber. $9^{\text {th }}$ International Symposium on Nondestructive Testing of Wood, September 22-24, Madison, WI. pp.141-150.

Kretschmann, D. and D. Green. 1999. Mechanical grading of oak timbers. Journal of Materials in Civil Engineering. 11(2): 91-97. 
Kretschmann, D. and D. Green. 1996. Modeling moisture content-mechanical property relationships for clear southern pine. Wood and Fiber Science 28(3): 320-337.

Lee, J. and J. Oh. 1999. Stress-wave technique for detecting decay in ancient structures. $11^{\text {th }}$ International Symposium on Nondestructive Testing of Wood, September 9-11, Madison, WI. pp.161-167.

Pellerin, R., J. Lavinder, R. Ross, R. Falk, and N. Volny. 1996. In-place detection of decay in timber bridges-an application of stress wave technology. FPL-GTR94. USDA Forest Products Laboratory, Madison, WI.

Ross, R., R. DeGroot, W. Nelson, P. Lebow, and R. Pellerin. 1996. Stress wave NDE of biologically degraded wood. International Wood Engineering Conference, October 28-31, New Orleans, LA. pp. 213-217.

Ross, R., J. Fuller, and J. Dramm. 1995. Nondestructive evaluation of green defect-prone red oak lumber: A pilot study. Forest Products Journal 45(11/12): $51-52$. 
Ross, R., J. Fuller, and J. Dramm. 1995. Nondestructive evaluation of wetwood and honeycomb. $23^{\text {rd }}$ Annual Hardwood Symposium, May 17-20, Cashiers, NC. pp. 61-67.

Ross, R., K. McDonald, D. Green, and K. Schad. 1997. Relationship between log and lumber modulus of elasticity. Forest Products Journal 47(2): 89-92.

Ross, R., M. Ritter, K. Schad. 1996. Determining the in-place modulus of elasticity of stress-laminated timber decks using NDE. National conference on wood transportation structures, October 23-25, Madison, WI. pp. 277-281.

Ross, R., R. Pellerin, J. Forsman, J. Erickson, and J. Lavinder. 2001. Relationship between stress wave transmission time and compressive properties of timbers removed from service. FPL-RN-0280. USDA Forest Products Laboratory, Madison, WI.

Ross, R., R. Pellerin, N. Volny, W. Salsig, and R. Falk. 1999. Inspection of timber bridges using stress wave timing nondestructive evaluation tools. FPL-GTR-114. Forest Products Laboratory, Madison, WI. 
Ross, Robert J. 1992. Nondestructive testing of wood. Nondestructive Evaluation of Civil Structures and Materials, May, University of Colorado, Boulder, Colorado. pp. 43-47.

Ross, R., L. Soltis, and P. Otton. 1998. Assessing wood members in the USS Constitution using non-destructive evaluation methods. Journal of Preservation Technology. 29(2): 21-25.

Ross, R., S. Willits, W. von Segen, T. Black, B. Brashaw, R. Pellerin. 1999. A stress wave based approach to NDE of logs for assessing potential veneer quality. Part 1. Small-diameter ponderosa pine. Forest Products Journal 49(11/12): 60-62.

Schad, K., D. Kretschmann, K. McDonald, R. Ross, and D. Green. 1995. Stress wave techniques for determining quality of dimensional lumber from switch ties. FPL-RN-0265. USDA Forest Products Laboratory, Madison, WI.

Schad, K., D. Schmoldt, and R. Ross. 1996. Nondestructive methods for detecting defects in softwood logs. FPL-RP-546. USDA Forest Products Laboratory, Madison, WI. 
Shibusawa, T., N. Nanami, M. Sato, T. Arima, and M. Kawai. 2000. Nondestructive testing for durability assessment of plywood used for woodframed houses. $12^{\text {th }}$ International Symposium on Nondestructive Testing of Wood, September 13-15, University of Western Hungary, Sopron, Hungary.

Simpson W. and X. Wang. 2001. Relationship between longitudinal stress wave transit time and moisture content of lumber during kiln-drying. Forest Products Journal 51(10): 51-54.

Simpson, William T. 1998. Relationship between speed of sound and moisture content of red oak and hard maple during drying. Wood and Fiber Science 30(4): 405-413.

Soltis, L., M. Hunt, R. Ross, X. Wang, and Z. Cai. 2000. Nondestructive structural evaluation of wood floor systems in historic buildings. $12^{\text {th }}$ International Symposium on Nondestructive Testing of Wood, September 13-15, University of Western Hungary, Sopron, Hungary. pp. 279-288.

Suprenant, B.A., J.L. Noland, M.P. Schuller. 1992. Non-destructive testing of wood. Nondestructive Evaluation of Civil Structures and Materials, May, University of Colorado, Boulder, Colorado. pp. 43-47. 
Tanaka, T., F. Divos, and T. Faczan. 1999. Nondestructive evaluation of residual bending strength of wood with artificial defects by stress wave. $11^{\text {th }}$ International Symposium on Nondestructive Testing of Wood, September 9-11, Madison, WI. pp. 83-91.

Wagner, F., T. Gorman, and D. Pollock. 2001. Stress-wave analysis of standing trees to predict mechanical properties of wood products. Inland Northwest Forest Products Research Consortium, University of Idaho, Moscow, ID.

Wang, X., R. Ross, J. Mattson, J. Erickson, J. Forsman, E. Geske, and M. Wehr. 2001. Several nondestructive evaluation techniques for assessing stiffness and MOE of small-diameter logs. FPL-RP-600. USDA Forest Products Laboratory, Madison, WI.

Wang, X., R. Ross, J. Erickson, J. Forsman, M. McClellan, J. Barbour, and R. Pellerin. 2000. Nondestructive evaluation of standing trees with stress wave methods. FPL-RP-585. USDA Forest Products Laboratory, Madison, WI.

Wang, X., R. Ross, J. Erickson, J. Forsman, G. McGinnis, and R. De Groot. 2000. Nondestructive methods for evaluating quality of wood in preservativetreated piles. FPL-RN-0274. USDA Forest Products Laboratory, Madison, WI. 
Wang, X., R. Ross, J. Erickson, J. Forsman, G. McGinnis, and R. De Groot. 2001. Nondestructive evaluation of potential quality of creosote-treated piles removed from service. Forest Products Journal 51(2): 63-68.

Winandy, J., P. Lebow, and W. Nelson. 1998. Predicting bending strength of fireretardant treated plywood from screw-withdrawal tests. FPL-RP-568. USDA Forest Products Laboratory, Madison, WI.

Winandy, J. and J. Morrell. 1993. Relationship between incipient decay, strength, and chemical composition of Douglas-fir heartwood. Wood and Fiber Science 25(3): 278-288.

Wipf, T., M. Ritter, and D. Wood. 1999. Dynamic evaluation and testing of timber highway bridges. Pacific Timber Engineering Conference, March 14-18, Rotorua, New Zealand. pp. 333-340.

Wu, Qinglin. 1999. Influence of moisture on stress-wave properties of woodbased panels. $11^{\text {th }}$ International Symposium on Nondestructive Testing of Wood, September 9-11, Madison, Wl. pp.19-25. 
Yang, V., W. Nelson, B. Illman, and R. Ross. 1999. Nondestructive evaluation of biodegraded oriented strandboard: Laboratory results. $2^{\text {nd }}$ Annual Conference on Durability and Disaster Mitigation in Wood-Frame Housing, November 6-8, Madison, WI. pp. 227-230. 
APPENDICES 


\section{Appendix I. - GLM of SWF vs. density for small specimens}

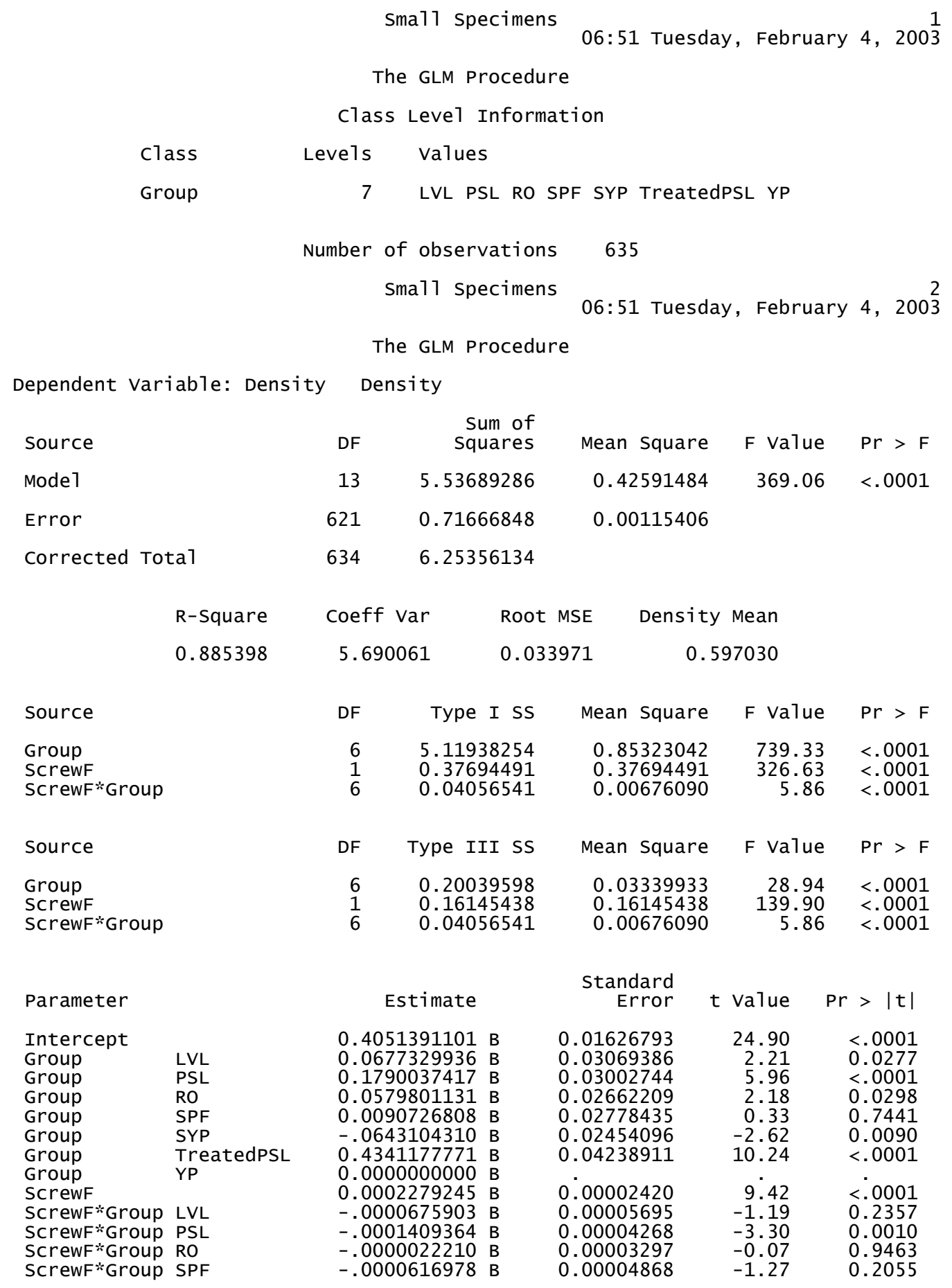




\section{Appendix I. cont.}

Sma11 Specimens 06:51 Tuesday, February 4, 2003

The GLM Procedure

Dependent Variable: Density Density

Parameter

Estimate

Standard Error

$t$ value $\operatorname{Pr}>|t|$

ScrewF*Group SYP

ScrewF*Group TreatedPSL

ScrewF*Group YP

$0.0000802843 \mathrm{~B}$

$-.0001620007$

0.00003563

0.00006444

2.25

0.0246

$0.0000000000 \mathrm{~B}$

.

$-2.51$

0.0122

NOTE: The $X^{\prime} X$ matrix has been found to be singular, and a generalized inverse was used to solve the normal equations. Terms whose estimates are followed by the letter 'B' are not uniquely estimable. 


\title{
Appendix II. - GLM of SWF vs. MOR for small specimens
}

\author{
Sma11 Specimens 06:51 Tuesday, February 4, 2003 \\ The GLM Procedure \\ Class Level Information \\ Class \\ Levels values \\ Group \\ 7 LVL PSL RO SPF SYP TreatedPSL YP \\ Number of observations 635 \\ Sma11 specimens 06:51 Tuesday, February 4, 2003 \\ The GLM Procedure
}

Dependent Variable: MOR MOR

\begin{tabular}{|c|c|c|c|c|c|c|}
\hline \multicolumn{2}{|l|}{ Source } & \multicolumn{3}{|c|}{ Sum of } & F value & $\mathrm{Pr}>\mathrm{F}$ \\
\hline \multicolumn{2}{|l|}{ Mode1 } & 13 & 2405587831 & 185045218 & \multirow[t]{2}{*}{116.36} & $<.0001$ \\
\hline Error & & 621 & 987550788 & 1590259 & & \\
\hline \multicolumn{2}{|c|}{ Corrected Total } & 634 & 3393138619 & & & \\
\hline & R-Square & Coef & f var & ot MSE & Mean & \\
\hline & 0.708957 & 11. & 85191 & 61.055 & 40.10 & \\
\hline \multicolumn{2}{|l|}{ Source } & $\mathrm{DF}$ & Type I SS & Mean Square & F Value & $\mathrm{Pr}>\mathrm{F}$ \\
\hline \multicolumn{2}{|l|}{$\begin{array}{l}\text { Group } \\
\text { ScrewF } \\
\text { ScrewF*Group }\end{array}$} & $\begin{array}{l}6 \\
1 \\
6\end{array}$ & $\begin{array}{r}724363482 \\
1594429455 \\
86794895\end{array}$ & $\begin{array}{r}120727247 \\
1594429455 \\
14465816\end{array}$ & $\begin{array}{r}75.92 \\
1002.62 \\
9.10\end{array}$ & $\begin{array}{l}<.0001 \\
<.0001 \\
<.0001\end{array}$ \\
\hline \multicolumn{2}{|l|}{ Source } & DF & Type III SS & Mean Square & F value & $\mathrm{Pr}>\mathrm{F}$ \\
\hline \multicolumn{2}{|l|}{$\begin{array}{l}\text { Group } \\
\text { ScrewF } \\
\text { ScrewF*Group }\end{array}$} & $\begin{array}{l}6 \\
1 \\
6\end{array}$ & $\begin{array}{r}104671040 \\
1064598487 \\
86794895\end{array}$ & $\begin{array}{r}17445173 \\
1064598487 \\
14465816\end{array}$ & $\begin{array}{r}10.97 \\
669.45 \\
9.10\end{array}$ & $\begin{array}{l}<.0001 \\
<.0001 \\
<.0001\end{array}$ \\
\hline Parameter & & \multicolumn{3}{|r|}{$\begin{array}{r}\text { Standard } \\
\text { Error }\end{array}$} & t value & $\operatorname{Pr}>|t|$ \\
\hline $\begin{array}{l}\text { Intercept } \\
\text { Group } \\
\text { Group } \\
\text { Group } \\
\text { Group } \\
\text { Group } \\
\text { Group } \\
\text { Group } \\
\text { ScrewF } \\
\text { ScrewF*Group } \\
\text { ScrewF*Group } \\
\text { ScrewF*Group } \\
\text { ScrewF*Group }\end{array}$ & $\begin{array}{l}\text { LVL } \\
\text { PSL } \\
\text { RO } \\
\text { SPF } \\
\text { SYP } \\
\text { TreatedPSL } \\
\text { YP } \\
\text { LVL } \\
\text { PSL } \\
\text { RO } \\
\text { SPF }\end{array}$ & \multicolumn{2}{|c|}{$\begin{array}{rl}-144.832314 & \mathrm{~B} \\
6641.321572 & \mathrm{~B} \\
3763.191219 & \mathrm{~B} \\
1123.245962 & \mathrm{~B} \\
-2643.638439 & \mathrm{~B} \\
327.823583 & \mathrm{~B} \\
1816.657841 & \mathrm{~B} \\
0.000000 & \mathrm{~B} \\
15.208697 & \mathrm{~B} \\
-4.942441 & \mathrm{~B} \\
-5.469488 & \mathrm{~B} \\
-3.548728 & \mathrm{~B} \\
7.126898 & \mathrm{~B}\end{array}$} & $\begin{array}{r}603.883012 \\
1139.389167 \\
1114.650892 \\
988.240577 \\
1031.384816 \\
910.986838 \\
1573.529349 \\
. \\
0.898501 \\
2.114057 \\
1.584326 \\
1.223976 \\
1.806962\end{array}$ & $\begin{array}{r}-0.24 \\
5.83 \\
3.38 \\
1.14 \\
-2.56 \\
0.36 \\
1.15 \\
16.93 \\
-2.34 \\
-3.45 \\
-2.90 \\
3.94\end{array}$ & $\begin{array}{l}0.8105 \\
<.0001 \\
0.0008 \\
0.2561 \\
0.0106 \\
0.7191 \\
0.2487 \\
. \\
<.0001 \\
0.0197 \\
0.0006 \\
0.0039 \\
<.0001\end{array}$ \\
\hline
\end{tabular}




\section{Appendix II. cont.}

Sma11 Specimens

The GLM Procedure

Dependent variable: MOR MOR

\begin{tabular}{|c|c|c|c|c|}
\hline Parameter & Estimate & $\begin{array}{r}\text { Standard } \\
\text { Error }\end{array}$ & t value & $\operatorname{Pr}>|t|$ \\
\hline $\begin{array}{ll}\text { ScrewF*Group SYP } \\
\text { ScrewF*Group TreatedPSL } \\
\text { ScrewF*Group YP }\end{array}$ & $\begin{array}{rl}-0.551905 & \mathrm{~B} \\
1.721898 & \mathrm{~B} \\
0.000000 & \mathrm{~B}\end{array}$ & $\begin{array}{l}1.322546 \\
2.391979\end{array}$ & $\begin{array}{r}-0.42 \\
0.72\end{array}$ & $\begin{array}{l}0.6766 \\
0.4719\end{array}$ \\
\hline
\end{tabular}

NOTE: The $X ' X$ matrix has been found to be singular, and a generalized inverse was used to solve the normal equations. Terms whose estimates are followed by the letter 'B' are not uniquely estimable. 


\section{Appendix III. - GLM of $E_{D}$ vs. $E_{A}$ for small specimens}

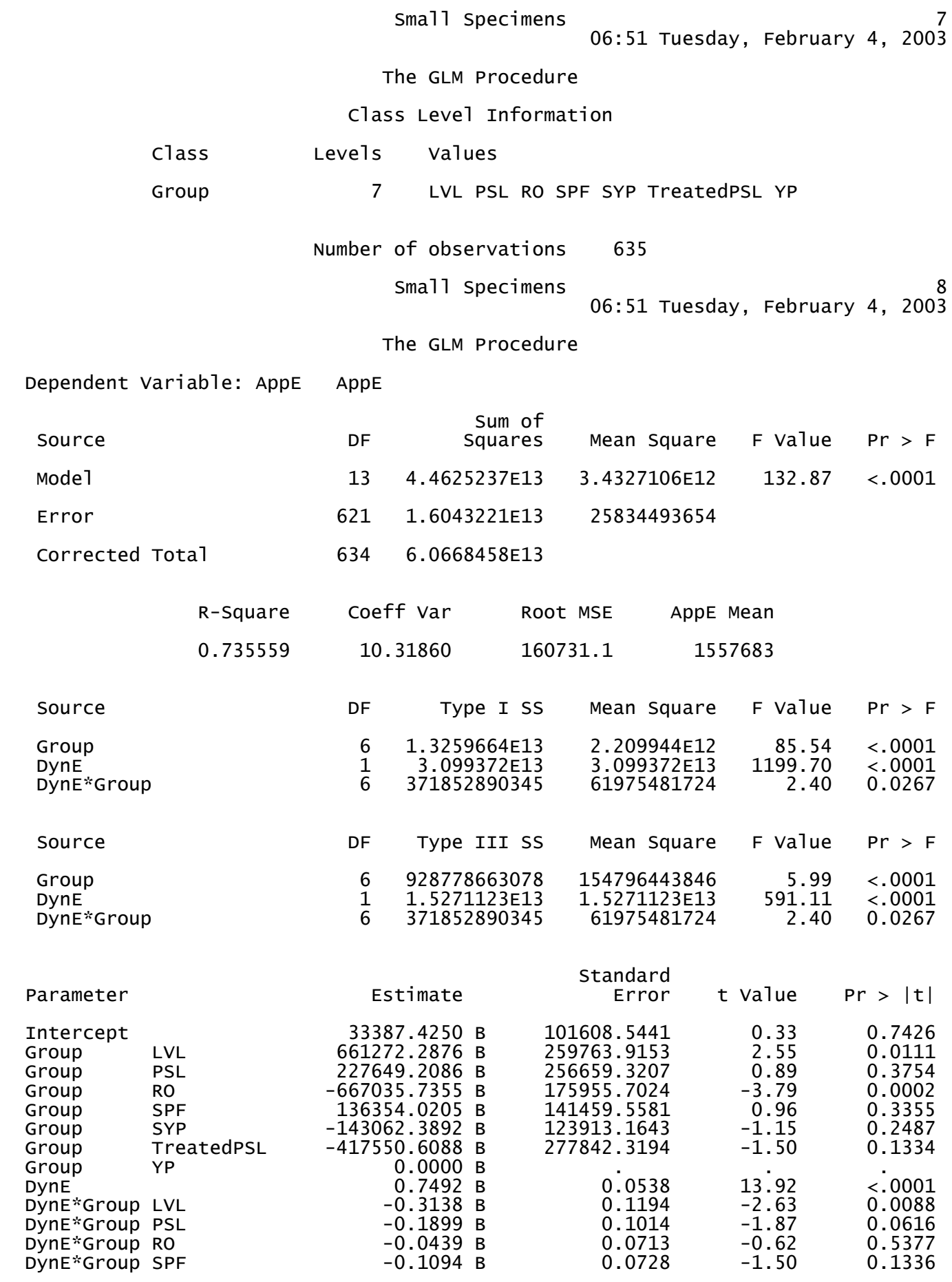




\section{Appendix III. cont.}

Sma11 Specimens 06:51 Tuesday, February 4, 2003

The GLM Procedure

Dependent Variable: AppE AppE

Parameter

DynE*Group SYP

DynE*Group TreatedPSL

DynE*Group YP

Estimate
$0.0025 \mathrm{~B}$
$0.0399 \mathrm{~B}$
$0.0000 \mathrm{~B}$

Standard Error

t value

$\operatorname{Pr}>|\mathrm{t}|$

0.0636

0.1085

0.04

0.37

0.9691

.

NOTE: The $X^{\prime} X$ matrix has been found to be singular, and a generalized inverse was used to solve the normal equations. Terms whose estimates are followed by the letter 'B' are not uniquely estimable. 


\title{
Appendix IV. - GLM of $E_{D}$ Vs. $E_{T}$ for structural size specimens
}

\author{
Structural Size 07:44 Tuesday, February 4, 2003 \\ The GLM Procedure \\ Class Level Information \\ Class Levels values \\ $\begin{array}{lll}\text { Group } & 6 & \text { LVL PSL RO SPF SYP YP }\end{array}$
}

Number of observations $\quad 600$

Structural size 07:44 Tuesday, February 4, 2003

The GLM Procedure

Dependent Variable: TrueE TrueE

$\begin{array}{lrrrrr}\text { Source } & \text { DF } & \begin{array}{r}\text { Sum of } \\ \text { Squares }\end{array} & \text { Mean Square } & \text { F value } & \text { Pr }>\text { F } \\ \text { Mode1 } & 11 & 5.9784098 \mathrm{E} 13 & 5.434918 \mathrm{E} 12 & 263.01 & <.0001 \\ \text { Error } & 588 & 1.2150563 \mathrm{E} 13 & 20664223401 & & \\ \text { Corrected Tota1 } & 599 & 7.1934661 \mathrm{E} 13 & & \end{array}$

$\begin{array}{lrrr}\text { R-Square } & \text { Coeff Var } & \text { Root MSE } & \text { TrueE Mean } \\ 0.831089 & 8.315454 & 143750.6 & 1728716\end{array}$

Source

Group

DynE

DynE*Group

Source

Group

DynE

DynE*Group

$\begin{array}{rrrrr}\text { DF } & \text { Type I SS } & \text { Mean Square } & \text { F value } & \text { Pr }>\text { F } \\ & 2.4208395 \mathrm{E} 13 & 4.841679 \mathrm{E} 12 & 234.30 & <.0001 \\ 5 & 3.499172 \mathrm{E} 13 & 3.499172 \mathrm{E} 13 & 1693.35 & <.0001 \\ 1 & 583983548533 & 116796709707 & 5.65 & <.0001\end{array}$

$\begin{array}{rrrrr}\text { DF } & \text { Type III SS } & \text { Mean Square } & \text { F Value } & \text { Pr }>\text { F } \\ 5 & 625260752873 & 125052150575 & 6.05 & <.0001 \\ 1 & 9.9888405 \mathrm{E} 12 & 9.9888405 \mathrm{E} 12 & 483.39 & <.0001 \\ 5 & 583983548533 & 116796709707 & 5.65 & <.0001\end{array}$

Parameter

Estimate

Standard

Error

t value

$\operatorname{Pr}>|\mathrm{t}|$

-43642.6842 B
105305.8287

422636.0768

254736.4626

138847.0517

141605.2192

119561.2516

0.0543

0.1899

0.1007

0.0700

0.0742

0.0618

$-0.41$

$-1.13$

2.89

2.91

0.12

$-0.56$

0.6787

0.2571

0.0040

0.0038

0.9051

0.0000 B

$0.2354 \mathrm{~B}$

$-0.3365 \mathrm{~B}$

$0.0215 \mathrm{~B}$

0.0344 B

$<.0001$

0.2156

0.0009

0.0361

0.7715
15.47

1.24

$-3.34$

$-2.10$

0.29

0.56 


\section{Appendix IV. cont.}

Structural size

07:44 Tuesday, February 4, 2003

The GLM Procedure

Dependent Variable: TrueE

TrueE

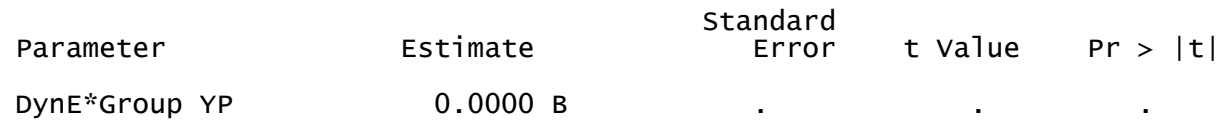

NOTE: The $X^{\prime} X$ matrix has been found to be singular, and a generalized inverse was used to solve the normal equations. Terms whose estimates are followed by the letter 'B' are not uniquely estimable. 


\section{Appendix V. - Regression analyses of $E_{T}$ vs. $E_{D}$}

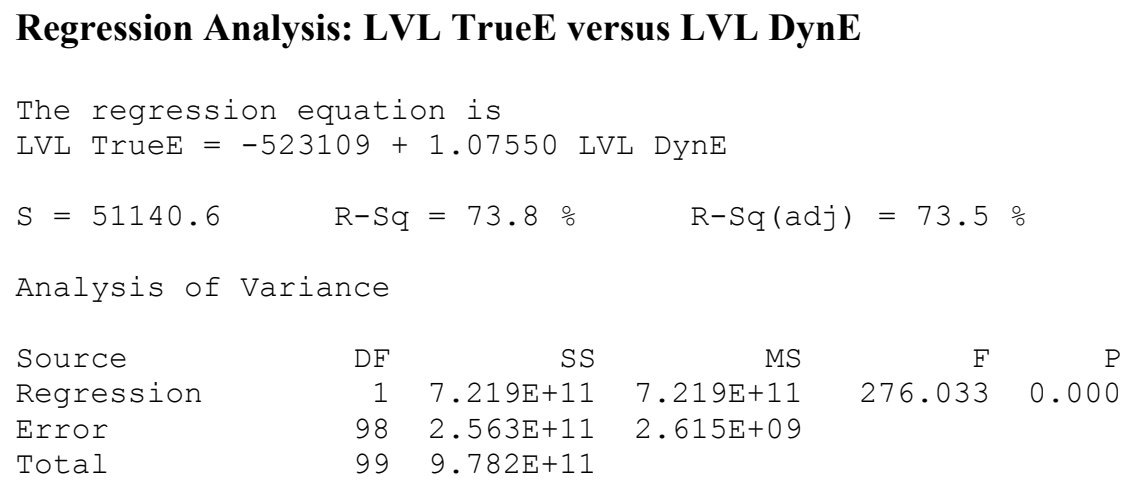

Fitted Line Plot: LVL TrueE versus LVL DynE

Regression Analysis: PSL TrueE versus PSL DynE

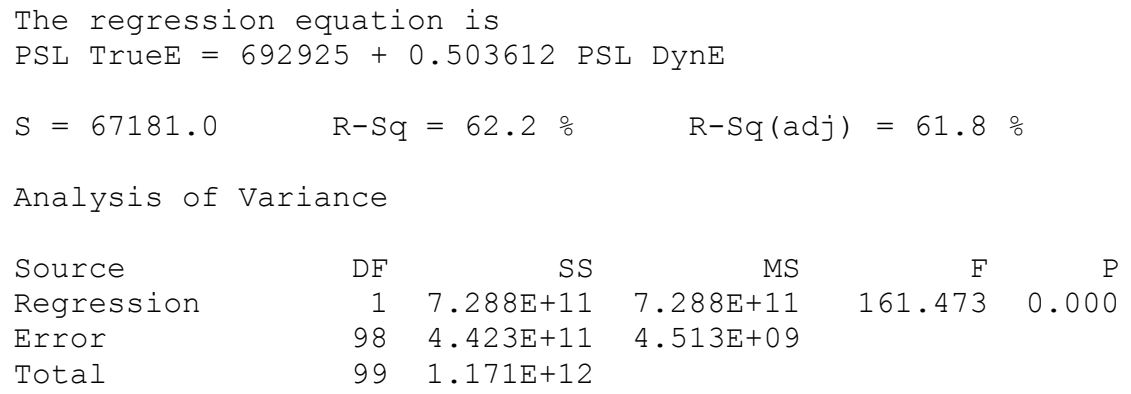

Fitted Line Plot: PSL TrueE versus PSL DynE

\section{Regression Analysis: RO TrueE versus RO DynE}

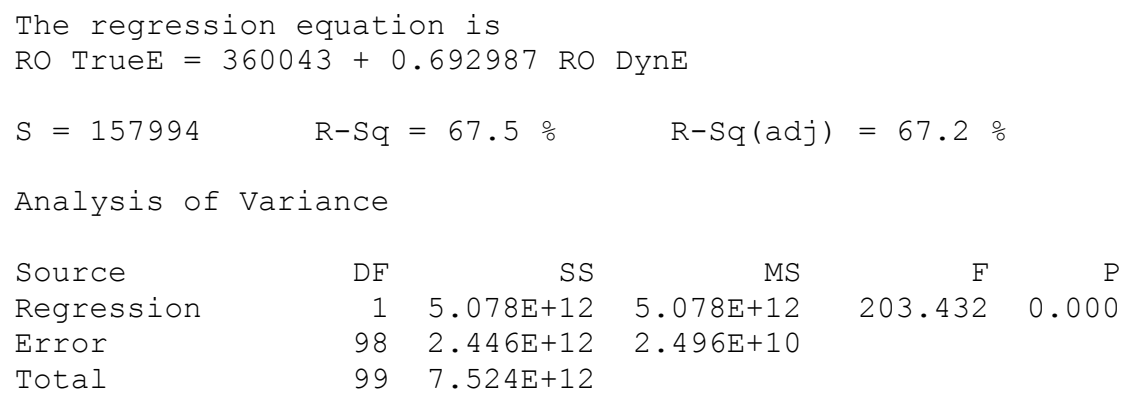

Fitted Line Plot: RO TrueE versus RO DynE 


\section{Appendix V. cont.}

Regression Analysis: SPF TrueE versus SPF DynE

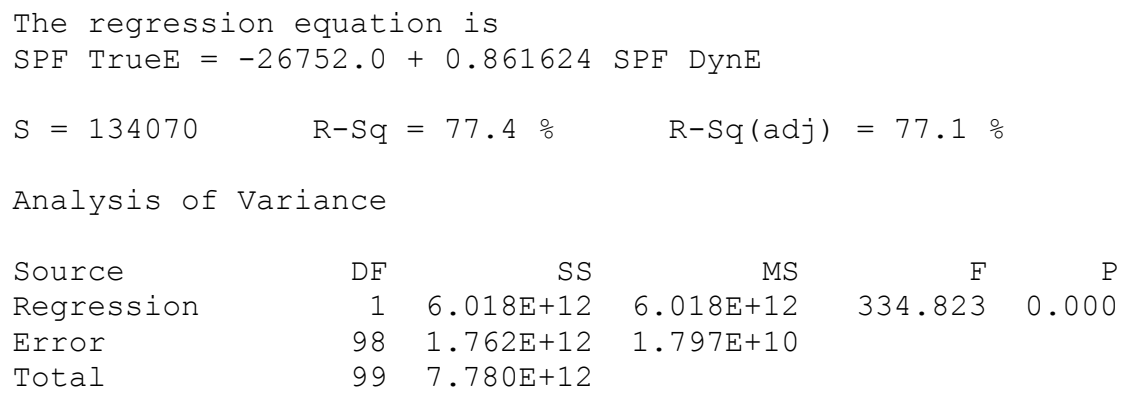

Fitted Line Plot: SPF TrueE versus SPF DynE

\section{Regression Analysis: SYP TrueE versus SYP DynE}

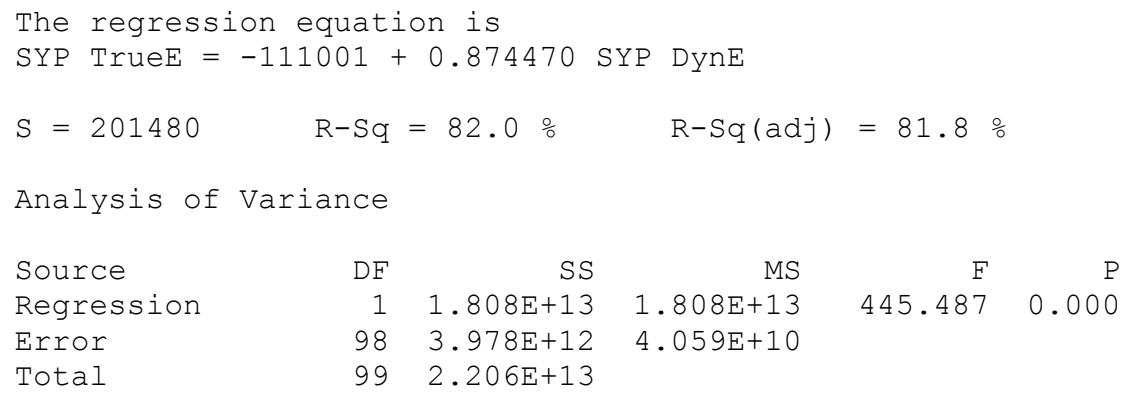

Fitted Line Plot: SYP TrueE versus SYP DynE

\section{Regression Analysis: YP TrueE versus YP DynE}

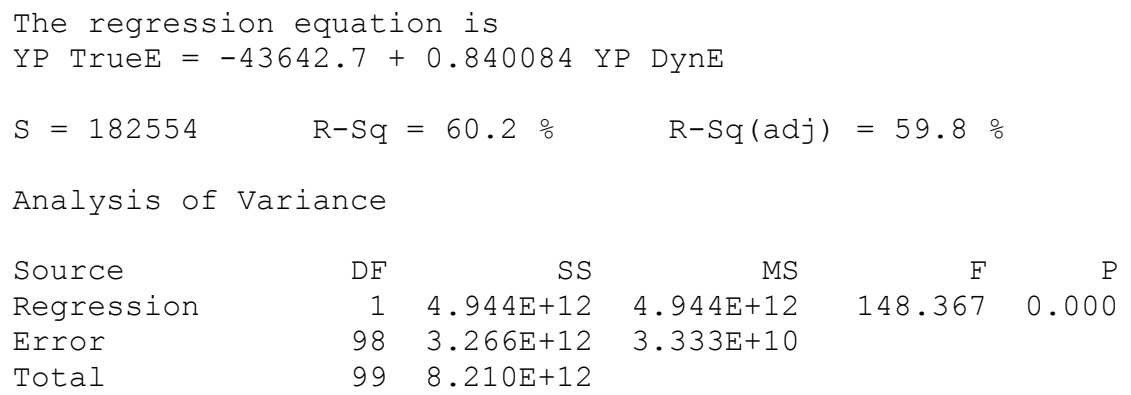

Fitted Line Plot: YP TrueE versus YP DynE 


\section{Appendix V. cont.}

\section{Regression Analysis: TrueE All versus DynE All}

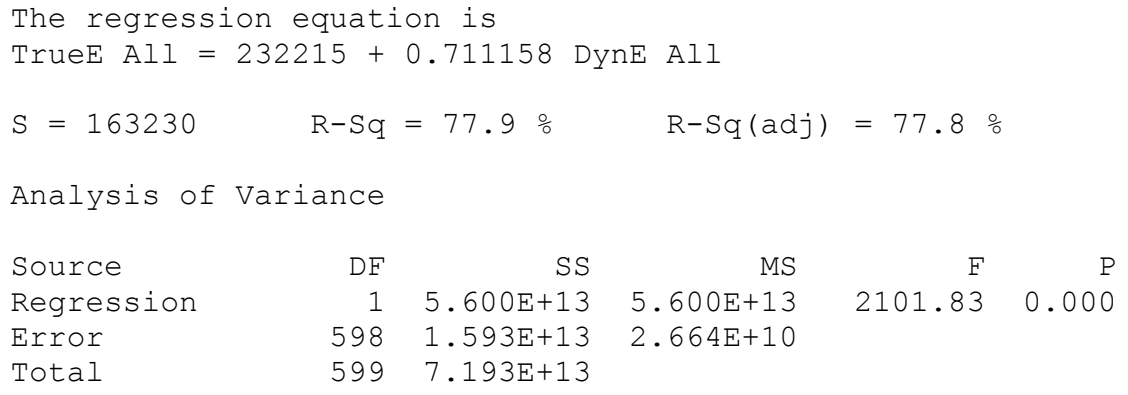

Fitted Line Plot: TrueE All versus DynE All 
Appendix VI. - Regression analyses of SWF vs. density; SWF vs. MOR; and $E_{D}$ vs. $E_{A}$ for small size specimens

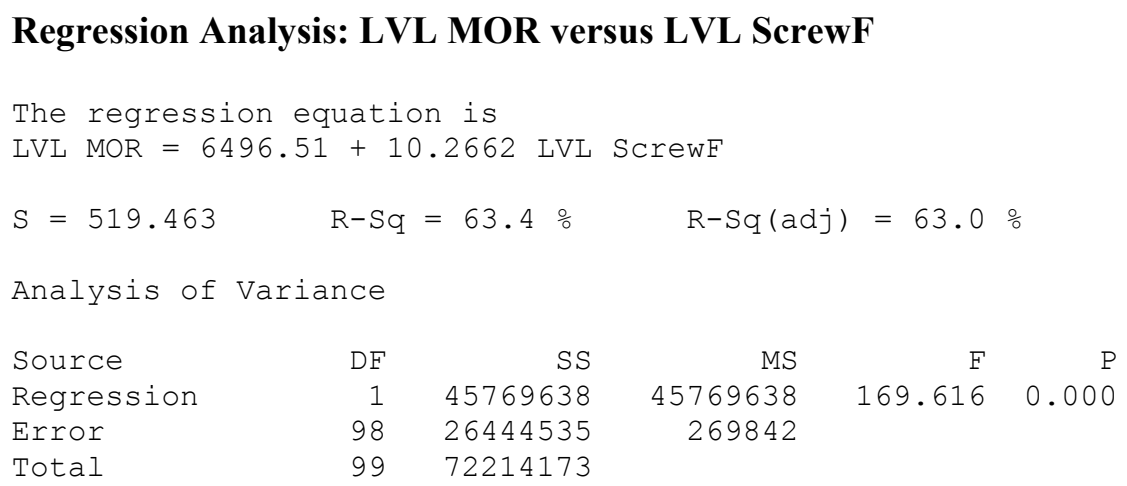

Fitted Line Plot: LVL MOR versus LVL ScrewF

Regression Analysis: LVL Density versus LVL ScrewF

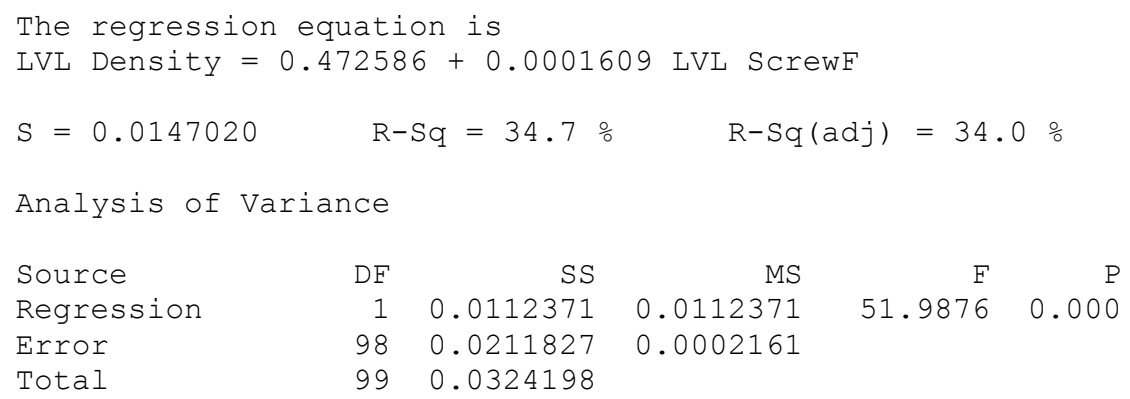

Fitted Line Plot: LVL Density versus LVL ScrewF

Regression Analysis: LVL AppE versus LVL DynE

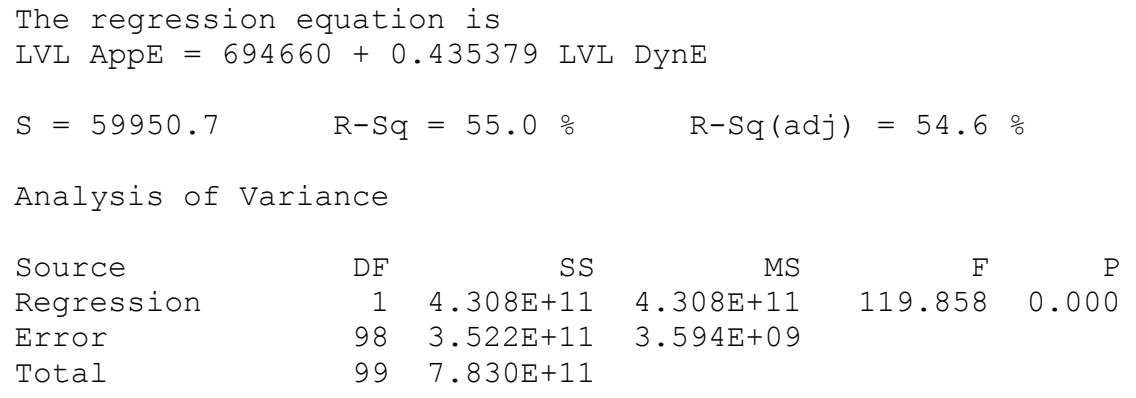

Fitted Line Plot: LVL AppE versus LVL DynE 


\section{Appendix VI. cont.}

\section{Regression Analysis: PSL MOR versus PSL ScrewF}

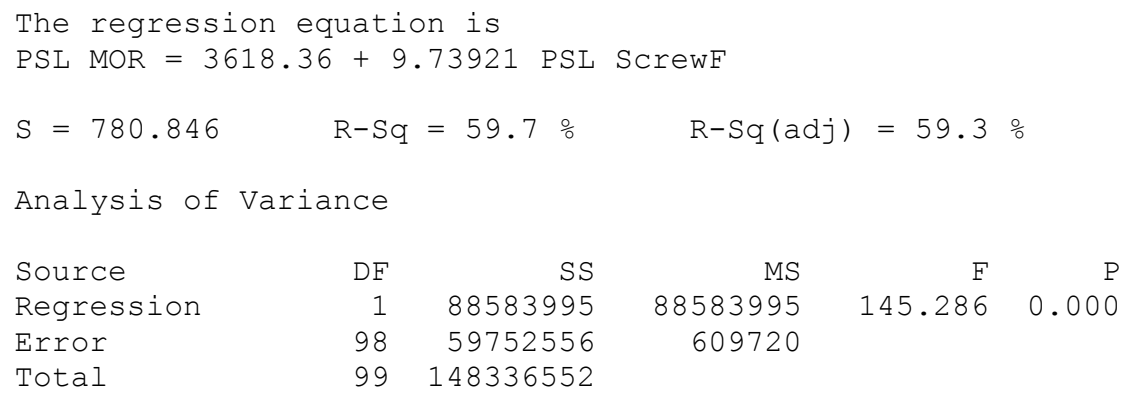

Fitted Line Plot: PSL MOR versus PSL ScrewF

\section{Regression Analysis: PSL Density versus PSL ScrewF}

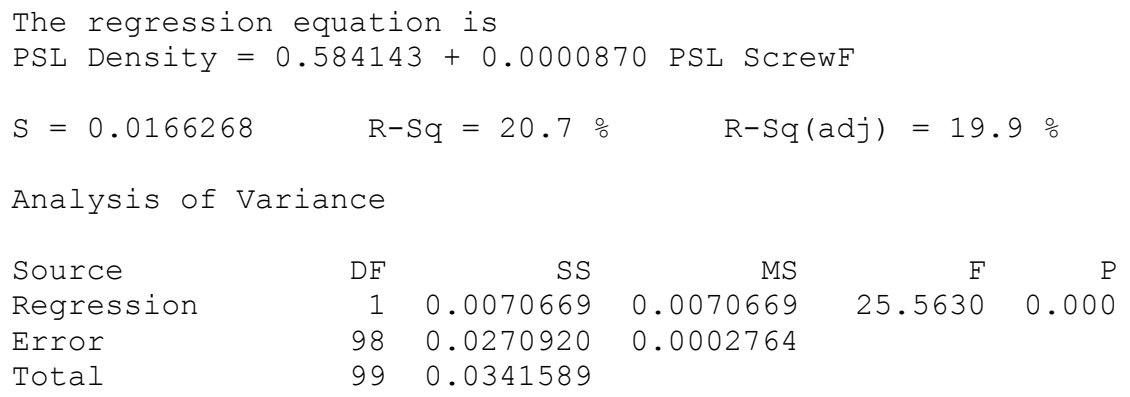

Fitted Line Plot: PSL Density versus PSL ScrewF

\section{Regression Analysis: PSL AppE versus PSL DynE}

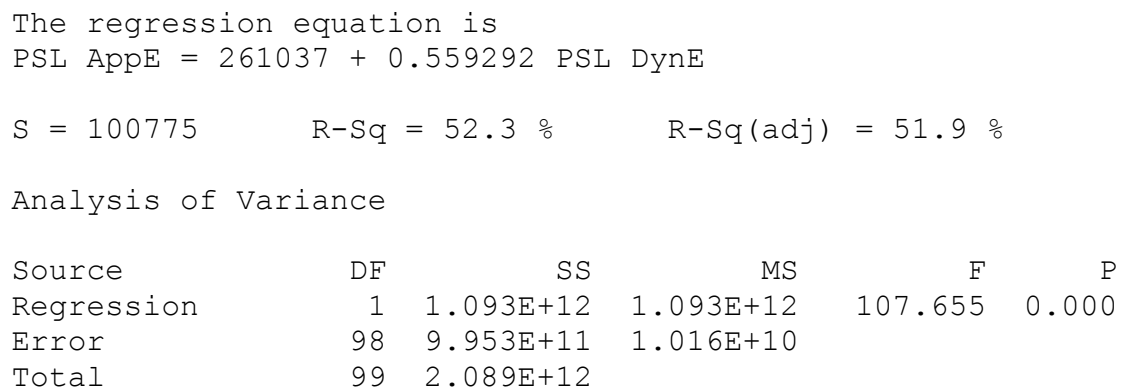

Fitted Line Plot: PSL AppE versus PSL DynE 


\section{Appendix VI. cont.}

\section{Regression Analysis: RO MOR versus RO ScrewF}

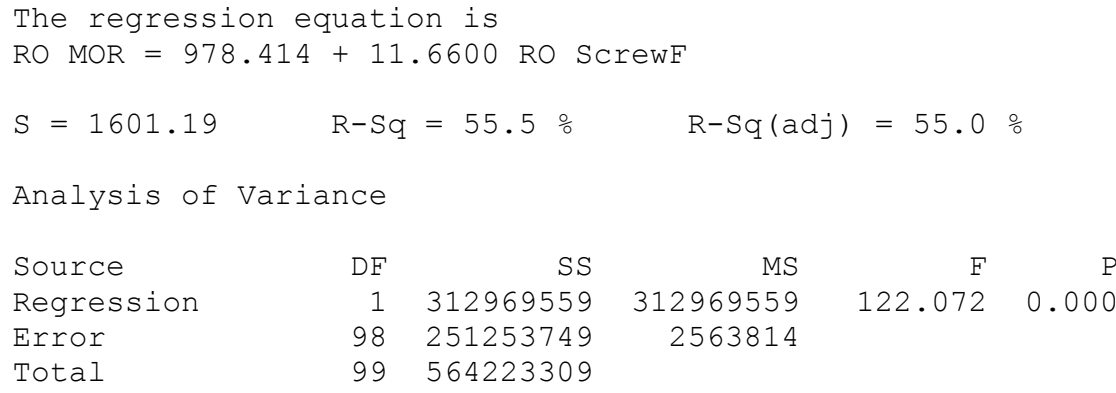

Fitted Line Plot: RO MOR versus RO ScrewF

\section{Regression Analysis: RO Density versus RO ScrewF}

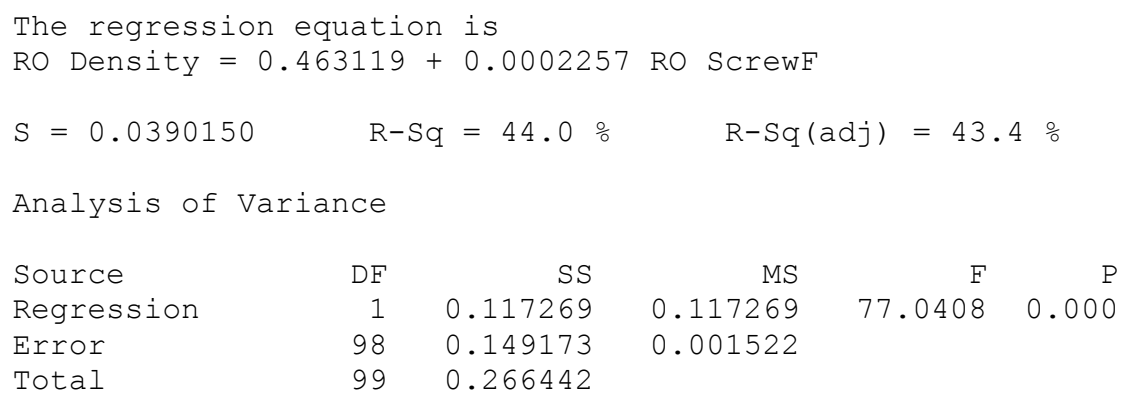

Fitted Line Plot: RO Density versus RO ScrewF

\section{Regression Analysis: RO AppE versus RO DynE}

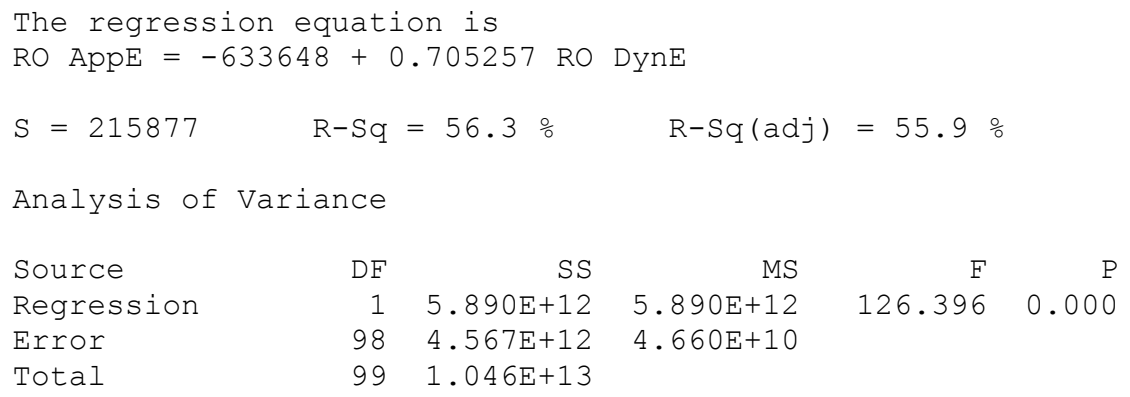

Fitted Line Plot: RO AppE versus RO DynE 


\section{Appendix VI. cont.}

\section{Regression Analysis: SPF MOR versus SPF ScrewF}

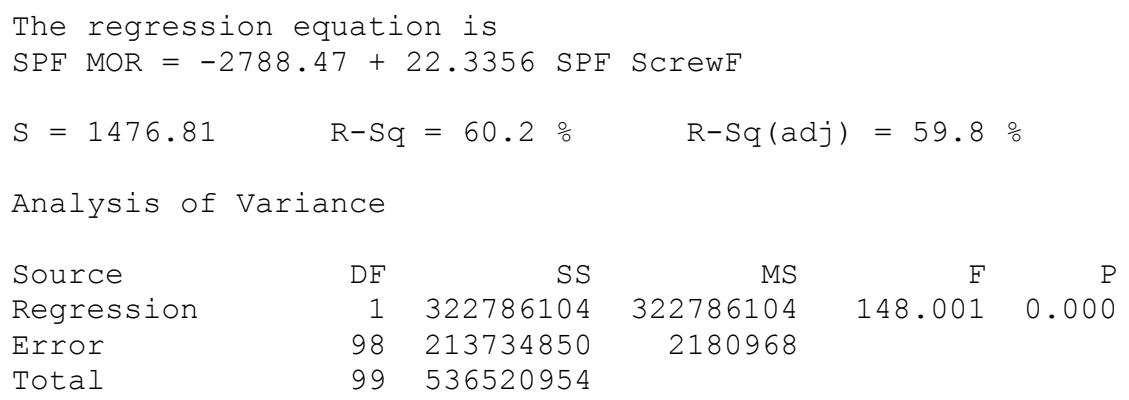

Fitted Line Plot: SPF MOR versus SPF ScrewF

\section{Regression Analysis: SPF Density versus SPF ScrewF}

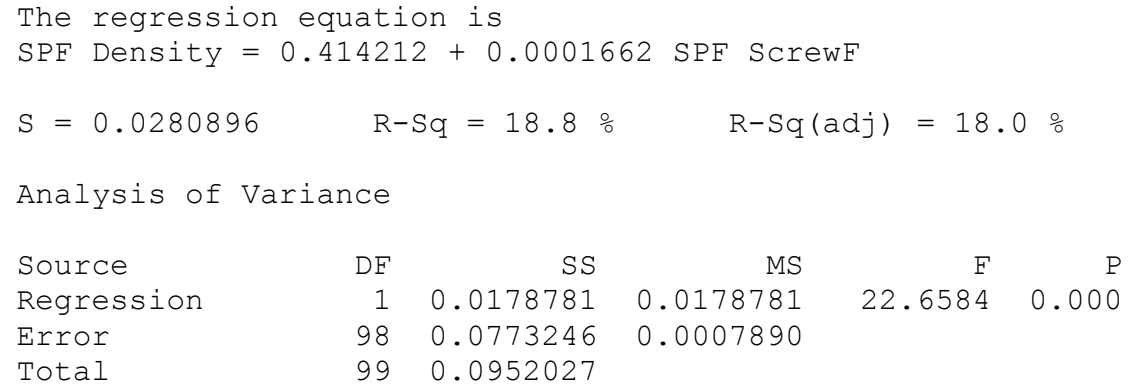

Fitted Line Plot: SPF Density versus SPF ScrewF

\section{Regression Analysis: SPF AppE versus SPF DynE}

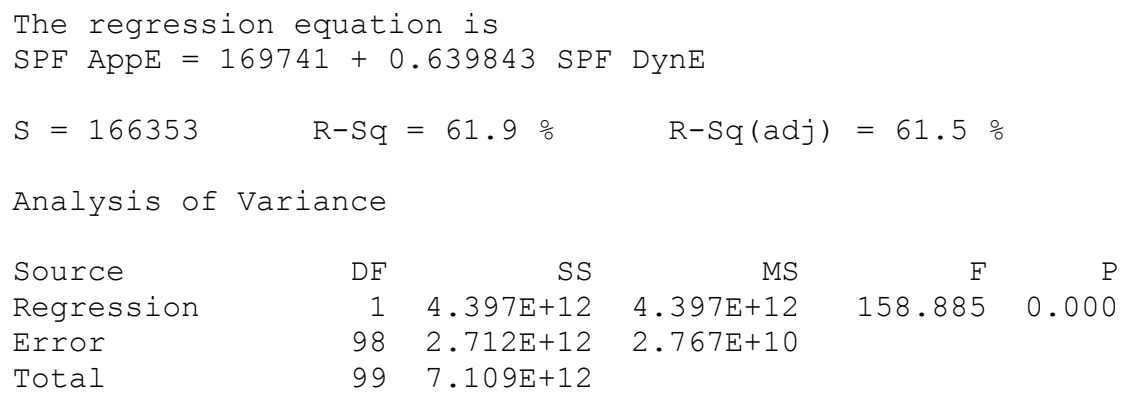

Fitted Line Plot: SPF AppE versus SPF DynE 


\section{Appendix VI. cont.}

\section{Regression Analysis: SYP MOR versus SYP ScrewF}

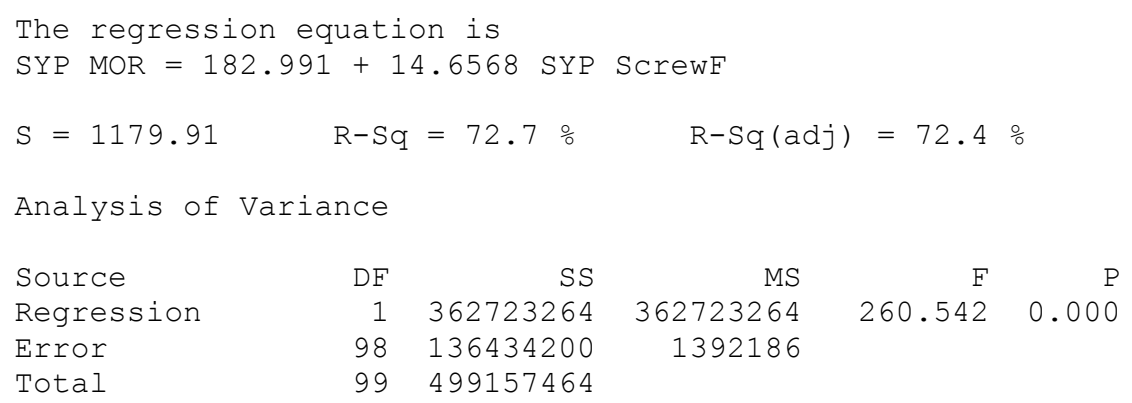

Fitted Line Plot: SYP MOR versus SYP ScrewF

\section{Regression Analysis: SYP Density versus SYP ScrewF}

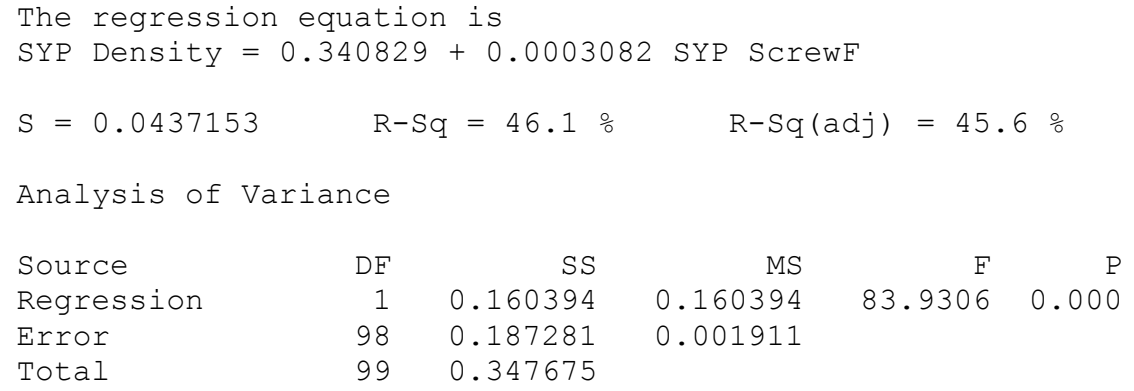

Fitted Line Plot: SYP Density versus SYP ScrewF

\section{Regression Analysis: SYP AppE versus SYP DynE}

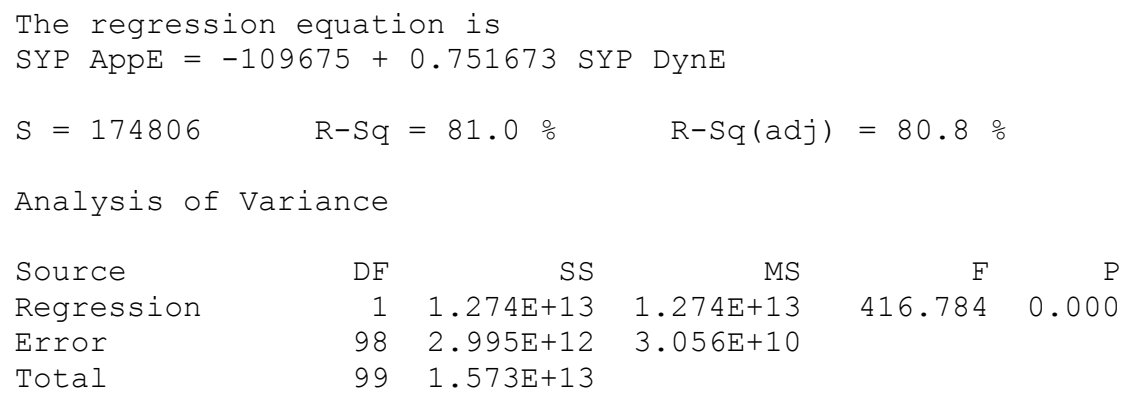

Fitted Line Plot: SYP AppE versus SYP DynE 


\section{Appendix VI. cont.}

\section{Regression Analysis: YP MOR versus YP ScrewF}

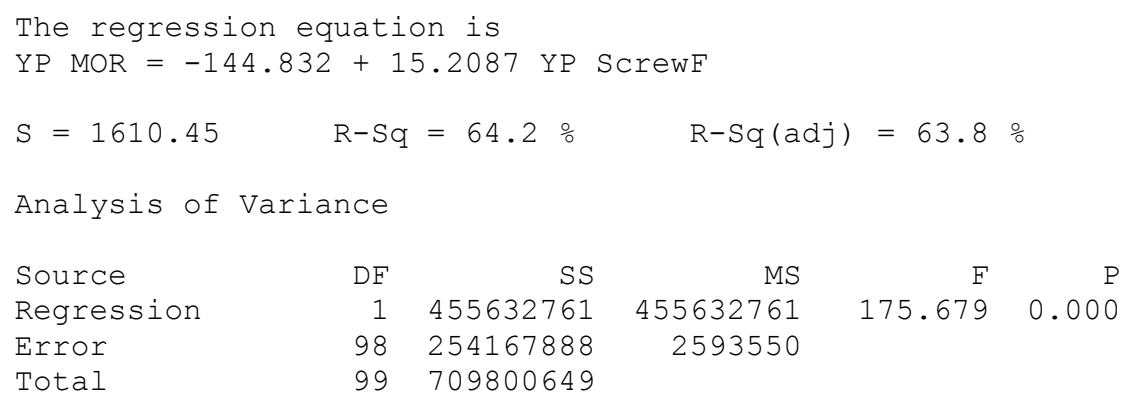

Fitted Line Plot: YP MOR versus YP ScrewF

\section{Regression Analysis: YP Density versus YP ScrewF}

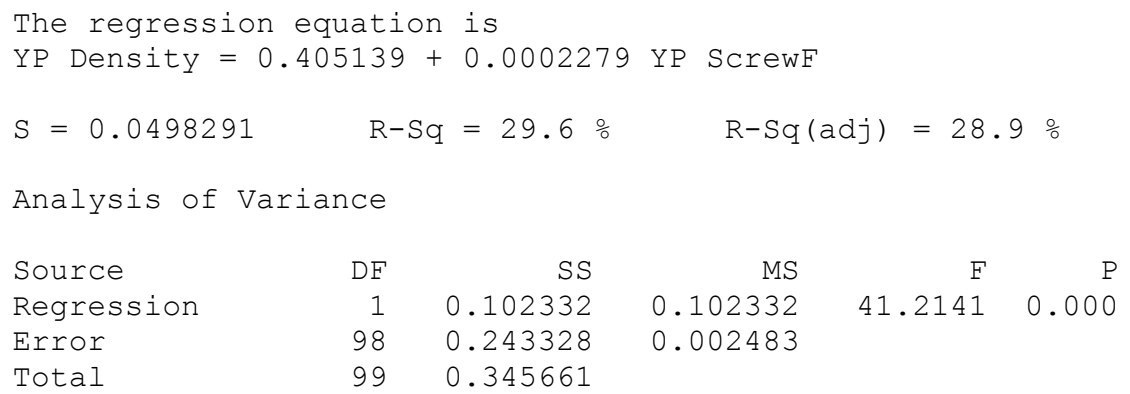

Fitted Line Plot: YP Density versus YP ScrewF

\section{Regression Analysis: YP AppE versus YP DynE}

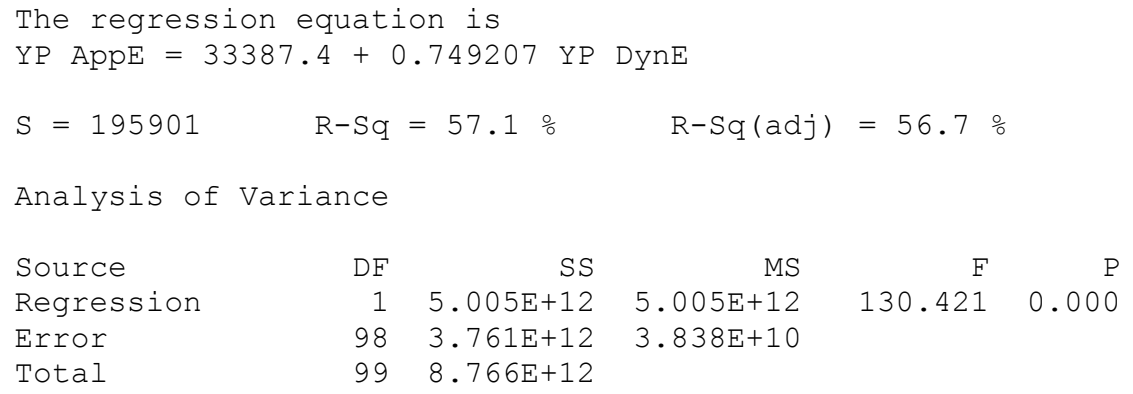

Fitted Line Plot: YP AppE versus YP DynE 


\section{Appendix VI. cont.}

\section{Regression Analysis: MOR ALL versus ScrewF ALL}

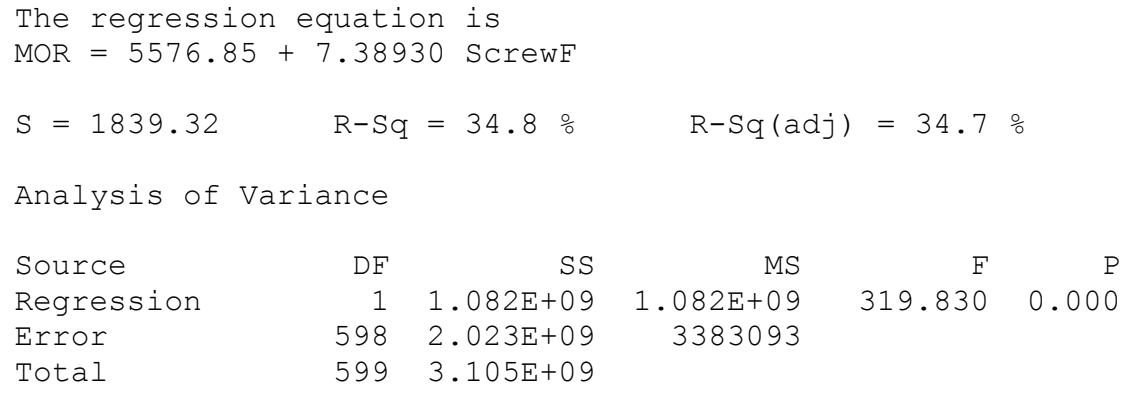

Fitted Line Plot: MOR ALL versus ScrewF ALL

Regression Analysis: Density ALL versus ScrewF ALL

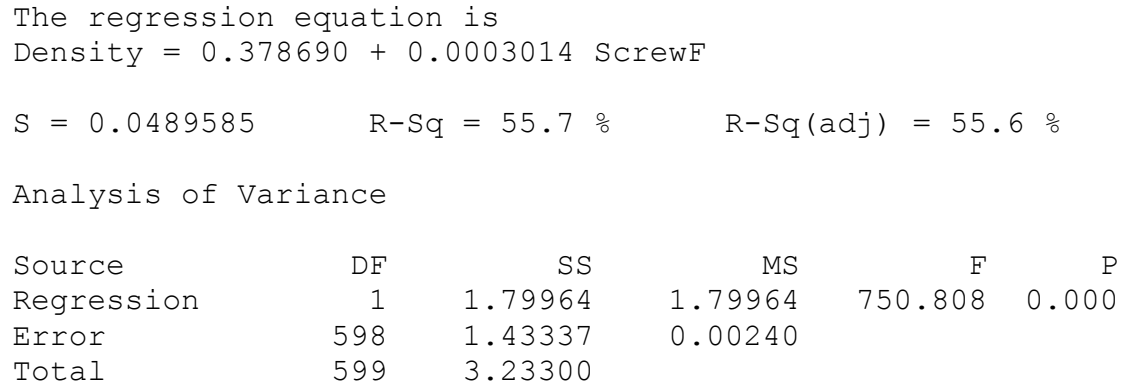

Fitted Line Plot: Density ALL versus ScrewF ALL

Regression Analysis: AppE ALL versus DynE ALL

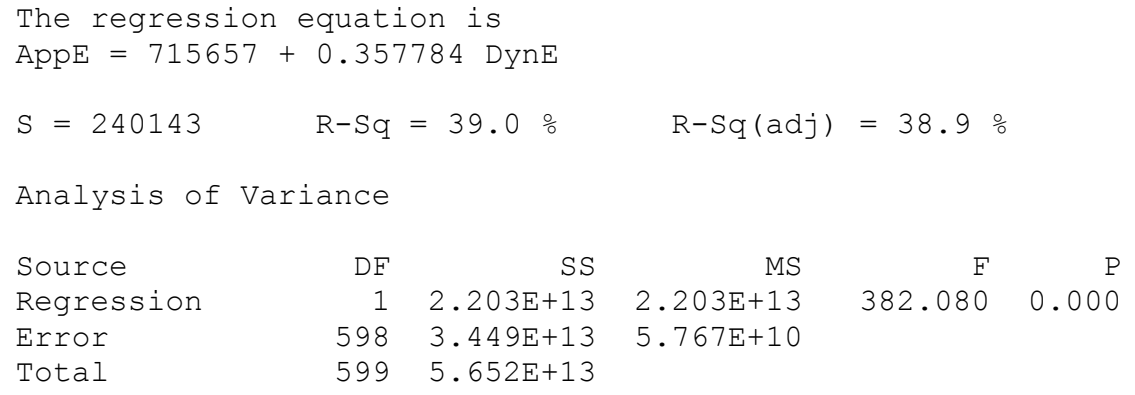

$\begin{array}{rrrrr}\text { DF } & \text { SS } & \text { MS } & F & P \\ 1 & 2.203 \mathrm{E}+13 & 2.203 \mathrm{E}+13 & 382.080 & 0.000 \\ 598 & 3.449 \mathrm{E}+13 & 5.767 \mathrm{E}+10 & & \\ 599 & 5.652 \mathrm{E}+13 & & & \end{array}$




\section{Appendix VI. cont.}

\section{Correlations: LVL MOR, LVL ScrewF}

Pearson correlation of LVL MOR and LVL ScrewF $=0.796$

$\mathrm{P}$-Value $=0.000$

\section{Correlations: LVL Density, LVL ScrewF}

Pearson correlation of LVL Density and LVL ScrewF $=0.589$

$\mathrm{P}-\mathrm{Value}=0.000$

Correlations: LVL AppE, LVL DynE

Pearson correlation of LVL AppE and LVL DynE $=0.742$

$\mathrm{P}-\mathrm{Value}=0.000$

\section{Correlations: PSL MOR, PSL ScrewF}

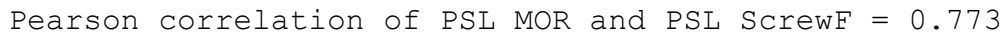

\section{Correlations: PSL Density, PSL ScrewF}

Pearson correlation of PSL Density and PSL ScrewF $=0.455$

$\mathrm{P}-\mathrm{Value}=0.000$

Correlations: PSL AppE, PSL DynE

Pearson correlation of PSL AppE and PSL DynE $=0.724$

$\mathrm{P}-\mathrm{Value}=0.000$

\section{Correlations: RO MOR, RO ScrewF}

Pearson correlation of $\mathrm{RO} \mathrm{MOR}$ and $\mathrm{RO}$ ScrewF $=0.745$

$\mathrm{P}-\mathrm{Value}=0.000$ 
Appendix VI. cont.

Correlations: RO Density, RO ScrewF

Pearson correlation of $\mathrm{RO}$ Density and $\mathrm{RO}$ ScrewF $=0.663$

$\mathrm{P}-\mathrm{Value}=0.000$

Correlations: RO AppE, RO DynE

Pearson correlation of RO AppE and RO DynE $=0.751$

$\mathrm{P}-\mathrm{Value}=0.000$

Correlations: SPF MOR, SPF ScrewF

Pearson correlation of SPF MOR and SPF ScrewF $=0.776$

$\mathrm{P}-\mathrm{Value}=0.000$

Correlations: SPF Density, SPF ScrewF

Pearson correlation of SPF Density and SPF ScrewF $=0.433$

$\mathrm{P}-\mathrm{Value}=0.000$

Correlations: SPF AppE, SPF DynE

Pearson correlation of SPF AppE and SPF DynE $=0.786$

$\mathrm{P}-$ Value $=0.000$

Correlations: SYP MOR, SYP ScrewF

Pearson correlation of SYP MOR and SYP ScrewF $=0.852$

$\mathrm{P}-\mathrm{Value}=0.000$

Correlations: SYP Density, SYP ScrewF

Pearson correlation of SYP Density and SYP ScrewF $=0.679$

$\mathrm{P}-\mathrm{Value}=0.000$ 


\section{Appendix VI. cont.}

\section{Correlations: SYP AppE, SYP DynE}

Pearson correlation of SYP AppE and SYP DynE $=0.900$

$\mathrm{P}-\mathrm{Value}=0.000$

Correlations: YP MOR, YP ScrewF

Pearson correlation of YP MOR and YP ScrewF $=0.801$

$\mathrm{P}-$ Value $=0.000$

\section{Correlations: YP Density, YP ScrewF}

Pearson correlation of YP Density and YP ScrewF $=0.544$

$\mathrm{P}-\mathrm{Value}=0.000$

Correlations: YP AppE, YP DynE

Pearson correlation of YP AppE and YP DynE $=0.756$

$\mathrm{P}-$ Value $=0.000$ 


\section{Appendix VII. - GLM between PSL and treated PSL for SWF vs. density, SWF vs. MOR, and $E_{D}$ vs. $E_{T}$}

\section{The SAS System}

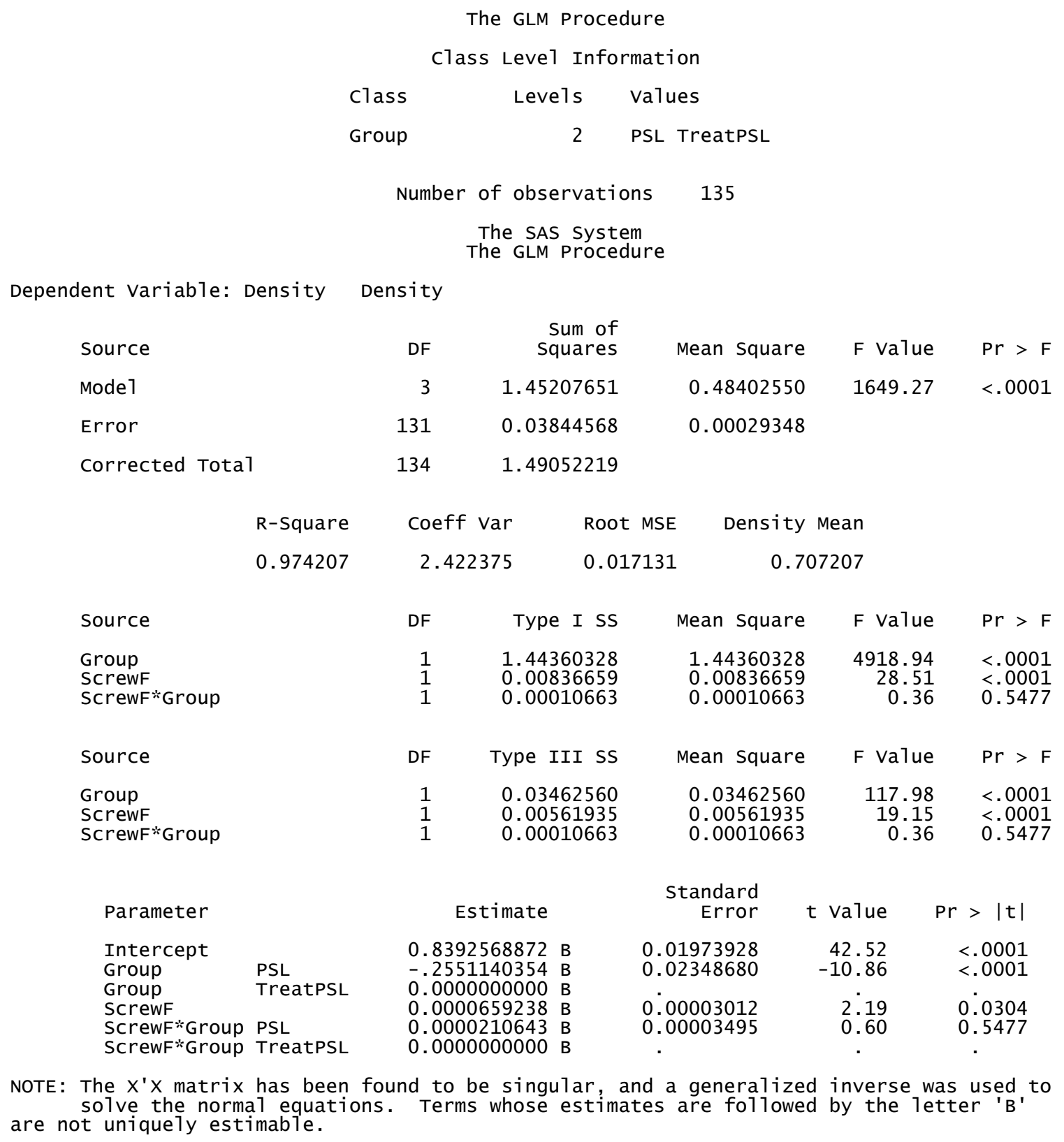




\title{
Appendix VII. cont.
}

\author{
The SAS System \\ The GLM Procedure \\ Class Level Information \\ class Levels values \\ Group 2 PSL TreatPSL \\ Number of observations 135 \\ The SAS system \\ The GLM Procedure
}

Dependent Variable: MOR MOR

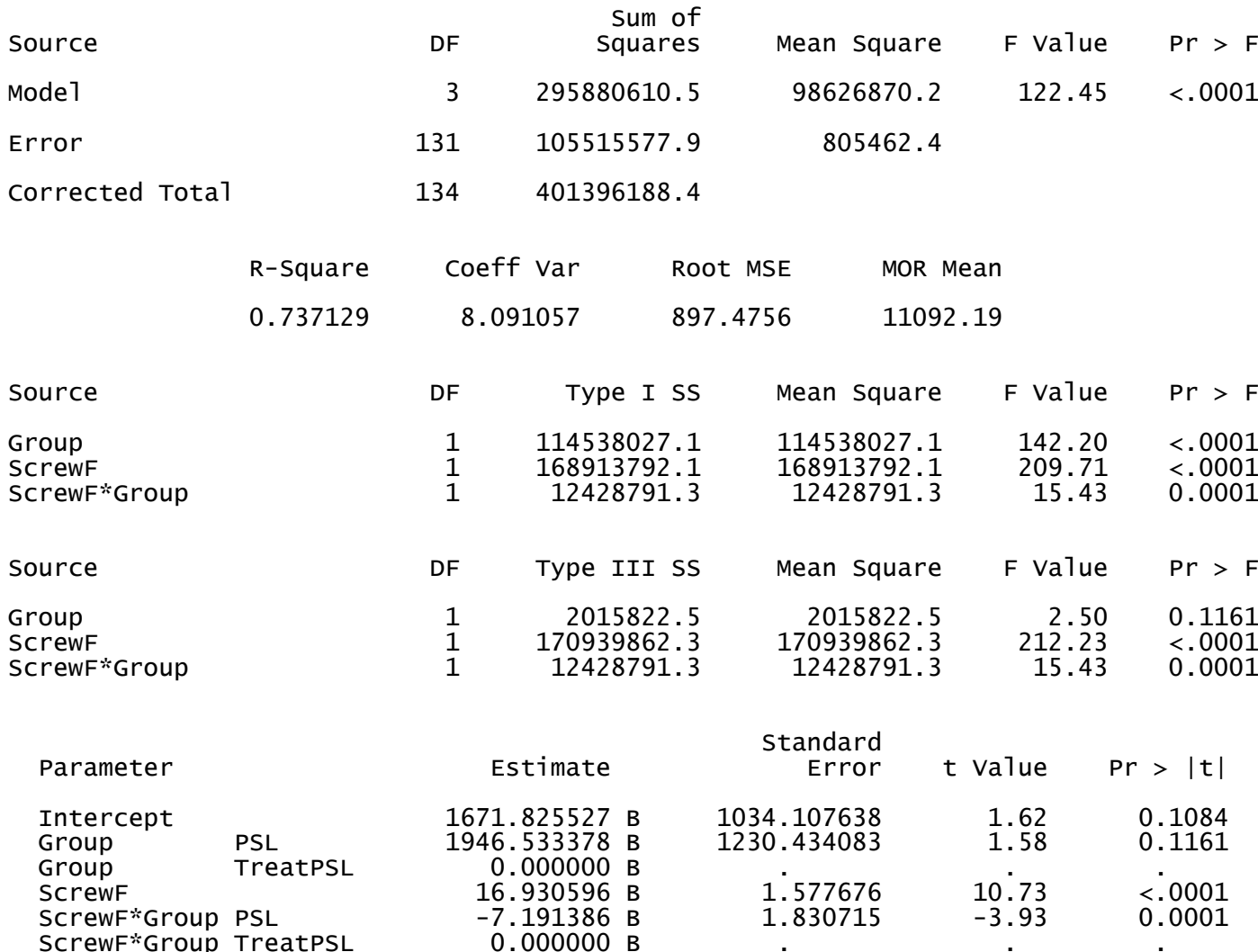

NOTE: The $X^{\prime} X$ matrix has been found to be singular, and a generalized inverse was used to solve the normal equations. Terms whose estimates are followed by the letter ' $B$ '

are

not uniquely estimable. 


\section{Appendix VII. cont.}

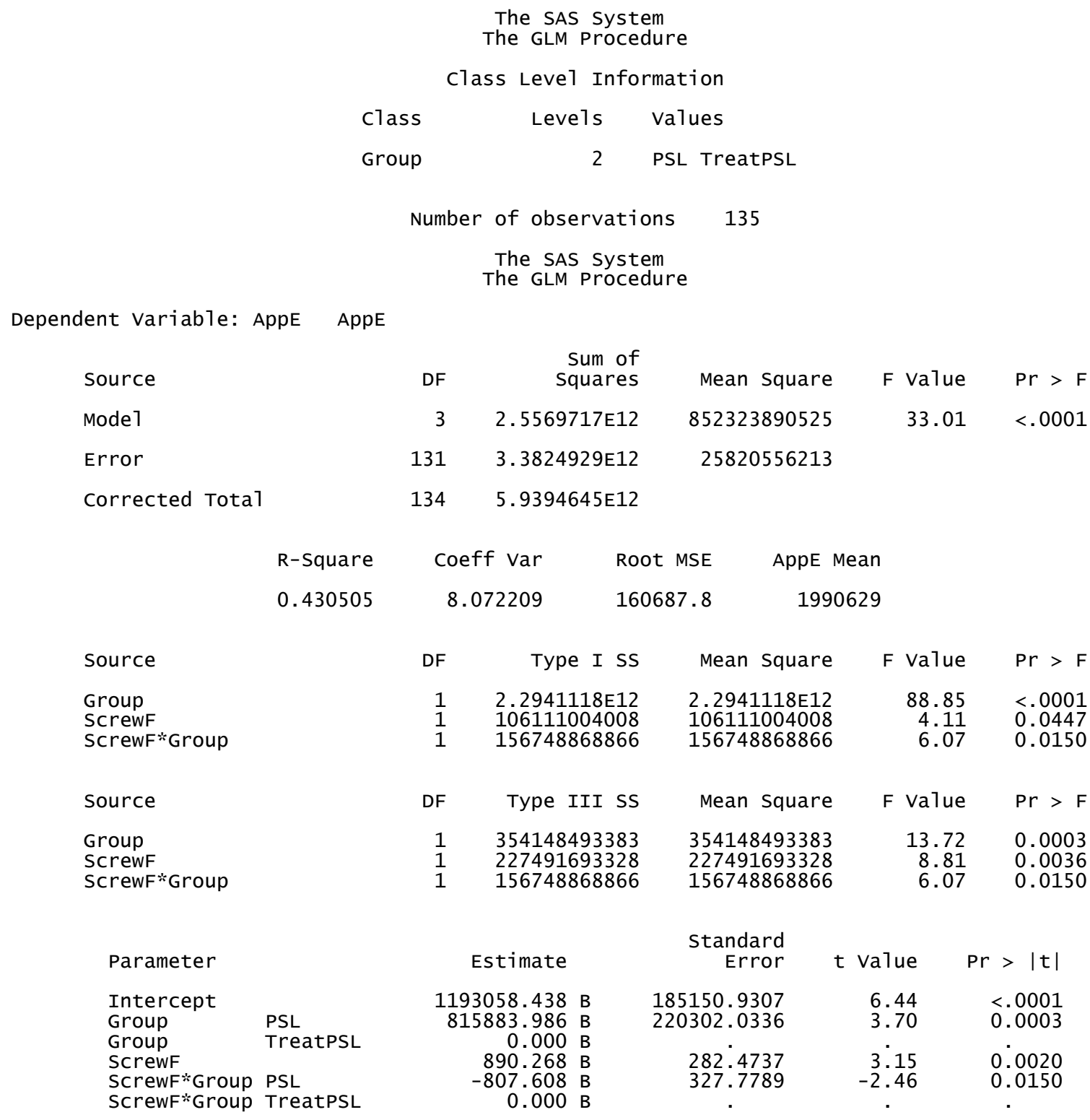

NOTE: The $X^{\prime} X$ matrix has been found to be singular, and a generalized inverse was used to solve the normal equations. Terms whose estimates are followed by the 1etter ' $B$ ' are not uniquely estimable. 


\section{Appendix VIII. - Backward stepwise regression results}

Backward stepwise regression:

Dependent variable: SYP-MOR

F-to-enter: $4.000 \mathrm{P}=0.048$

F-to-remove: $3.900 \quad \mathrm{P}=0.051$

Standard error estimate $=1128.308$

Analysis of variance:

\begin{tabular}{lllllr}
$\begin{array}{lll}\text { Group } \\
\text { Residual96 }\end{array}$ & DF & SS & MS & F & P \\
\multicolumn{1}{l}{ 122215493.629 } & \multicolumn{1}{l}{1273078.059} & & \\
Variables in Model & & & & \\
Group & Coef. & Std.Coeff. & Std.Error & F-to-remove & P \\
Constant & 2442.888 & & 4855.782 & & \\
SF & 18.352 & 1.067 & 6.882 & 260.542 & $<0.001$ \\
Density & -7369.986 & -0.195 & 9311.599 & 11.260 & 0.001 \\
SF x Den. & -1.886 & -0.0871 & 12.634 & 0.0223 & 0.882
\end{tabular}

Variables not in Model

Group $\quad$ F-to-Enter P

Step 1:SF x Den. Removed

$\mathrm{R}=0.869 \quad$ Rsqr $=0.755 \quad$ Adj Rsqr $=0.750$

Standard Error of Estimates $=1122.607$

Analysis of variance:

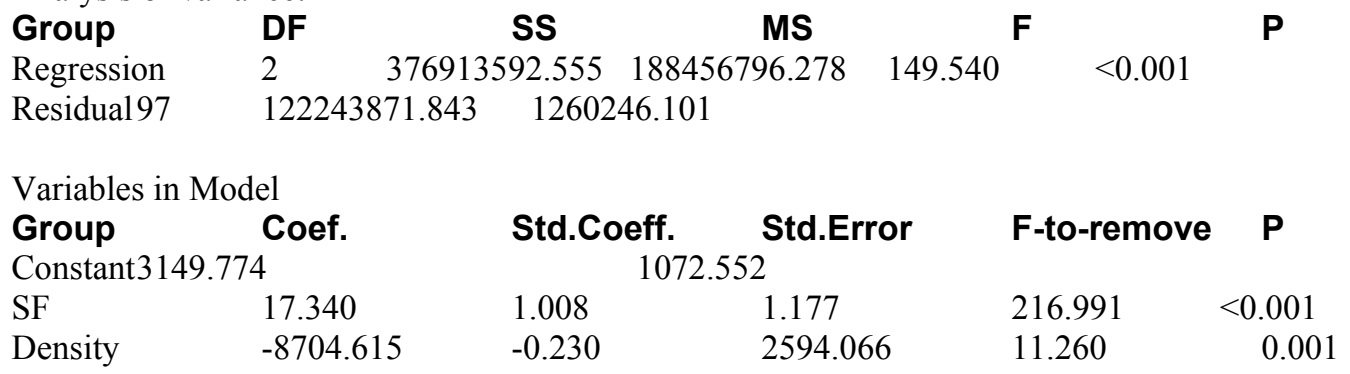

Summary Table

$\begin{array}{lccccc}\text { Step \# } & \text { Vars. Entered Vars. Removed } & \mathbf{R} & \mathbf{R s q r} & \text { Delta Rsqr } & \text { Vars. In Model } \\ 1 & \text { SF x Den. } & 0.869 & 0.755 & 0.755 & 2\end{array}$

The dependent variable SYP-MOR can be predicted from a linear combination of the independent variables:

$\begin{array}{ll} & \mathbf{P} \\ \text { SF } & <0.001 \\ \text { Density } & 0.001\end{array}$

The following variables did not significantly add to the ability of the equation to predict SYP-MOR and were not included in the final equation: SF x Den.

Normality Test: Passed $(\mathrm{P}=0.894)$

Constant Variance Test: Passed $(\mathrm{P}=0.140)$

Power of performance test with alpha $=0.050: 1.00$ 


\section{Appendix VIII. cont.}

Backward stepwise regression:

Dependent variable: YP-MOR

F-to-enter: $4.000 \mathrm{P}=0.048$

F-to-remove: $3.900 \quad \mathrm{P}=0.051$

Standard error estimate $=1576.050$

Analysis of variance:

\begin{tabular}{|c|c|c|c|c|c|}
\hline Group & DF & SS & MS & $\mathbf{F}$ & $\mathbf{P}$ \\
\hline Residual96 & 238457684.872 & \multicolumn{2}{|c|}{2483934.217} & & \\
\hline \multicolumn{6}{|c|}{ Variables in Model } \\
\hline Group & Coef. & Std.Coeff. & Std.Error & F-to-remove & $\mathbf{P}$ \\
\hline Constant & -4087.417 & & 6203.510 & & \\
\hline SF & 28.254 & 1.488 & 10.124 & 175.679 & $<0.001$ \\
\hline Density & 4831.912 & 0.107 & 11023.643 & 5.016 & 0.027 \\
\hline SF x Den. & -19.807 & -0.781 & 17.416 & 1.293 & 0.258 \\
\hline
\end{tabular}

Variables not in Model

Group $\quad$ F-to-Enter P

Step 1:SF x Den. Removed

$\mathrm{R}=0.814 \quad$ Rsqr $=0.663 \quad$ Adj Rsqr $=0.656$

Standard Error of Estimates $=1569.473$

Analysis of variance:

\begin{tabular}{|c|c|c|c|c|c|c|}
\hline Group & DF & SS & MS & \multicolumn{2}{|r|}{$\mathbf{F}$} & \multirow[t]{2}{*}{$\mathbf{P}$} \\
\hline Regression & 470865 & 733.980 & 235432866.990 & 95.578 & \multirow[t]{2}{*}{$<0.001$} & \\
\hline Residual97 & 238934914.961 & 24632 & 246.546 & & & \\
\hline \multicolumn{7}{|c|}{ Variables in Model } \\
\hline Group & Coef. & \multirow{2}{*}{\multicolumn{3}{|c|}{$\begin{array}{l}\text { Std.Coeff. } \\
904.793\end{array}$}} & \multirow[t]{2}{*}{ F-to-remove } & $\mathbf{P}$ \\
\hline \multicolumn{2}{|c|}{ Constant-1397.602 } & & & & & \\
\hline SF & 24.137 & 1.272 & 3.760 & & 41.199 & $<0.001$ \\
\hline Density & -12.500 & -0.493 & 5.027 & & 6.184 & 0.015 \\
\hline
\end{tabular}

Summary Table

$\begin{array}{lllccc}\text { Step \# } & \text { Vars. Entered Vars. Removed } & \mathbf{R} & \text { Rsqr } & \text { Delta Rsqr } & \text { Vars. In Model } \\ 1 & \text { Density } & 0.814 & 0.663 & 0.663 & 2\end{array}$

The dependent variable SYP-MOR can be predicted from a linear combination of the independent variables:

$\begin{array}{ll} & \mathbf{P} \\ \text { SF } & <0.001 \\ \text { Density } & 0.015\end{array}$

The following variables did not significantly add to the ability of the equation to predict SYP-MOR and were not included in the final equation: Density

Normality Test: Failed $(\mathrm{P}=<0.001)$

Constant Variance Test: Failed $(\mathrm{P}=0.006)$

Power of performance test with alpha $=0.050: 1.00$ 


\section{Appendix VIII. cont.}

Backward stepwise regression:

Dependent variable: SPF-MOR

F-to-enter: $4.000 \mathrm{P}=0.048$

F-to-remove: $3.900 \quad \mathrm{P}=0.051$

Standard error estimate $=1483.469$

Analysis of variance:

\begin{tabular}{lllllr}
$\begin{array}{llll}\text { Group } \\
\text { Residual96 }\end{array}$ & DF & SS & MS & F & P \\
\multicolumn{2}{l}{ Variables in Model } & & & & \\
Group & Coef. & Std.Coeff. & Std.Error & F-to-remove & P \\
Constant & 10681.763 & & 13869.691 & & \\
SF & 0.399 & 0.0139 & 25.170 & 148.001 & $<0.001$ \\
Density & -26652.513 & -0.355 & 26945.059 & 0.323 & 0.571 \\
SF x Den. & 43.178 & 0.960 & 48.271 & 0.800 & 0.373
\end{tabular}

Variables not in Model

Group $\quad$ F-to-Enter P

Step 1:SF x Den. Removed

$\mathrm{R}=0.779 \quad$ Rsqr $=0.606 \quad$ Adj Rsqr $=0.598$

Standard Error of Estimates=1475.804

Analysis of variance:

\begin{tabular}{|c|c|c|c|c|c|c|}
\hline Group & DF & SS & MS & \multicolumn{2}{|r|}{$\mathbf{F}$} & \multirow[t]{3}{*}{$\mathbf{P}$} \\
\hline Regression & $2 \quad 32525$ & 107.164 & 162627553.582 & 74.668 & \multirow[t]{2}{*}{$<0.001$} & \\
\hline Residual97 & 211265847.239 & 21779 & 98.425 & & & \\
\hline \multicolumn{7}{|c|}{ Variables in Model } \\
\hline Group & Coef. & Std.Co & \multicolumn{2}{|c|}{ Std.Error } & F-to-remove & $\mathbf{P}$ \\
\hline \multicolumn{2}{|c|}{ Constant 10897.570} & \multicolumn{3}{|c|}{2681.108} & & \\
\hline SF & -27067.085 & -0.361 & 6518.3 & & 17.243 & $<0.001$ \\
\hline Density & 43.941 & 0.977 & 3.904 & & 126.666 & $<0.001$ \\
\hline
\end{tabular}

Summary Table

$\begin{array}{lccccc}\text { Step \# } & \text { Vars. Entered Vars. Removed } & \mathbf{R} & \text { Rsqr } & \text { Delta Rsqr } & \text { Vars. In Model } \\ 1 & \text { SF } & 0.779 & 0.606 & 0.606 & 2\end{array}$

The dependent variable SYP-MOR can be predicted from a linear combination of the independent variables:

$\begin{array}{ll} & \mathbf{P} \\ \text { SF } & <0.001 \\ \text { Density } & <0.001\end{array}$

The following variables did not significantly add to the ability of the equation to predict SYP-MOR and were not included in the final equation: SF

Normality Test: Passed $(\mathrm{P}=0.312)$

Constant Variance Test: Passed $(\mathrm{P}=0.062)$

Power of performance test with alpha $=0.050: 1.00$ 


\section{Appendix VIII. cont.}

Backward stepwise regression:

Dependent variable: RO-MOR

F-to-enter: $4.000 \mathrm{P}=0.048$

F-to-remove: $3.900 \quad \mathrm{P}=0.051$

Standard error estimate $=1518.314$

Analysis of variance:

\begin{tabular}{|c|c|c|c|c|c|}
\hline Group & DF & SS & MS & $\mathbf{F}$ & $\mathbf{P}$ \\
\hline Residual96 & 221306661.367 & 2305277 & & & \\
\hline \multicolumn{6}{|c|}{ Variables in Model } \\
\hline $\begin{array}{l}\text { Group } \\
\text { Constant }\end{array}$ & $\begin{array}{l}\text { Coef. } \\
2740.620\end{array}$ & Std.Coeff. & $\begin{array}{l}\text { Std.Error } \\
9974.875\end{array}$ & F-to-remove & $\mathbf{P}$ \\
\hline SF & 19.845 & 1.268 & 10.417 & 122.072 & $<0.001$ \\
\hline Density & -7153.527 & -0.155 & 14717.176 & 12.856 & $<0.001$ \\
\hline SF x Den. & -7.224 & -0.435 & 14.879 & 0.236 & 0.628 \\
\hline
\end{tabular}

Variables not in Model

Group $\quad$ F-to-Enter P

Step 1:SF x Den. Removed

$\mathrm{R}=0.779 \quad$ Rsqr $=0.607 \quad$ Adj Rsqr $=0.599$

Standard Error of Estimates $=1512.321$

Analysis of variance:

\begin{tabular}{|c|c|c|c|c|c|c|}
\hline Group & DF & SS & MS & \multicolumn{2}{|r|}{$\mathbf{F}$} & \multirow[t]{2}{*}{$\mathbf{P}$} \\
\hline Regression & $2 \quad 342373$ & 84.202 & 171186592.101 & 74.848 & \multirow[t]{2}{*}{$<0.001$} & \\
\hline Residual97 & 221850124.299 & 22871 & 14.683 & & & \\
\hline \multicolumn{7}{|c|}{ Variables in Model } \\
\hline Group & Coef. & Std.Cc & \multicolumn{2}{|c|}{ Std.Error } & F-to-remove & $\mathbf{P}$ \\
\hline \multicolumn{2}{|c|}{ Constant 7480.441} & \multicolumn{3}{|c|}{2041.691} & & \\
\hline $\mathrm{SF}$ & 14.829 & 0.947 & 1.332 & & 123.856 & $<0.001$ \\
\hline Density & -14039.640 & -0.305 & 3915.6 & & 12.856 & $<0.001$ \\
\hline
\end{tabular}

Summary Table

$\begin{array}{lclccc}\text { Step \# } & \text { Vars. Entered Vars. Removed } & \mathbf{R} & \text { Rsqr } & \text { Delta Rsqr } & \text { Vars. In Model } \\ 1 & \text { SF x Density } & 0.779 & 0.607 & 0.607 & 2\end{array}$

The dependent variable SYP-MOR can be predicted from a linear combination of the independent variables:

$\begin{array}{ll} & \mathbf{P} \\ \text { SF } & <0.001 \\ \text { Density } & <0.001\end{array}$

The following variables did not significantly add to the ability of the equation to predict SYP-MOR and were not included in the final equation: SF x Den.

Normality Test: Failed $(\mathrm{P}=0.034)$

Constant Variance Test: Passed $(\mathrm{P}=0.375)$

Power of performance test with alpha $=0.050: 1.00$ 


\section{Appendix VIII. cont.}

Backward stepwise regression:

Dependent variable: PSL-MOR

F-to-enter: $4.000 \mathrm{P}=0.048$

F-to-remove: $3.900 \quad \mathrm{P}=0.051$

Standard error estimate $=765.914$

Analysis of variance:

\begin{tabular}{|c|c|c|c|c|c|}
\hline Group & DF & SS & MS & $\mathbf{F}$ & $\mathbf{P}$ \\
\hline Residual96 & 56315992.709 & \multicolumn{2}{|c|}{586624.924} & & \\
\hline \multicolumn{6}{|c|}{ Variables in Model } \\
\hline Group & Coef. & Std.Coeff. & Std.Error & F-to-remove & $\mathbf{P}$ \\
\hline Constant & 498.113 & \multicolumn{2}{|c|}{17416.455} & & \\
\hline $\mathrm{SF}$ & 3.899 & 0.309 & 24.353 & 59.121 & $<0.001$ \\
\hline Density & 5863.089 & 0.0890 & 27225.160 & 5.598 & 0.020 \\
\hline SF x Den. & 7.575 & 0.429 & 37.900 & 0.0399 & 0.842 \\
\hline
\end{tabular}

Variables not in Model

Group $\quad$ F-to-Enter P

Step 1:SF x Den. Removed

$\mathrm{R}=0.788 \quad$ Rsqr $=0.620 \quad$ Adj Rsqr $=0.612$

Standard Error of Estimates $=762.115$

Analysis of variance:

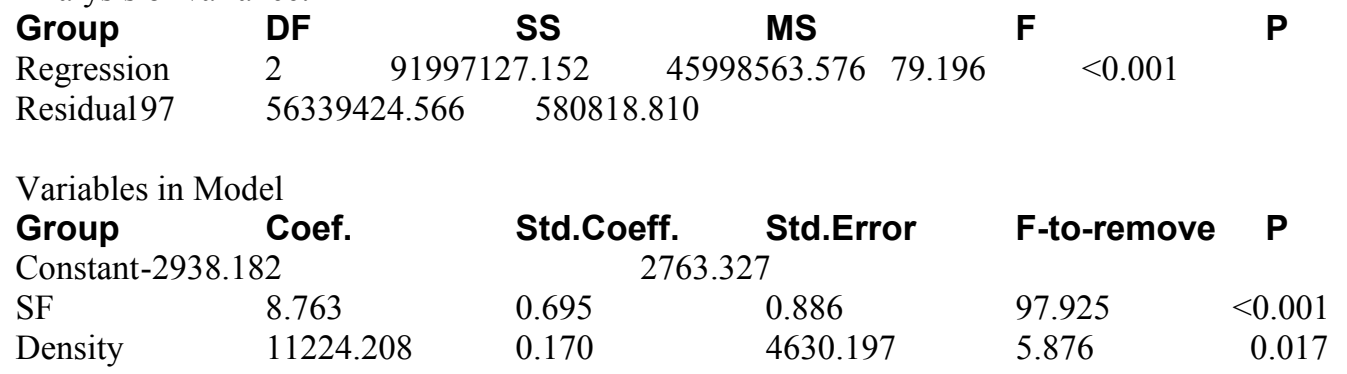

Summary Table

$\begin{array}{lclccc}\text { Step \# } & \text { Vars. Entered Vars. Removed } & \mathbf{R} & \text { Rsqr } & \text { Delta Rsqr } & \text { Vars. In Model } \\ 1 & \text { SF x Density } & 0.788 & 0.620 & 0.620 & 2\end{array}$

The dependent variable SYP-MOR can be predicted from a linear combination of the independent variables:

$\begin{array}{ll} & \mathbf{P} \\ \text { SF } & <0.001 \\ \text { Density } & 0.017\end{array}$

The following variables did not significantly add to the ability of the equation to predict SYP-MOR and were not included in the final equation: SF x Den.

Normality Test: Passed $(\mathrm{P}=0.112)$

Constant Variance Test: Passed $(\mathrm{P}=0.464)$

Power of performance test with alpha $=0.050: 1.00$ 


\section{Appendix VIII. cont.}

Backward stepwise regression:

Dependent variable: LVL-MOR

F-to-enter: $4.000 \mathrm{P}=0.048$

F-to-remove: $3.900 \quad \mathrm{P}=0.051$

Standard error estimate $=485.073$

Analysis of variance:

Group DF

Residual96 22588436.449

SS 235296.213

Variables in Model

$\begin{array}{ll}\text { Group } & \text { Coef. } \\ \text { Constant } & -5572.754 \\ \text { SF } & 20.170\end{array}$

Density $\quad 23640.417$

SF x Den. $\quad-21.487$

Variables not in Model

\section{Group}

\section{F-to-Enter}

\section{Std.Error 10032.421 \\ 20.739}

17998.433

36.940
$\mathbf{F}$

$\begin{array}{lc}\text { F-to-remove } & \mathbf{P} \\ 62.747 & <0.001 \\ 13.995 & <0.001 \\ 0.338 & 0.562\end{array}$

Step 1:SF x Den. Removed

$\mathrm{R}=0.828 \quad$ Rsqr $=0.686 \quad$ Adj Rsqr $=0.680$

Standard Error of Estimates $=483.416$

Analysis of variance:

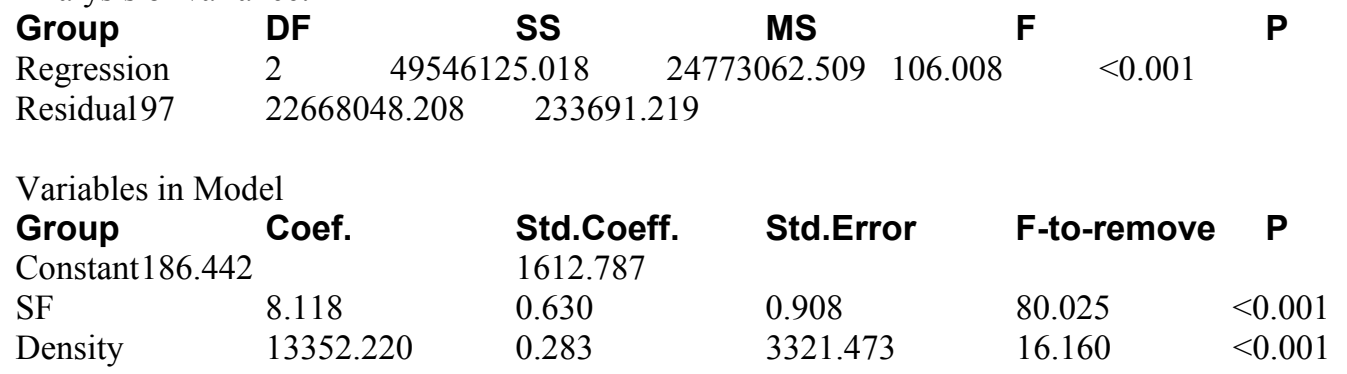

Summary Table

$\begin{array}{lccccc}\text { Step \# } & \text { Vars. Entered Vars. Removed } & \mathbf{R} & \mathbf{R s q r} & \text { Delta Rsqr } & \text { Vars. In Model } \\ 1 & \text { SF x Density } & 0.828 & 0.686 & 0.686 & 2\end{array}$

The dependent variable SYP-MOR can be predicted from a linear combination of the independent variables:

$\begin{array}{ll} & \mathbf{P} \\ \text { SF } & <0.001 \\ \text { Density } & <0.001\end{array}$

The following variables did not significantly add to the ability of the equation to predict SYP-MOR and were not included in the final equation: SF x Den.

Normality Test: Passed $(\mathrm{P}=0.796)$

Constant Variance Test: Passed $(\mathrm{P}=0.767)$

Power of performance test with alpha $=0.050: 1.00$ 
Jody Gray was born in Fairmont, WV on December 30, 1973. Son of Joseph and Arlene Gray, he was the first of three children. Jody attended high school at Morgantown High, in Morgantown WV, graduating in 1992. In 1997 Jody enrolled in the Wood Science program at West Virginia University, located in Morgantown WV. He obtained his undergraduate degree in Wood Science in May 2001 and was accepted into graduate school, under the same field of study, that same year. Jody graduated the Masters program at WVU in May 2003.

Jody was married to his wife Leslie in July 1997 and their son Joseph was born on June 8,1998. At the time this research concluded, Jody and Leslie were expecting the birth on a second child in July of 2003. 